\title{
“Percepción en gerentes y docentes de la pertinencia de incorporación de competencias profesionales de ingenieros informáticos en el \\ Perú"
}

Tesis para optar el grado académico de Doctor en educación

\section{BEATRIZ ZAKIMI MIYASATO}

Lima - Perú

2012 
A mis padres e hijos,

Tsutomu, Teru, André y Nuria. 


\section{Asesora: \\ Dra. Norma Reátegui Colareta}




\section{Índice de contenidos}

Introducción 1

Computación en el Marco Internacional ___ 1

Computing Curricula __ 2

Ingeniería de Computación (Computer Engineering CE) __ 6

Ciencias de la computación (Computer Science CS)___ 7

Ingeniería de software (Software Engineering $S E$ )__ 8

Sistemas de Información (Information Systems IS) _ 9

Tecnologías de la Información (Information Technology IT) _ 10

Ingeniería de Sistemas _ 12

Computación en el Marco Peruano ___ 13

Marco Teórico ___ 16

Problema de investigación ____ 20

Objetivos ___ 23

Objetivo General ___ 23

Objetivos específicos _ 23

Método__ 25

Tipo y diseño de la Investigación ___ 25

Variables ___ 25

Participantes ___ 27

Instrumento de Investigación ___ 29

Procedimiento _ $\mathbf{3 0}$

Revisión Bibliográfica _ 30

Selección de participantes _ 30

Establecimiento de la muestra — 30

Construcción del Instrumento _ 31

Aplicación del instrumento _ 31

Análisis de resultados __ 31

Resultados _ 32

Análisis descriptivo de los resultados obtenidos __ 32

Dimensión de comunicación__ 32

Dimensión de actitud y aptitud personal __ 33

Dimensión de relación interpersonal y social __ 38

Dimensión de emprendimiento _ 39

Dimensión específica de informática __ 40

Dimensión específica de gestión empresarial __ 45

Dimensión de conocimientos declarativos_ 46

Análisis comparativo de los resultados de los grupos de gerentes y de docentes ___ 51

Dimensión de comunicación __ 51

Dimensión de actitud y aptitud personal _ 51

Dimensión de relación interpersonal y social _ـ 52

Dimensión de emprendimiento _ 52

Dimensión específica de informática __ 52

Dimensión específica de gestión empresarial __ 53

Dimensión de conocimiento declarativo _ـ 54 
Discusión, conclusiones y sugerencias

Conclusiones

Sugerencias 65

Referencias 68

Anexos 70

Anexo 1: Instrumento de la Investigación

Anexo 2. Prueba de validez de $\mathrm{V}$ de Aiken

Anexo 3: Análisis de homogeneidad de varianzas y significancia de medias para la dimensión de comunicación 76

Anexo 4: Análisis de homogeneidad de varianzas y significancia de medias para la dimensión de actitud y aptitud personal. 78

Anexo 5: Análisis de homogeneidad de varianzas y significancia de medias para la dimensión de relación interpersonal y social

Anexo 6: Análisis de homogeneidad de varianzas y significancia de medias para la dimensión de emprendimiento

Anexo 7: Análisis de homogeneidad de varianzas y significancia de medias para la dimensión específica de informática

Anexo 8: Análisis de homogeneidad de varianzas y significancia de medias para la dimensión específica de gestión empresarial 88

Anexo 9: Análisis de homogeneidad de varianzas y significancia de medias para la dimensión de conocimientos declarativos. 


\section{Índice de tablas}

Tabla 1. Variable Competencia Profesional, sus dimensiones e indicadores 26

Tabla 2. Participantes de la muestra según el sector económico al que pertenecen 28

Tabla 3. Conformación de la muestra___ 28

Tabla 4. Datos de los participantes de la muestra___ 29

Tabla 5. Escala para indicadores estudiados __ 29

Tabla 6. Resultados obtenidos para el indicador capacidad de comunicación oral y escrita en lengua nativa

Tabla 7. Resultados obtenidos para el indicador capacidad de comunicación oral y escrita en una segunda lengua

Tabla 8. Resultados obtenidos para el indicador capacidad de abstracción, análisis y síntesis

Tabla 9. Resultados obtenidos para el indicador capacidad de razonamiento crítico 34

Tabla 10. Resultados obtenidos para el indicador capacidad de organización y planificación

Tabla 11. Resultados obtenidos para el indicador capacidad de identificar, plantear, resolver problemas y tomar decisiones 35

Tabla 12. Resultados obtenidos para el indicador capacidad de aprender y actualizarse permanentemente

Tabla 13. Resultados obtenidos para el indicador capacidad de adaptarse a nuevas situaciones

Tabla 14. Resultados obtenidos para el indicador capacidad de aplicar conocimientos a la práctica 36

Tabla 15. Resultados obtenidos para el indicador capacidad de investigación 37

Tabla 16. Resultados obtenidos para el indicador compromiso hacia la calidad 37

Tabla 17. Resultados obtenidos para el indicador capacidad de trabajo en equipos con miembros del área de informática

Tabla 18. Resultados obtenidos para el indicador capacidad de trabajo en equipos interdisciplinarios

Tabla 19. Resultados obtenidos para el indicador compromiso ético 39

Tabla 20. Resultados obtenidos para el indicador capacidad de liderazgo 39

Tabla 21. Resultados obtenidos para el indicador capacidad creativa, de iniciativa y espíritu emprendedor 40

Tabla 22. Resultados obtenidos para el indicador capacidad para elaborar, entender y evaluar especificaciones técnicas y funcionales 40 
Tabla 23. Resultados obtenidos para el indicador capacidad de entender, seleccionar $y$ aplicar productos y/o tendencias tecnológicas al sector empresarial

Tabla 24. Resultados obtenidos para el indicador capacidad de planificar, organizar, dirigir y controlar proyectos

Tabla 25. Resultados obtenidos para el indicador capacidad de evaluar y validar requisitos y necesidades de hardware y software

Tabla 26. Resultados obtenidos para el indicador capacidad de programar computadoras

Tabla 27. Resultados obtenidos para el indicador capacidad de diseñar y administrar bases de datos

Tabla 28. Resultados obtenidos para el indicador capacidad de diseñar y especificar la arquitectura de sistemas de información

Tabla 29. Resultados obtenidos para el indicador capacidad de ensamblar, reparar y/o dar soporte a computadoras

Tabla 30. Resultados obtenidos para el indicador capacidad de diseñar, implantar, validar, mantener y administrar redes de computadoras

Tabla 31. Resultados obtenidos para el indicador capacidad de configurar, administrar y dar soporte a equipos de comunicaciones

Tabla 32. Resultados obtenidos para el indicador comprensión de las ciencias de la gestión empresarial

Tabla 33. Resultados obtenidos para el indicador comprensión de la visión y misión del negocio 46

Tabla 34. Resultados obtenidos para el indicador conocimientos generales de la ingeniería informática

Tabla 35. Resultados obtenidos para el indicador conocimientos generales de las ciencias de la gestión empresarial

Tabla 36. Resultados obtenidos para el indicador otros conocimientos y habilidades adquiridas en la universidad

Tabla 37. Resultados obtenidos para el indicador otros conocimientos y habilidades adquiridas en la práctica pre profesional

Tabla 38. Resultados obtenidos para el indicador otros conocimientos y habilidades adquiridas en cursos de certificación o especialización

Tabla 39. Nivel de mayor aceptación para los indicadores estudiados en ambos grupos

Tabla 40. Resultado de la comparación entre el grupo de gerentes y docentes para la dimensión de comunicación

Tabla 41. Resultado de la comparación entre el grupo de gerentes y docentes para la dimensión de actitud y aptitud personal 51 
Tabla 42. Resultado de la comparación entre el grupo de gerentes y docentes para la dimensión de relación interpersonal y social

Tabla 43. Resultado de la comparación entre el grupo de gerentes y docentes para la dimensión de emprendimiento

Tabla 44. Resultado de la comparación entre el grupo de gerentes y docentes para la dimensión específica de informática

Tabla 45. Resultado de la comparación entre el grupo de gerentes y docentes para la dimensión específica de gestión empresarial

Tabla 46. Resultado de la comparación entre el grupo de gerentes y docentes para la dimensión de conocimiento declarativo 54

Tabla 47. Resultado de la comparación entre el grupo de gerentes y docentes para todos los indicadores 


\section{Índice de figuras}

Figura 1. Disciplinas de computación según Computing Curricula de ACM (2005)__ 3

Figura 2. Evolución de las carreras según la Computing Curricula de ACM (2005) _ 4

Figura 3. El espacio del problema en computación de ACM (2005)_ 5

Figura 4. Alcance de Ingeniería de Computación (ACM, 2005)__ 6

Figura 5. Alcance de Ciencias de la Computación (ACM, 2005) _ 7

Figura 6. Alcance de Ingeniería de Software (ACM, 2005)__ 9

Figura 7. Alcance de Sistemas de Información (ACM, 2005)__ 10

Figura 8. Alcance de Tecnologías de la información (ACM, 2005) ___ 11

Figura 9. Alcance de la percepción de los gerentes respecto a la competencia profesional del ingeniero informático

Figura 10. Alcance de la percepción de los docentes respecto a la competencia profesional del ingeniero informático 


\title{
Resumen
}

Este trabajo de investigación, de tipo descriptivo comparativo, es un estudio para determinar si la formación universitaria en informática en el Perú, cubre las expectativas de la empresa peruana en cuanto a las competencias requeridas para un profesional en informática. Se aplicaron encuestas, a una muestra formada por personas con cargos ejecutivos y profesores universitarios, con el objetivo de obtener información respecto a qué tipo de competencias deberían estar presentes en estos profesionales. Se compararon los resultados obtenidos en ambos grupos, usando el SPPS, a fin de que las competencias requeridas por las empresas sean incorporadas en el plan de estudios de una carrera de ingeniería informática. A partir de estos resultados se confirmaría la necesidad de incluir en la formación de un ingeniero Informático, las competencias de gestión empresarial orientando el perfil del egresado más a la toma de decisiones que a tareas operativas tecnológicas.

\begin{abstract}
This research, descriptive comparative is a study to determine if the university education in Informatics in Peru covers the Peruvian company's expectations regarding the professional skills required for a computer professional. Surveys were applied, in a sample of persons with executive positions and university professors, with the aim of obtaining information about what kind of skills should be present in these professionals. We compared the results obtained in both groups using the SPPS, in order that the skills required by companies will be incorporated into the curriculum of a career in informatics engineering. The results would confirm the need to include in the formation of an informatics engineer, business management skills to guide the graduate profile closer to decision making than to technology operational tasks.
\end{abstract}




\section{Introducción}

\section{Computación en el Marco Internacional}

A fines de los 40, con la aparición de las primeras computadoras se acuña el término "computing" (Colegio de Ingenieros del Perú CIP, 2006), en español computación, informática; en el año 2005 la Association for Computing Machines (ACM) establece "Computing: is a broad discipline that crosses the boundaries between mathematics, science, engineering and business", (ACM, 2005, p.3) que ubica a computación como un área del conocimiento que comprende: matemáticas, ciencias, ingeniería y negocios.

Esta nueva disciplina comprende básicamente dos aspectos importantes de las computadoras, de un lado la parte física denominada "hardware" refiriéndose a los aspectos relacionados con componentes de la computadora como un dispositivo electrónico; y de otro, la parte no tangible, formada por componentes lógicos denominado "software" que permiten que la computadora ejecute determinadas tareas con el objetivo de resolver un problema.

Como expone Beekman (1995), debido al nacimiento de las primeras computadoras, con el objetivo básico de resolver cálculos numéricos de manera más rápida, surge la necesidad de formar profesionales que, por un lado, puedan diseñar y construir las computadoras y por otro lado, estén preparados para desarrollar software, también mencionado en el informe del año 2006 del CIP.

Para satisfacer estas necesidades, aparecen en USA las carreras de ingeniería de computación (Computing Engineering) dirigidas al estudio y desarrollo del hardware y las carreras de ciencias de la computación (Computer Science) mas relacionadas al estudio y desarrollo del software (CIP, 2006).

A mediados de los 60 en Francia se acuña el término "informatique", por un lado porque computing era un vocablo extraño para ellos, que usaban el término ordenateur, y adicionalmente porque estos equipos ya no se usaban solamente para cálculos numéricos (cómputo) como fue su objetivo inicial, sino que se usaban para procesar información. Esta denominación se hizo común en el resto de los países europeos como Alemania, Italia, Suiza, España entre otros (CIP, 2006).

Dentro de la Declaración de Bolonia (Asamblea General de la Conferencia de Rectores de la Universidad Española, 2000), surge un proceso de adecuación a la normativa del nuevo Espacio Europeo de Educación Superior. Como corolario, 
España ha normado que a partir del 2008, la educación superior ofrezca, para cubrir mejor los requerimientos del mercado laboral, los siguientes perfiles profesionales: Profesional en Desarrollo de software, Profesional en Gestión y Explotación de Tecnologías de Información y Profesional en Sistemas (CIP, 2006).

Paralelamente surgen las asociaciones profesionales que agrupan estudiantes y trabajadores del área, cuya una de sus preocupaciones principales es definir adecuadamente los perfiles profesionales de sus asociados. Así tenemos a la Association for Computing Machinery (ACM), Computer Society miembro del Institute of Electrical and Electronic Engineering (IEEE), Association for Information Systems (AIS), Association for Information Technology Professionals (AITP) y la International Federation for Information Processing (IFIP) (CIP, 2006).

Debido a que computación, como disciplina relativamente nueva, cruza sus límites con otras, surge la necesidad, tanto por parte de la sociedad académica como profesional, de establecer más claramente los conocimientos que debería comprender esta nueva disciplina, de manera tal que la formación de sus profesionales se diferencie de otras, mejor definidas, como la ingeniería de sistemas, una de las disciplinas con mayor coincidencia. Esta coincidencia sería el origen de la confusión entre ambas disciplinas, principalmente en países de Latinoamérica, como se expondrá más adelante.

Ingeniería de sistemas, definida como un campo de estudio interdisciplinario que envuelve a la tecnología, la administración y las ciencias sociales, enmarca sus actividades en programas de estudios de diferentes áreas como Tecnología Política; Ingeniería; Administración e Innovación; Emprendimiento; Sistemas y Análisis de Decisiones; Investigación de Operaciones; Manufactura; Desarrollo de Productos e Ingeniería Industrial (CIP, 2006, p.59). Estos profesionales están agrupados en asociaciones como la International Council on System Engineering (INCOSE), International Society for the Systems Sciences (ISSS) y el Concilio de Universidades de Ingeniería de Sistemas, entre otras según explica CIP (2006).

\section{Computing Curricula}

Esta propuesta curricular, descrita en ACM (2005), es el resultado de un trabajo conjunto de asociaciones profesionales como la ACM, IEEE, AIS y AITP y es uno de los trabajos más representativos, a nivel mundial, por establecer los conocimientos necesarios en la formación de un profesional informático y al mismo tiempo, dado el 
avance de la tecnología, proponer una clasificación de este tipo de profesionales de acuerdo al ámbito de acción de los mismos.

A seguir presentaremos la Computing Curricula Overview 2005 (ACM, 2005) que permitirá aclarar las áreas de actuación e influencia en computación.

Para programas de pregrado en computación se proponen cinco grandes disciplinas:

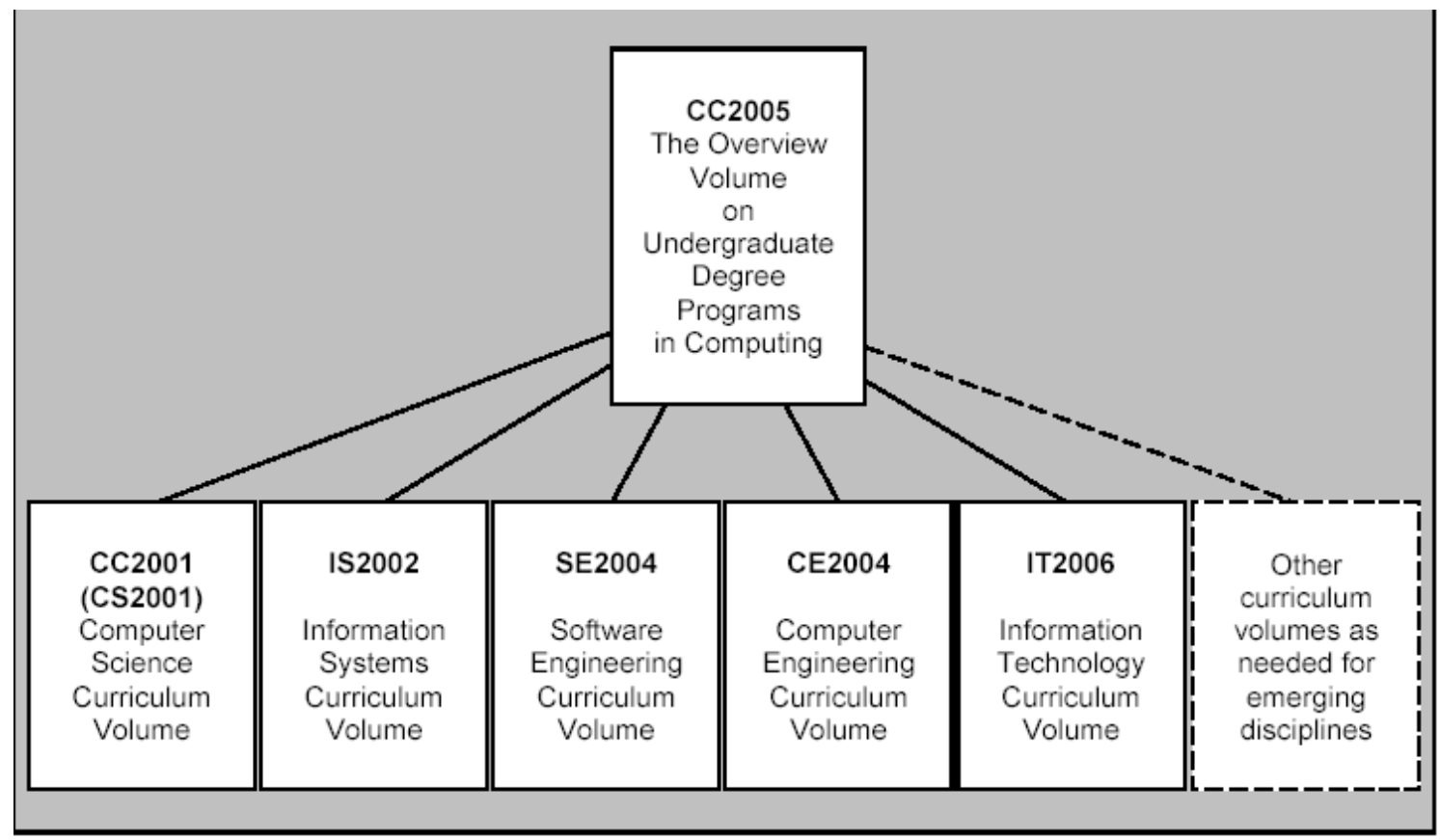

Figura 1. Disciplinas de computación según Computing Curricula de ACM (2005)

CE Computer Engineering (Ingeniería de Computación)

CS Computer Sciences (Ciencias de la computación)

IS Information Systems (Sistemas de Información)

SE Software Engineering (Ingeniería de Software)

IT Information Technology (Tecnologías de Información).

Como expuesto, el término "computing" ha sufrido y seguirá sufriendo grandes cambios debido al crecimiento constante en su cuerpo de conocimientos, siendo necesaria la división de algunas disciplinas para dar paso a otras nuevas. En la Figura 2, se muestra la evolución de las carreras en los últimos años. En esta figura se muestra una disciplina adicional: EE Electrical Engineering (ingeniería eléctrica), que debido a los avances en tecnología relacionados con el hardware, tiene una gran influencia en computación. 


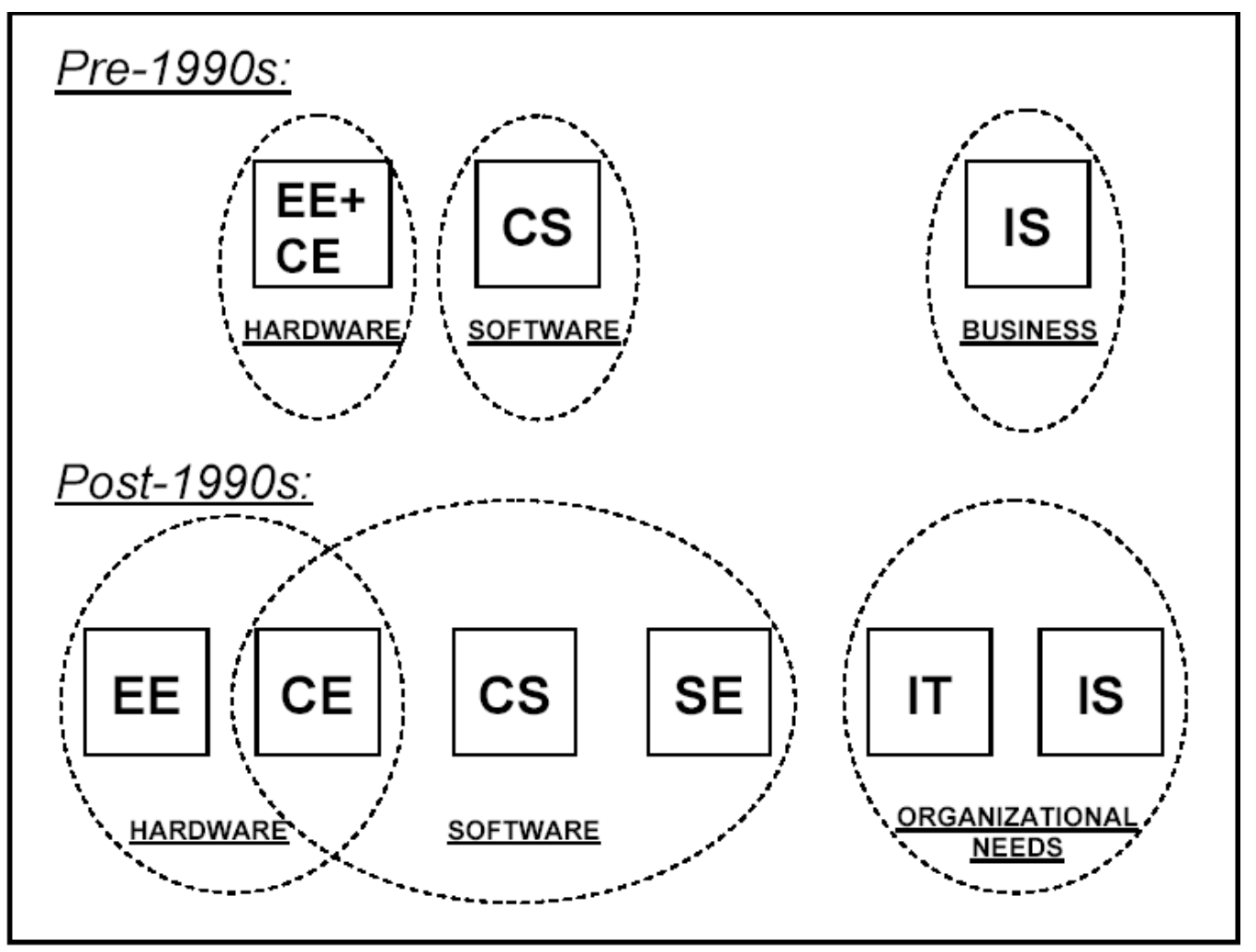

Figura 2. Evolución de las carreras según la Computing Curricula de ACM (2005)

Para entender mejor las diferencias y coincidencias de las diferentes disciplinas de computación, usaremos los gráficos expuestos en ACM (2005). Esta propuesta está considerada como uno de los referentes más importantes a nivel mundial. En el Perú, por ejemplo algunas universidades ya han asumido esta clasificación como válida e imparten carreras siguiendo sus pautas.

Analizando la Figura 3, se observa que el eje horizontal varía desde teoría y sus principios (Theory, Principles Theory) a la izquierda, hacia despliegue de aplicaciones (Applications Deployment), a la derecha. Entendiendo que una carrera que se orienta al trabajo en un laboratorio diseñando nuevos dispositivos o en el desarrollo de nuevos principios y/o teorías, tendrá una orientación sesgada hacia el lado izquierdo. De otro lado, una carrera que se orienta al servicio directo de las empresas y ayudarlas a escoger o usar apropiadamente la tecnología, o a aprender la forma de integrar productos para resolver problemas empresariales, estará más orientada hacia el lado derecho. Podemos ver claramente que este eje nos indica la cercanía hacia las teorías y sus principios o el alejamiento de la generación de estas teorías y más bien su énfasis será la aplicación de esas teorías en la solución de problemas. Debido a que existe una gran variedad de trabajos y tareas que se pueden 
ubicar entre estos dos extremos, no se debería mirar únicamente la izquierda o la derecha, sino más bien el rango de opciones entre estos extremos.

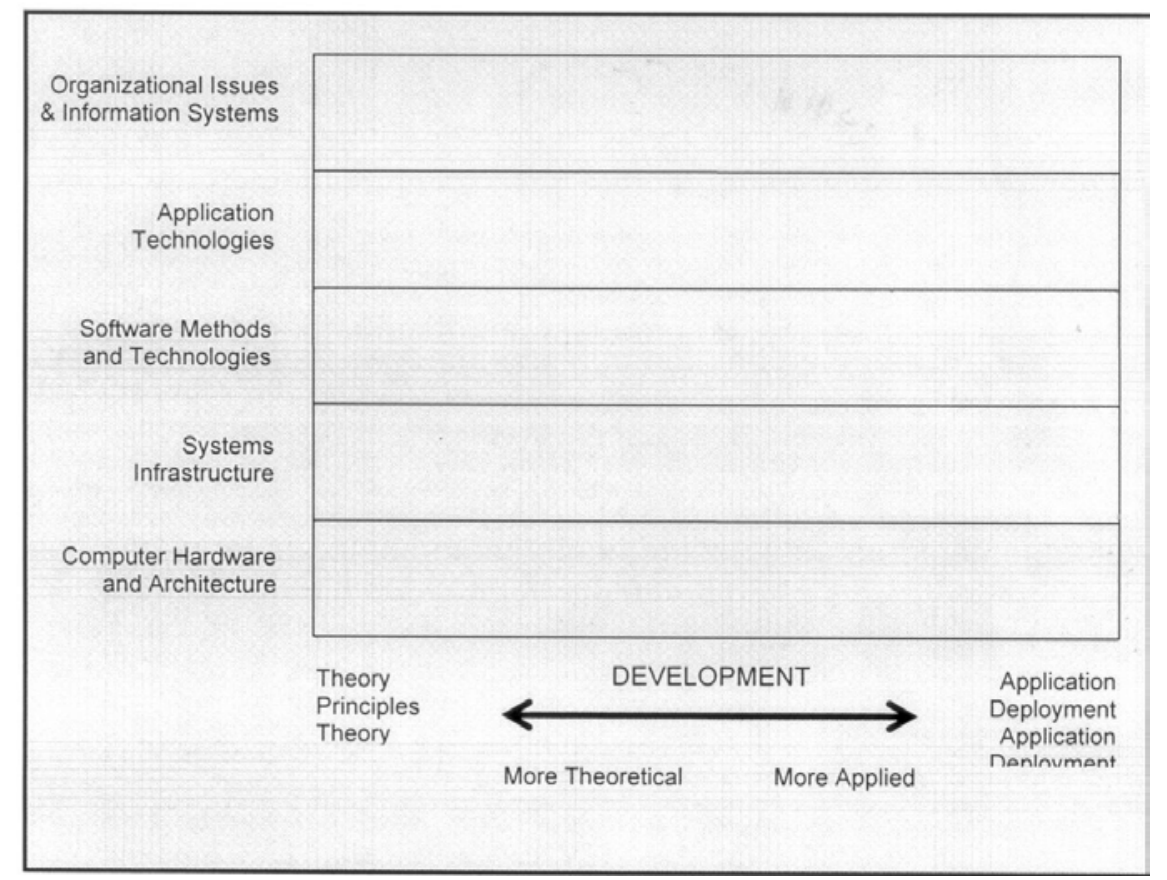

Figura 3. El espacio del problema en computación de ACM (2005)

Se observa que el eje vertical varía desde computadora hardware y arquitectura (Computer, Hardware and Architecture) en la parte inferior, hacia sistemas de información y temas organizacionales (Organizational Issues \& Informations Sytems) en la parte superior. En esta parte superior del eje, el foco está dirigido a solucionar problemas de las empresas y del manejo de la información, mientras que la parte inferior del eje, está más dirigida a los dispositivos y los datos compartidos entre estos dispositivos. Por tanto, si una carrera se orienta a diseñar y construir circuitos o al trabajo interno de las computadoras, estará ubicada en la parte inferior del espacio, mientras que una carrera que se orienta a la forma de cómo la tecnología puede trabajar en beneficio de las empresas o a estudiar el impacto de la tecnología de la información ( $\mathrm{TI})$ en las organizaciones, estará ubicada hacia la parte superior del espacio.

Obviamente se deben considerar ambas dimensiones al mismo tiempo. Por ejemplo, una carrera que se orienta al trabajo para las empresas pero está interesada en diseñar nuevos dispositivos, estará ubicada en la parte inferior derecha, pero otra que desea desarrollar nuevas teorías acerca de cómo la información afecta a las organizaciones, estará ubicada en el espacio superior izquierdo. 
Pasaremos, a continuación a exponer la descripción de ACM (2005), para cada una de las carreras mostradas en la Figura 1.

\section{Ingeniería de Computación (Computer Engineering CE)}

Estas carreras están orientadas a la adquisición de conocimientos relativos al diseño y construcción de computadoras y de los sistemas basados en computadoras. Esto involucra el estudio del hardware, software, comunicaciones y la interacción entre ellos. Sus planes de estudios se enfocan en las teorías, principios y prácticas de la ingeniería eléctrica tradicional y de las matemáticas, para aplicarlas a los problemas del diseño de computadoras y dispositivos basados en computadoras.

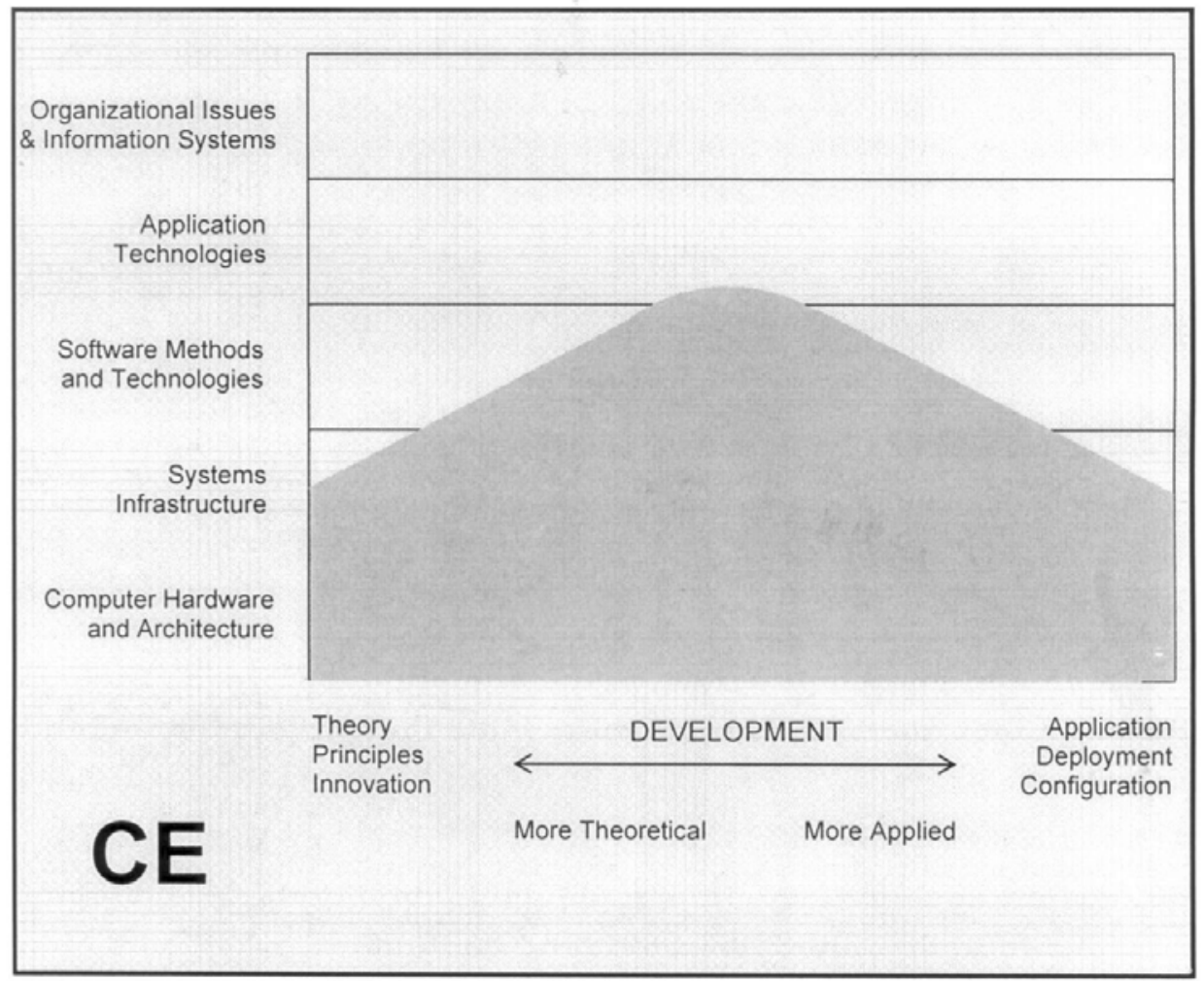

Figura 4. Alcance de Ingeniería de Computación (ACM, 2005)

Los estudiantes de ingeniería de computación se preparan para el diseño de sistemas digitales de hardware, incluyendo sistemas de comunicación, computadoras y de dispositivos que contienen computadoras. También estudian el desarrollo de software enfocado al software usado por dispositivos digitales y sus interfaces con usuarios y otros dispositivos. El estudio de CE puede enfatizar el hardware más que el software o puede tener un énfasis balanceado, con una fuerte tendencia a la ingeniería. 
Actualmente un área dominante dentro de CE son los sistemas embutidos, es decir el desarrollo de dispositivos que tienen software y hardware incorporados en ellos (teléfonos celulares, equipos de video y audio digital).

\section{Ciencias de la computación (Computer Science CS)}

Las carreras de CS, engloban un amplio rango de estudios de la computación que abarcan desde sus fundamentos teóricos y algorítmicos, hasta desarrollos avanzados en robótica, sistemas inteligentes, bioinformática y otras innovadoras áreas. Se dedican a diseñar e implementar software, a supervisar programadores manteniéndolos informados de los nuevos avances, crean nuevas maneras de usar las computadoras (nuevas redes de computadoras, nuevas bases de datos), desarrollan maneras efectivas de resolver problemas de computación (mejores formas de almacenamiento de información, de enviar datos por la red, entre otros).

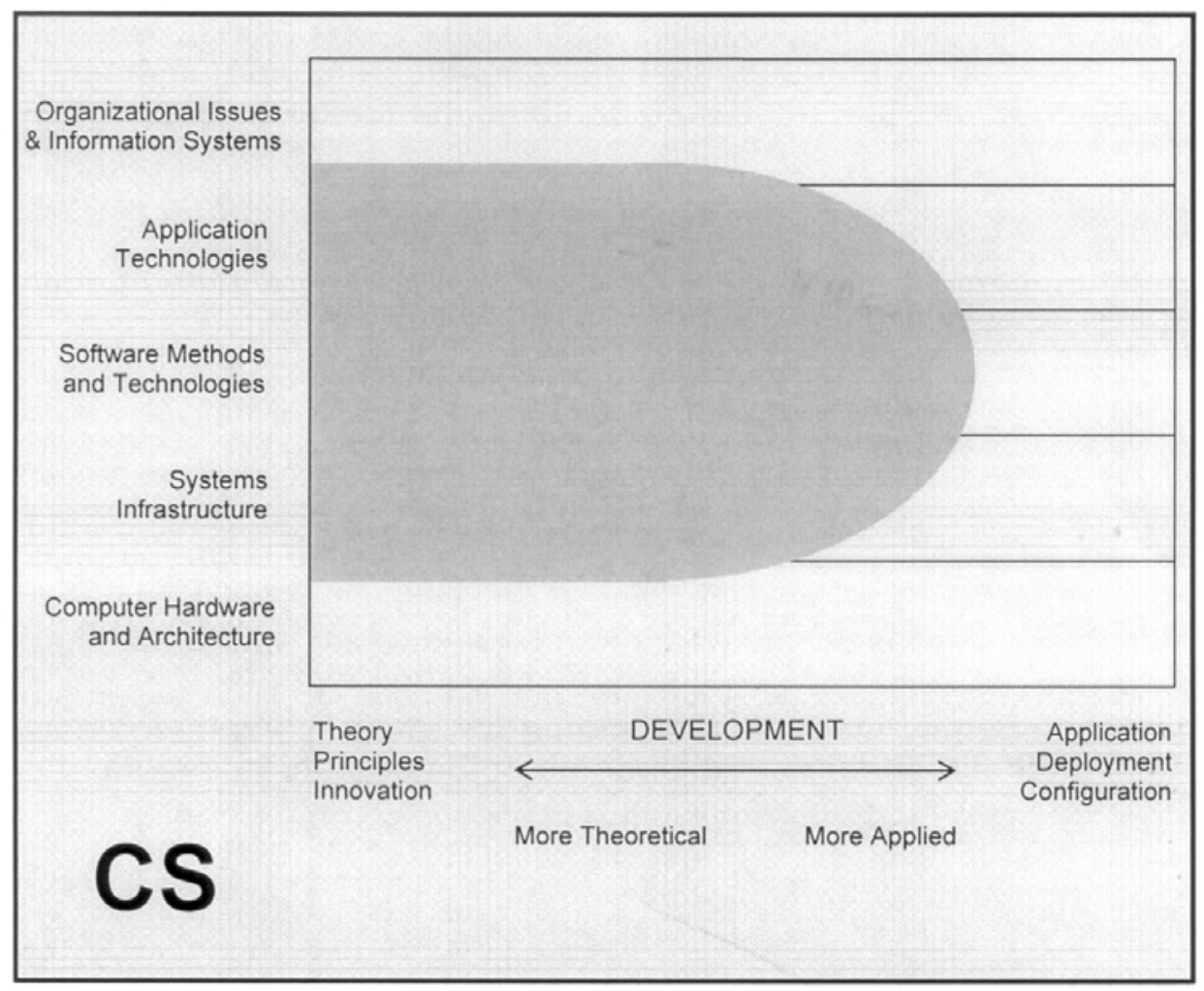

Figura 5. Alcance de Ciencias de la Computación (ACM, 2005)

Los planes de estudios reflejan una gran amplitud de conocimientos que van desde la fundamentación teórica a la programación, por lo cual muchas veces son criticados por fallar en preparar graduados para trabajos específicos de la empresa, ya que su foco principal es la computadora como tal y los avances que se puedan obtener de ella. Mientras otras disciplinas pueden producir graduados con habilidades más 
relevantes para el trabajo inmediato, CS ofrece los fundamentos que permiten a sus graduados adaptarse a las nuevas tecnologías.

\section{Ingeniería de software (Software Engineering SE)}

En las carreras de ingeniería de software, el énfasis es el desarrollo y mantenimiento de sistemas de software para que su comportamiento sea confiable y eficiente, que sean factibles de desarrollar, de mantener y que satisfagan todos los requerimientos que los clientes hayan definido para estos sistemas. También estudian y/o proponen metodologías de desarrollo de software e investigan métricas para medir el desempeño de los sistemas.

Más recientemente han evolucionado en respuesta a nuevos factores que se desprenden del avance tecnológico, como por ejemplo el creciente impacto de grandes y costosos sistemas de software en un amplio rango de situaciones y el incremento de la importancia del software en aplicaciones de seguridad crítica. Como ejemplo de estos grandes sistemas están los denominados Enterprise Resource Planning (ERP), que son grandes sistemas de información, ciertamente costosos, que son desarrollados para atender las necesidades típicas de las empresas, como por ejemplo sistemas de planillas.

La ingeniería de software busca integrar los principios de las matemáticas y las ciencias de la computación con las prácticas de la ingeniería desarrolladas para artefactos físicos tangibles, pero SE es diferente en su carácter respecto de otras disciplinas de ingeniería, debido tanto a la naturaleza intangible del software como a la naturaleza discontinua de la operación del software. 


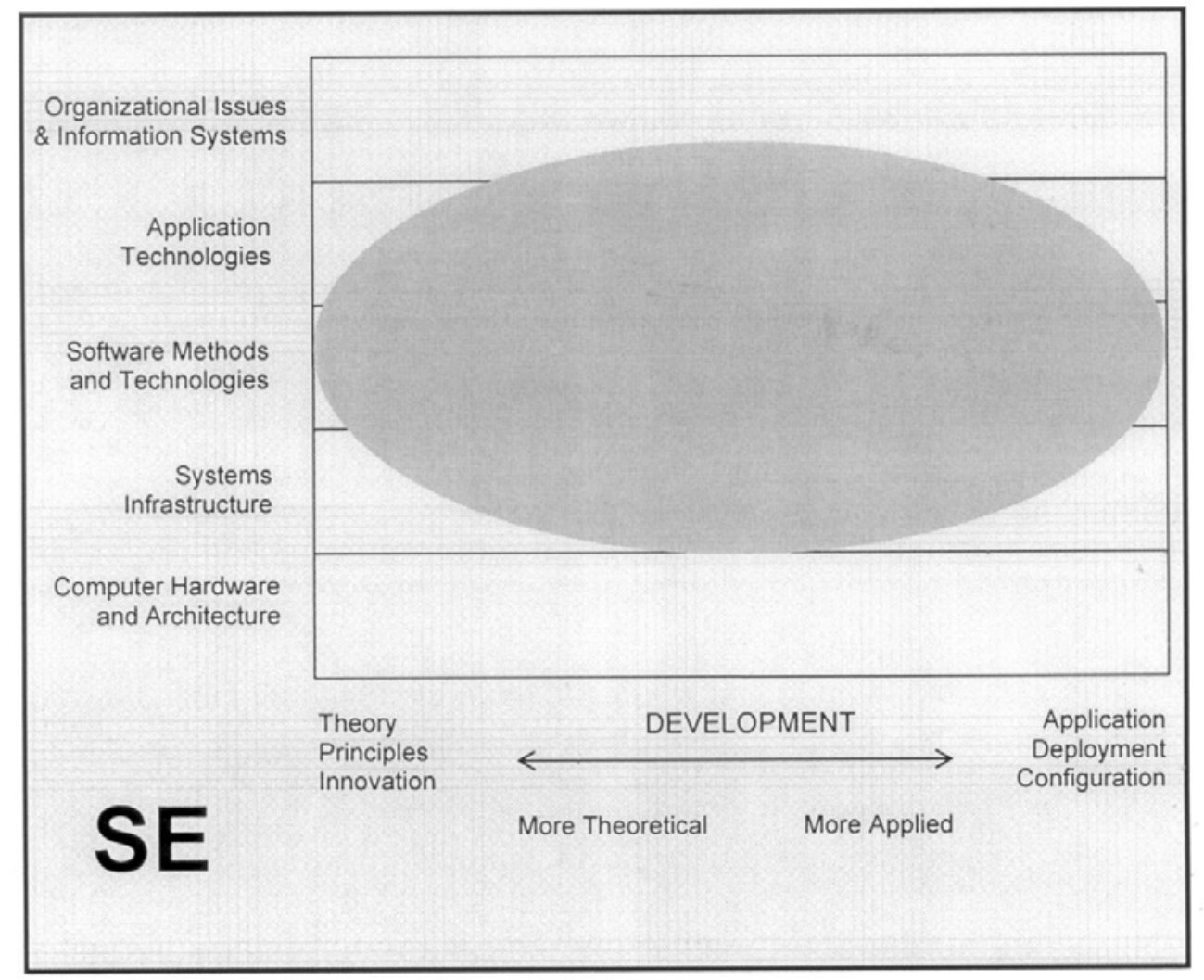

Figura 6. Alcance de Ingeniería de Software (ACM, 2005)

Los estudiantes de SE deben asegurarse de entender las necesidades de los clientes y desarrollar software utilizable, que satisfaga estas necesidades. Uno de los principales objetivos en la formación de estos profesionales es conocer cómo lograr que el software sea genuinamente útil y utilizable por sus usuarios.

\section{Sistemas de Información (Information Systems IS)}

Las carreras de sistemas de información se enfocan en integrar las soluciones de tecnologías de información y los procesos de negocios para cumplir con las necesidades de información de las organizaciones, permitiéndoles alcanzar sus objetivos de una manera efectiva y eficiente. Estas carreras enfatizan la información y, en este sentido, asumen la tecnología como un instrumento que permite la generación, procesamiento y distribución de la información requerida por la empresa. Los profesionales de esta disciplina están principalmente interesados en la información que los sistemas de información pueden proporcionar, de manera a ayudar a una empresa a definir y alcanzar sus metas, igualmente se focaliza en los procesos que una empresa puede implementar y/o mejorar usando tecnologías de información. Ellos deben comprender tanto factores tecnológicos como organizacionales, y deben ser 
capaces de ayudar a una organización a determinar cómo la información y los procesos de negocios obtenidos gracias a la tecnología, pueden proporcionar una ventaja competitiva.

Los especialistas en IS juegan un rol clave en determinar los requerimientos de los sistemas de información de una organización y están inmersos en su especificación, diseño e implementación. Como resultado, estos profesionales, requieren de un sólido entendimiento de los principios y prácticas organizacionales, de manera que puedan servir como un puente entre la comunidad tecnológica y comunidad administrativa de una organización, permitiéndoles trabajar en armonía para asegurar que la organización tenga la información y los sistemas que necesita para soportar sus operaciones. En la actualidad un gran número de estos programas han sido ubicados en escuelas de negocios y denominados genéricamente como Management Information Systems.

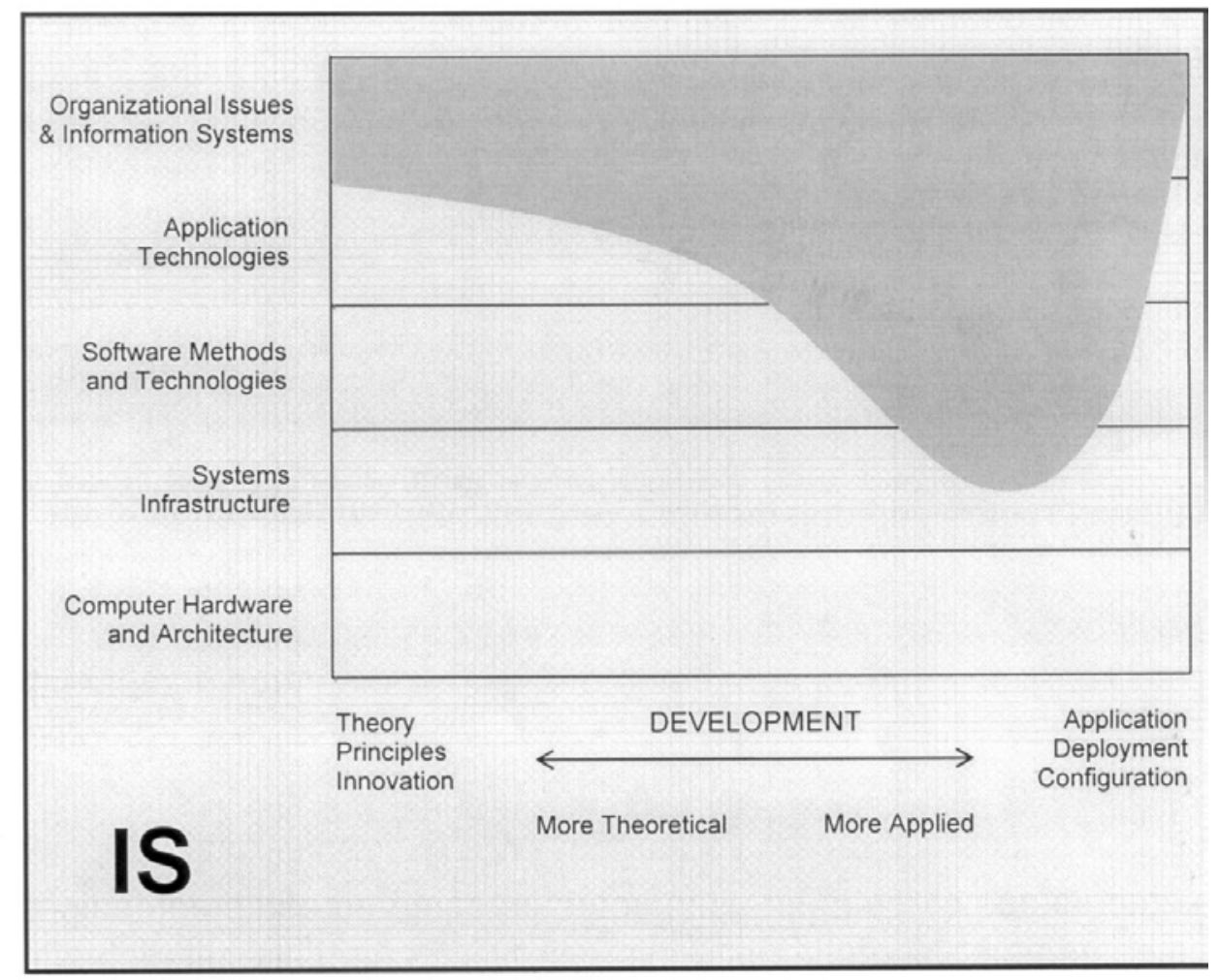

Figura 7. Alcance de Sistemas de Información (ACM, 2005)

\section{Tecnologías de la Información (Information Technology IT)}

Es importante precisar que el término information technology tiene dos acepciones, en un sentido amplio information technology es usado para referirse a computación como un todo, incluyendo hardware y software. En el ámbito académico, 
se utiliza para referirse a los programas de pregrado que preparan estudiantes para satisfacer las necesidades tecnológicas de las organizaciones. Por ejemplo, cuando de se dice que las tecnologías de la información están, hoy en día, presentes en todas las empresas, se usa IT con el sentido de la primera acepción expuesta. Para en esta parte del trabajo, obviamente se usa IT con la segunda acepción ya que se refiere a disciplinas de computación y su alcance tanto en conocimientos como su aplicación en la sociedad.

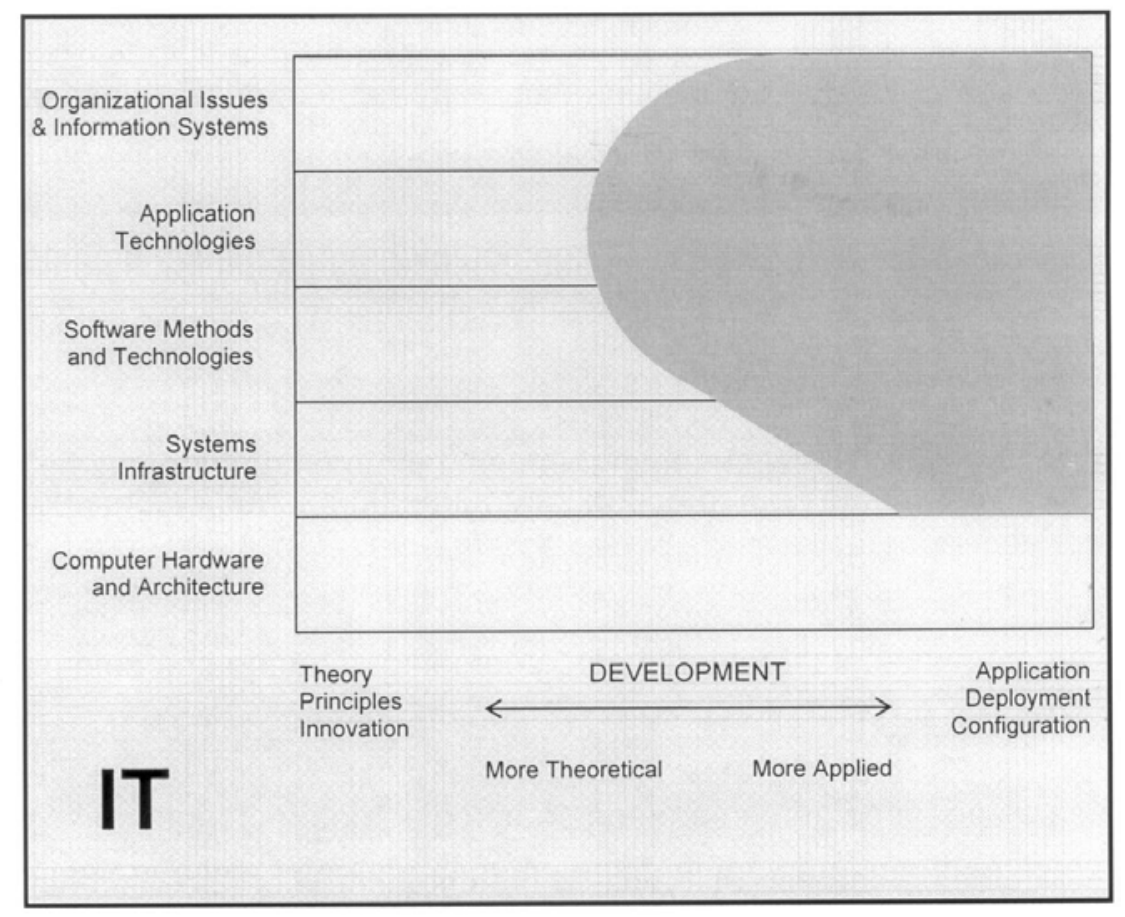

Figura 8. Alcance de Tecnologías de la información (ACM, 2005)

Como ya se expuso information systems se enfoca en los aspectos de información, en este sentido information technology es el complemento de dicha perspectiva: su énfasis está en la tecnología en sí misma, más que en la información que procesa. IT es una disciplina nueva y con un rápido crecimiento, que empezó como una respuesta a las necesidades prácticas y cotidianas de las organizaciones. Hoy en día organizaciones de todo tipo dependen de las tecnologías de la información. Las necesitan para tener sistemas apropiados que funcionen adecuadamente, que sean seguros y posibles de mejorar, que sean pasibles de mantenimiento y de ser reemplazados cuando sea necesario. Las personas en una organización requieren el soporte del equipo de tecnología de la información, un equipo que entienda los sistemas de las computadoras y su software y que estén preparados para resolver 
cualquier problema que pudieran tener relacionado a las computadoras. Los graduados de programas de information technology satisfacen estas necesidades.

Los programas en IT surgen porque las carreras de las otras disciplinas de la computación no estaban produciendo una adecuada oferta de graduados capaces de manejar las necesidades expuestas, los graduados de CS, SE e IS están más orientados al software y no tanto así al hardware. Los programas de IT existen para producir graduados que posean la correcta combinación de conocimiento y la práctica: la experiencia práctica del manejo de la infraestructura de las tecnologías de la información de una organización, así como la atención de los problemas que tienen las personas que la utilizan. Los especialistas de IT asumen la responsabilidad de seleccionar los productos de hardware y software apropiados para una organización, integrando estos productos con las necesidades organizacionales y su infraestructura; instalando, adecuando y manteniendo estas aplicaciones para los usuarios de las computadoras de la organización. Ejemplos de estas responsabilidades incluyen: la instalación de redes; administración y seguridad de redes; el diseño de páginas web; el desarrollo de recursos multimedia; la instalación de componentes de comunicación; la supervisión de productos e-mail; el planeamiento y administración del ciclo de vida tecnológico por el cual, la tecnología de una organización es mantenida, mejorada y remplazada.

\section{Ingeniería de Sistemas}

En la sección anterior se presentaron las cinco tendencias en el área de computación de más difusión y aceptación en la comunidad académica de computación, pero para el presente estudio es necesario hacer una presentación similar para ingeniería de sistemas que, aunque no es estrictamente una disciplina de computación a nivel internacional, su exposición es requerida para entender la problemática del Perú, que se presentará posteriormente.

Como se expone en CIP (2006), tratar de establecer un perfil de la carrera de ingeniería de sistemas es un asunto complicado, debido a la falta de documentos fundamentales, que si existen en el caso de computación por tratarse de un área nueva y que, por el avance tecnológico, ha sufrido grandes cambios que motivaron la necesidad de establecer perfiles orientados a las diferentes áreas de computación.

Según la Internacional Council on Systems Engineering INCOSE (2006) los orígenes de la ingeniería de sistemas se remontan a los años 1900 y los primeros intentos por enseñar ingeniería de sistemas son de 1950 en el Massachusetts Institute 
of Technology (MIT). Así mismo define un sistema como un conjunto de elementos diferentes que como conjunto producen resultados que no se pueden obtener de los elementos por sí solos. Los elementos pueden ser personas, hardware, software, instalaciones, políticas y documentos.

También hace una distinción en las siguientes áreas: la ingeniería de sistemas que se focaliza en el sistema como un todo y en todo el ciclo de vida del sistema, mientras que la ingeniería de componentes se focaliza en el diseño detallado y en la implementación, en tanto que la ingeniería de software tiene como foco central el desarrollo del software considerado como el conjunto de programas, instrucciones y reglas informáticas para ejecutar ciertas tareas en una computadora.

En INCOSE (2006) se menciona que A. Wayne fundó el primer Departamento Académico de ingeniería de sistemas del mundo en la Universidad de Arizona en 1960. Fue el pionero de la ingeniería de sistemas basada en las matemáticas y lideró el cambio de hacia la ingeniería de sistemas basada en modelos.

\section{Computación en el Marco Peruano}

Según lo expuesto por CIP (2006), podemos aceptar, en relación a computación, que básicamente se han desarrollado dos tendencias respecto a la denominación usada para esta nueva área del conocimiento, la angloamericana con el término computación y la europea con el término informática. En el entorno latinoamericano se han venido usando los dos términos indistintamente como consecuencia de la influencia de ambas corrientes.

A pesar del continuo debate sobre si computación es ciencia o no, y considerando el campo de acción de "computer sciencies" propuesto por ACM (2005), y para justificar la denominación de computación como ciencia usada en los párrafos siguientes, utilizamos y compartimos el argumento expuesto por Denning (2005), en el sentido de que computación es una ciencia aplicada que se centra en el conocimiento de utilidad demostrable y que estudia el procesamiento de la información.

Si consideramos, por un lado, que la ingeniería de sistemas tiene poco más de un siglo de desarrollo (conceptos bien definidos y formalizados), en tanto que computación/informática, como nueva ciencia, tiene poco más de medio siglo de desarrollo (consecuentemente los conceptos no están estrictamente definidos y formalizados) y, por otro lado, que con la globalización de Internet, que nos permite comparar los conceptos usados a nivel mundial, CIP (2006, p.67) afirma que se ha 
generado "una situación casi caótica" porque se cuestionan el "uso de términos y conceptos que hasta ayer nos parecían inamovibles".

Analizando la definición de computación como palabra válida del idioma español, reconocida por el Diccionario de la Real Academia Española (DRAE) (informática: Conjunto de conocimientos científicos y técnicas que hacen posible el tratamiento automático de la información por medio de ordenadores), notamos que es un anglicismo por su procedencia, y que además es un americanismo, procedente de la palabra computing y que se emplea frecuentemente en los países del continente americano.

De otro lado la palabra informática también es una palabra válida del idioma español, reconocido por el DRAE, notamos que es un galicismo por su procedencia y que en un comienzo (década de los 60 y 70) era un hispanismo pero que actualmente ha extendido su uso en nuestros países, como expone CIP (2006).

De lo expuesto se puede concluir que los términos computación e informática son sinónimos en el idioma español, aun cuando en el contexto latinoamericano se viene usando con una ligera diferencia semántica. Según (CIP, 2006):

Así, se emplea computación cuando se quiere asociar a aspectos más técnicos o científicos, como en 'algoritmos computacionales' o 'ciencias de la computación' y se emplea informática cuando hacemos referencia a las aplicaciones o temas más afines a los usuarios, como en 'aplicaciones informáticas' o en 'informática jurídica' o en 'derecho informático'. (p.66).

A fines de los años 60 aparece en el Perú, la denominación de ingeniero de sistemas empleada por las empresas de software como IBM o NCR, para denominar a su personal especialmente preparado, en sus productos, para proponer soluciones a las necesidades de procesamiento de datos de sus clientes (CIP, 2006). Es importante resaltar que este uso de la denominación "ingeniero de sistemas" no requería de ningún requisito de formación académica universitaria, la capacitación la otorgaban las propias casa de software que especializaban a su personal en el uso específico de los productos de su marca.

En 1969 la Universidad Nacional Mayor de San Marcos (UNMSM) firma un convenio de cooperación bilateral con el gobierno francés y recibe a cooperantes franceses, quienes crean la especialidad de computación, dentro de la carrera de 
matemática pura, con un plan de estudios que contenía principalmente cursos de matemática, estadística, investigación operativa y física. Esta especialidad incorporaba algunos cursos de computadoras como circuitos lógicos y digitales, programación de computadoras y teoría de la información. Años después se crea el programa académico de computación, siempre dentro de la Facultad de Matemática, incorporando esta vez, mayor cantidad de cursos asociados a computación, dejando de lado muchos cursos de matemática. Esta carrera formaba los licenciados en computación, denominación única en el Perú, que fueron los pioneros de esta disciplina en el país. En 1995 la UNMSM extingue la carrera de computación y crea en remplazo la carrera de ingeniería sistemas e informática, con un plan de estudios muy similar al plan de estudios de la carrera de computación.

En la década de los 60 la Universidad Nacional de Ingeniería (UNI) recibe una computadora IBM 1130 y la asigna a la Facultad de Ingeniería Industrial y Sistemas. Esta computadora adquiere un gran protagonismo, al convertirse en la herramienta ideal para realizar de manera rápida y eficiente los cálculos necesarios a la optimización de sistemas.

Posteriormente en 1974, la UNI crea el Programa Académico de Ingeniería de Sistemas dentro de la Facultad de Ingeniería Industrial y Sistemas con un plan de estudios que incluía cursos de matemática, física, química, dibujo técnico, geometría descriptiva, teoría de sistemas, métodos numéricos, física, resistencia de materiales, sistemas computacionales, lenguajes algorítmicos, análisis y diseño de sistemas, administración de empresas, economía, contabilidad, entre otros. Se puede apreciar, por los cursos impartidos, que la idea de esta profesión no era tener especialistas en computadoras (CIP, 2006).

Con el avance constante de la computación, frente a la estabilidad de los conceptos matemáticos que rigen la ingeniería de sistemas, computación gana protagonismo en la carrera de ingeniería de sistemas de la UNI y la sociedad peruana se habitúa a asociar el conocimiento de computación a la mencionada carrera.

Se puede notar que el uso generalizado de ingeniería de sistemas en el Perú, se debe, por un lado al uso de esta denominación por las casas de software y a su vez porque la misma denominación fue usada en la UNI para una carrera profesional que, como explicado, con los años le da mayor protagonismo a la computación. Si a esta situación aunamos el liderazgo indiscutible de la UNI en el campo de la ingeniería en 
el Perú, tenemos como consecuencia un difundido uso de ingeniería de sistemas para un profesional de computación.

En la década de los años 70 y 80 el mercado comienza a demandar profesionales en computación y ante la escasa oferta, básicamente los licenciados egresados de San Marcos y los ingenieros de sistemas de la UNI, esta necesidad fue cubierta en su gran mayoría por ingenieros industriales que aprendieron la tecnología en el ámbito laboral.

En la década de los años 80, con la aparición de las computadoras personales (del inglés personal computers PC's) surge una creciente necesidad de profesionales especializados, con lo cual aparecen propuestas educativas a nivel universitario y técnico, cada una usando los términos computación, informática y sistemas de manera indistinta y/o combinada, sin tener en cuenta el verdadero significado de los términos. La idea era cubrir la necesidad del mercado laboral que demandaba profesionales con conocimientos de computación.

La diversidad de propuestas educativas se multiplica con el correr de los años hasta llegar a la situación actual, de tener más de 70 propuestas educativas para el área de computación/informática con variadas denominaciones, combinando ingeniería de sistemas, computación e informática de diversas maneras como ingeniería de computación e informática; ingeniería de computación y sistemas; ingeniería informática; ingeniería informática y sistemas; entre otras como explicado en CIP (2006).

Considerando la situación en el Perú, referente al uso no formalizado de los términos computación, informática y sistemas, expuesta en el acápite anterior, teniendo presente la propuesta de las cinco áreas de computación de la ACM (2005) pero tratando de establecer qué tipo de profesional es requerido por la empresa en el Perú, en esta investigación no usaremos ninguno de los nombres propuestos por la ACM, para no sesgar el estudio a una de las áreas propuestas por la ACM, usaremos la denominación "ingeniería informática" como objeto de nuestro estudio.

\section{Marco Teórico}

Según Rodríguez (2007), los cambios, en la actual llamada Sociedad del Conocimiento, los continuos avances científicos, generan como consecuencia, la creación de nuevas empresas y de nuevas formas de trabajo, que a su vez requieren 
formas diferentes de enseñanza-aprendizaje en la educación. Estos cambios exigen una visión moderna del desempeño basado en competencias para el trabajo.

Esta tendencia de focalizar la educación en la formación por competencias se venía discutiendo en diversos foros internacionales, como pasaremos a exponer de manera resumida, a fin de establecer que la formación por competencias es una tendencia mundial.

En 1998 se realiza en Paris la primera Conferencia Mundial sobre la Educación Superior, promovida por la UNESCO, en la cual se reúnen representantes de gobiernos, de la academia, y de diversos sectores empresariales, con el objetivo de debatir sobre temas relativos a la educación superior y llegar a un acuerdo sobre el tipo de educación superior que se quiere para el siglo próximo, para qué sociedad y para qué mundo. Una de las conclusiones importantes de esta reunión es que el rol de la educación debe cambiar y no tener únicamente como misión la función tradicional de la enseñanza, sino más bien preocuparse por el desarrollo de valores personales y sociales en los estudiantes. Otro punto importante destacado en esta reunión es la interacción entre la educación superior y el mundo del trabajo.

Posteriormente en 1999, se firma la Declaración de Bolonia, acuerdo que tenía como objetivo facilitar el intercambio de titulados en Europa y adaptar el contenido de los estudios universitarios a las demandas sociales para mejorar su calidad y competitividad. Como corolario de esta declaración, surge en 2001 el proyecto Tuning Europa, que da inicio al proyecto Alfa Tuning Latinoamérica que tiene como uno de sus objetivos establecer la lista de competencias genéricas y específicas que debería tener un egresado de una universidad, de acuerdo a lo expuesto en el informe final del Proyecto Tuning (2007).

En este contexto, el Proyecto 6X4 UELAC (2008) analiza los factores que inciden en la formación de profesionales, tales como la globalización y el desarrollo de las tecnologías, que generan cambios en las destrezas necesarias en los profesionales, lo que implica en planes de estudio flexibles, una educación continua, un enfoque colectivo más que individual y en asegurar que el flujo del conocimiento entre universidad y mercados exista.

Se puede notar claramente de las referencias mencionadas que existe una clara tendencia al cambio del modelo de la Educación Superior hacia un modelo de formación por competencias, que privilegia la participación del estudiante como un 
elemento activo del proceso de aprendizaje y está orientado a la adquisición de habilidades y valores personales.

Originalmente el concepto de competencia fue relacionado a aspectos laborales, como menciona UELAC (2008), pero en otros trabajos, como el de Reátegui, Arakaki y Flores (2001), que define:

Competencia es el desempeño eficiente y eficaz de una actividad, y entraña una compleja red de saberes (saber qué, el saber cómo y el saber ser) respecto a un segmento grande o pequeño de la experiencia humana en el mundo. Implica, asimismo tener conciencia sobre el propio desempeño. (p.30).

Se trata entonces de establecer las competencias requeridas en un profesional para su buen desempeño como tal, de acuerdo a su profesión y con el objetivo de cubrir los requerimientos del mercado que lo necesita.

En el caso del proyecto Tuning Latinoamérica (2007), se plantea una lista de 27 competencias genéricas, que fueron obtenidas en base a las 30 definidas por el proyecto Tuning Europa. El foco de estas competencias está centrado en capacidades consideradas importantes para el desempeño futuro de un egresado de la universidad y están relacionadas a valores, actitudes, aptitudes y relacionamiento social. En relación a competencias específicas, si bien abarcan el campo de las ingenierías, específicamente ingeniería civil, no son específicas para ingeniería informática.

En lo referente a conocimientos específicos para computación, uno de los trabajos más importantes es el de ACM, (2004) que establece un modelo de plan de estudios para programas de pregrado en las diferentes áreas de la computación, en tanto que en ACM (2005) se determinan las especialidades y los perfiles profesionales, como ya fue expuesto, pero focalizado en clasificar las áreas de conocimiento de computación.

Una propuesta interesante para competencias específicas para carreras de computación, se presenta en el año 2005, en el Libro Blanco de la Agencia Nacional de Evaluación de la Calidad y Acreditación (ANECA), que tiene como uno de sus objetivos el estudio de la carrera de ingeniería informática en España, su estructura curricular y su relación con el mercado laboral, la estructura de las materias básicas, la ampliación de horizontes de los graduados, entre otros aspectos. 
En ese libro se exponen los conocimientos indispensables que un ingeniero informático debería tener, cuáles las funciones a desempeñar, pero también propone una lista de competencias genéricas inherentes a su formación. Lo interesante de esta propuesta es la clasificación que realiza de las competencias genéricas, denominándolas competencias instrumentales (incluye conocimientos de lenguas, aptitudes de análisis, organización, gestión y toma de decisiones); competencias personales (relativas básicamente a relación interpersonal) y competencias sistémicas (incluyendo aspectos relativos a actitudes y su relación con el entorno). Así mismo propone una lista de competencias específicas relacionadas con habilidades adquiridas en los cursos del plan de estudios, tanto en cursos específicos de computación, así como cursos de otras áreas como matemática, estadística, comercial y empresarial. En relación a los conocimientos declarativos propone los generales de la ingeniería informática, los específicos de la especialización, otros conocimientos y habilidades adquiridas en la universidad así como habilidades adquiridas en la práctica pre profesional.

En el ámbito Latinoamericano tenemos el trabajo de Lacerda (2002), que realiza un estudio analizando la formación y posterior inserción laboral de los egresados de la carrera computación e informática de la Universidad Federal de Rio de Janeiro en el Brasil. El estudio realizado por Lacerda (2002) en los docentes, en cuanto a competencias específicas, se centra en los cursos de su plan curricular. En tanto que el estudio realizado en el mercado laboral, realizado en sus egresados, está focalizado en otros aspectos tales como continuidad de los estudios a nivel post grado, cargos ocupados, salarios, tipo de empresa empleadora, detalle de uso de tecnología (por marca), entre otros.

En el Perú uno de los trabajos más importantes fue desarrollado por una Comisión creada por el Colegio de Ingenieros del Perú, que publicó en 2006 el informe "Denominaciones y perfiles de las carreras en ingeniería de sistemas, computación e informática" con recomendaciones para estandarizar la enseñanza universitaria de las carreras relacionadas a computación en el Perú. Este trabajo, basado en la propuesta de la ACM (2005), está más orientado a aclarar los términos usados en el país para las carreras del área de computación, tratando de adecuarlas a la propuesta de la ACM.

Los trabajos mencionados, entre otros, servirán de base, con algunas modificaciones, para la presente investigación ya que sus resultados establecen tanto 
competencias genéricas (Proyecto Tunning, 2007) como específicas (Libro Blanco, 2005).

De otro lado trabajos como el de Gottschalk (2007) y Camilo (2007) muestran la tendencia de países desarrollados, donde está cambiando el rol del gerente de informática, de un profesional centrado únicamente en la tecnología, a un profesional que podría alcanzar la posición de gerente general, ofreciendo a las empresas un análisis teórico y recomendaciones, desde el lado de las tecnologías de la información, de forma a mejorar la toma de decisiones. Estos trabajos parecerían indicar que además de las competencias genéricas y específicas de un ingeniero informático, se deberían plantear competencias relacionadas a la gestión empresarial, de manera tal que se prepare al Ingeniero Informático para ocupar el cargo de Gerente General.

Ubicándonos en un entorno educativo, más precisamente en la Universidad, es claro que el objetivo de ésta es formar profesionales que puedan desempeñarse eficientemente en el mercado laboral, para lo cual es necesario que los alumnos egresen de las aulas universitarias con las competencias y conocimientos requeridos por este mercado.

\section{Problema de investigación}

Desde la aparición de la primera computadora, se han realizado grandes avances tecnológicos que van desde la parte física de las computadoras (hardware), pasando por el desarrollo de programas (software) y por sobre todo, de la forma como el ser humano encara el uso de las computadoras para obtener beneficios que hagan su trabajo más eficiente.

Desde el punto de vista de hardware, la evolución de la tecnología ha sido, es y seguirá siendo vertiginosa. La sociedad está acostumbrada a ver constantemente las innovaciones de la computación tales como la aparición de nuevos modelos de computadoras, nuevos dispositivos y nuevas formas de comunicación que como mencionado en Beekman (1995), Norton (2003) y Gates (1995) están cambiando el comportamiento de la sociedad, dando origen a nuevas herramientas, nuevas demandas y nuevas formas de aprendizaje.

Según Beekman (1995), acompañando el desarrollo tecnológico en hardware, surgen las nuevas tendencias en el uso de computadoras con nuevas tecnologías de comunicación, como ejemplo podemos observar que inicialmente se trabajaba con las computadoras aisladas, luego se usan las computadoras en redes locales y hoy en día 
el trabajo se realiza en redes mucho amplias, como Internet. Por otro lado y como consecuencia natural del avance tecnológico del hardware, las herramientas de desarrollo de software han evolucionado de una forma de trabajo textual (entorno en sistema operativo D.O.S.) a herramientas cada vez cada vez más amigables (entornos gráficos como el sistema operativo Windows) y con mayores capacidades de procesamiento de información, como mencionado en Norton (2003).

En un entorno tan cambiante, continúa Norton (2003), queda claro que desarrollar y dar mantenimiento a los sistemas soportados por computadoras es un trabajo complejo, que requiere las competencias de profesionales especializados, que van desde programadores, pasando por analistas técnicos, hasta gerentes de tecnologías de la información (TI). La tarea de formar estos especialistas no es una tarea sencilla por cuanto se necesita incorporar continuamente los cambios tecnológicos mencionados anteriormente.

De otro lado, inicialmente las computadoras eran vistas como un instrumento para realizar los procesos empresariales de una manera más rápida y eficiente, con lo cual su gran ventaja era el ahorro del costo de mano de obra, es decir se usaban las computadoras para realizar los trabajos rutinarios de una manera más eficiente y consecuentemente más barata. El uso constante de las computadoras, con sus sistemas de información, permitió que las empresas consiguieran tener grandes volúmenes de datos almacenados de una manera estructurada, bien organizada y de fácil y rápido acceso a los mismos. Surge entonces la necesidad de obtener provecho de estos datos almacenados, lo que induce a técnicas de manejo de información que permiten realizar una mejor toma de decisiones basada en la información histórica con la que cuenta una empresa, que está manifestado en INEI (1997).

La computación entonces, cambia su rol inicial de ser únicamente un instrumento para realizar los trabajos de manera más rápida, a un instrumento que permita a la empresa, con el concurso de los profesionales especializados, realizar una mejor toma de decisiones para obtener ventajas competitivas en el mercado en el cual actúan. La expectativa de TI siendo un proveedor de tecnología, ha cambiado a ser un proveedor de servicios, el foco de los usuarios de negocios ahora está dirigido hacia cómo la TI puede proveer algún valor agregado a la adquisición de tecnología.

Actualmente el gerente de informática trabaja muy estrechamente ligado al gerente general de la empresa y como responsable del manejo de toda la información empresarial tiene un conocimiento detallado de la problemática de la empresa, lo que 
lo ubica en una posición laboral privilegiada. Debido a esto, se ve una clara tendencia, en los países desarrollados, de que el gerente de informática ocupe el cargo de gerente general. El rol de los gerentes de informática en los últimos años está estrechamente ligado a la rentabilidad del negocio y a la optimización de los procesos de producción. Si se incorporan los conceptos como visión de negocio o de innovación, estaríamos ante un nuevo gerente de informática, más vinculado a la estrategia del negocio que a la gestión tecnológica, más cercano a la línea estratégica que a la línea operativa. Hay una tendencia a reducir la separación entre la tecnología informática y el negocio, lo que obviamente traerá como consecuencia la difícil búsqueda de profesionales de la informática con conocimientos de negocios (Camilo, 2007).

Si tenemos en cuenta lo expuesto anteriormente, esto es, por un lado, los cambios vertiginosos de la tecnología, tanto en hardware como en software, y de otro lado, las nuevas tendencias en las funciones laborales del profesional informático, es necesario estudiar los requerimientos actuales del mercado en cuanto a la formación universitaria de este tipo de profesional.

Adicionalmente se debe considerar que hoy en día la informática hace parte del quehacer cotidiano de cualquier empresa y que por tanto la demanda de profesionales informáticos está presente en los diferentes sectores de la sociedad, se trata entonces de estudiar las características de un profesional que actuará en los diferentes sectores empresariales y cuyos resultados podrían influenciar a un gran sector de la sociedad.

Es importante determinar las competencias del profesional informático requeridas por la empresa y compararlas con las competencias que los docentes consideran deben estar presentes en la formación de un profesional informático. En base a los resultados se podrán sugerir lineamientos para un plan de estudios de una carrera de ingeniería informática que busque la incorporación de esas competencias, de manera tal que la universidad esté realmente orientada a satisfacer la demanda profesional del sector informático.

De lo expuesto surge de manera natural la interrogante: ¿La percepción en gerentes y docentes de la pertinencia de incorporación de competencias profesionales de ingenieros informáticos en el Perú es la misma?

Con este estudio se busca comparar la percepción de los gerentes respecto a la pertinencia de la incorporación de competencias profesionales de ingenieros informáticos en el Perú, con la percepción de los docentes respecto a estas 
competencias. Los resultados de esta comparación permitirán establecer si existen diferencias de percepción entre ambos grupos, y si fuera el caso cuáles son éstas.

El conocimiento de estas diferencias caso existan, permitirían realizar las sugerencias correctivas en el plan de estudios de una carrera de ingeniería informática que incluirían la percepción de ambos grupos de profesionales como una propuesta de formación universitaria para este tipo de profesionales.

\section{Objetivos}

Por la naturaleza de este trabajo de investigación de tipo descriptivo comparativo y de acuerdo a lo afirmado por Arias (1999, p.16): "En las investigaciones de nivel exploratorio y en algunas de carácter descriptivo comúnmente no se plantean hipótesis de manera explícita, es decir, se trabaja por objetivos.", no se plantea una hipótesis de forma explícita, pero podríamos suponer, para este estudio, que la formación universitaria en ingeniería informática está más orientada a impartir conocimientos de tecnología, dejando de lado las competencias profesionales requeridas por el mercado laboral.

\section{Objetivo General}

Comparar la percepción de los gerentes con la percepción de los docentes en relación a las competencias profesionales para los ingenieros informáticos.

\section{Objetivos específicos}

1. Comparar la percepción de los gerentes con la de los docentes en relación a la dimensión de comunicación.

2. Comparar la percepción de los gerentes con la de los docentes en relación a la dimensión de actitud y aptitud personal.

3. Comparar la percepción de los gerentes con la de los docentes en relación a la dimensión de relación interpersonal y social.

4. Comparar la percepción de los gerentes con la de los docentes en relación a la dimensión de emprendimiento.

5. Comparar la percepción de los gerentes con la de los docentes en relación a la dimensión específica de informática.

6. Comparar la percepción de los gerentes con la de los docentes en relación a la dimensión específica de gestión empresarial. 
7. Comparar la percepción de los gerentes con la de los docentes en relación a la dimensión de conocimiento declarativo. 


\section{Método}

\section{Tipo y diseño de la Investigación}

Esta investigación es de naturaleza descriptivo comparativo (Hernández, Fernandez y Baptista, 2006), buscando obtener información de las competencias profesionales que las empresas requerirían de los profesionales de ingeniería informática y paralelamente de las competencias que los docentes universitarios considerarían importante en la formación de este tipo de profesionales. Del análisis de los resultados obtenidos, se obtendría información para establecer si la educación universitaria impartida por los docentes cubriría las expectativas de la empresa.

\section{Variables}

Las variables a estudiar en este trabajo son las competencias profesionales requeridas para un profesional informático, considerando la definición de competencia de Reátegui et al. (2001, p.30) “...una red compleja de saberes (saber qué, el saber y el saber ser)..."

Teniendo en cuenta los trabajos anteriores como los del Proyecto Tuning (2007) y ANECA (2005), se compilaron las competencias genéricas y específicas para un ingeniero informático que se consideraron las requeridas a este tipo de profesional. La lista fue sometida al juicio de expertos, cuya sugerencia fue ordenar la lista y hacer una clasificación de las competencias para mejor entendimiento, resultando la variable competencia profesional, sus dimensiones e indicadores mostrados en la Tabla 1. 
Tabla 1. Variable Competencia Profesional, sus dimensiones e indicadores

\begin{tabular}{|c|c|c|}
\hline Variable & Dimensiones & Indicadores \\
\hline \multirow{33}{*}{$\begin{array}{l}\text { Competencia } \\
\text { profesional }\end{array}$} & \multirow[t]{2}{*}{ De Comunicación } & Capacidad de comunicación oral y escrita en la lengua nativa \\
\hline & & Capacidad de comunicación en una segunda lengua \\
\hline & \multirow{9}{*}{$\begin{array}{l}\text { De actitud y aptitud } \\
\text { personal }\end{array}$} & Capacidad de abstracción, análisis y síntesis \\
\hline & & Capacidad de razonamiento crítico \\
\hline & & Capacidad de organización y planificación \\
\hline & & Capacidad de Identificar, plantear, resolver problemas y tomar decisiones \\
\hline & & Capacidad de aprender y actualizarse permanentemente \\
\hline & & Capacidad de adaptarse a situaciones nuevas \\
\hline & & Capacidad de aplicar conocimientos en la práctica \\
\hline & & Capacidad de investigación \\
\hline & & Compromiso hacia la calidad \\
\hline & \multirow{3}{*}{$\begin{array}{l}\text { De relación } \\
\text { interpersonal y } \\
\text { social }\end{array}$} & Capacidad de trabajo en equipos con miembros del área de informática \\
\hline & & Capacidad de trabajo en equipos interdisciplinarios \\
\hline & & Compromiso ético \\
\hline & \multirow[t]{2}{*}{ De emprendimiento } & Capacidad de Liderazgo \\
\hline & & Capacidad creativa, de Iniciativa y espíritu emprendedor \\
\hline & \multirow[t]{10}{*}{$\begin{array}{l}\text { Específica de } \\
\text { informática }\end{array}$} & $\begin{array}{l}\text { Capacidad para elaborar, entender y evaluar especificaciones técnicas y } \\
\text { funcionales }\end{array}$ \\
\hline & & $\begin{array}{l}\text { Capacidad de entender, seleccionar y aplicar productos y/o tendencias } \\
\text { tecnológicas al sector empresarial }\end{array}$ \\
\hline & & Capacidad de planificar, organizar, dirigir y controlar proyectos \\
\hline & & $\begin{array}{l}\text { Capacidad de evaluar y validar requisitos y necesidades de hardware y } \\
\text { software }\end{array}$ \\
\hline & & Capacidad de programar computadoras \\
\hline & & Capacidad de diseñar y administrar bases de datos \\
\hline & & $\begin{array}{l}\text { Capacidad de diseñar y especificar la arquitectura de sistemas de } \\
\text { información }\end{array}$ \\
\hline & & Capacidad de ensamblar, reparar y/o dar soporte a computadoras \\
\hline & & $\begin{array}{l}\text { Capacidad de diseñar, implantar, validar, mantener y administrar redes de } \\
\text { computadoras }\end{array}$ \\
\hline & & $\begin{array}{l}\text { Capacidad de configurar, administrar y dar soporte a equipos de } \\
\text { comunicaciones (Hub, switch, router, etc.) }\end{array}$ \\
\hline & \multirow{2}{*}{$\begin{array}{l}\text { Específica de } \\
\text { gestión empresarial }\end{array}$} & Capacidad de compresión de las ciencias de la gestión empresarial \\
\hline & & Compresión de la visión y misión del negocio \\
\hline & \multirow{5}{*}{$\begin{array}{l}\text { De conocimiento } \\
\text { declarativo }\end{array}$} & Conocimientos generales de la Ingeniería Informática \\
\hline & & Conocimientos generales de las ciencias de la Gestión Empresarial \\
\hline & & Otros conocimientos y habilidades adquiridas en la Universidad \\
\hline & & Otros conocimientos y habilidades adquiridas en la práctica pre profesional \\
\hline & & $\begin{array}{l}\text { Otros conocimientos y habilidades adquiridas en cursos de certificación o } \\
\text { especialización }\end{array}$ \\
\hline
\end{tabular}

Nota: Elaboración propia, basada en Proyecto Tuning (2007) y ANECA (2005) y sometida a juicio de expertos. 


\section{Participantes}

La naturaleza de este proyecto nos orienta al establecimiento de una muestra intencional (Arias, 1999), formada por empresas e incluyendo una universidad. El estudio se realizó con la participación de representantes de estas empresas.

La muestra intencional de empresas está compuesta por empresas de diferentes sectores (industria, comercio, servicios, etc.), éstas fueron consideradas en la muestra por los siguientes motivos:

o Son empresas que por su tamaño, tienen procesos administrativos complejos, lo que implica que sus necesidades informáticas requieren técnicas sofisticadas para cubrir sus necesidades de procesamiento de información.

o Son empresas que por estar a la vanguardia del uso de la tecnología requieren personal altamente calificado para sus departamentos de informática, cosa que no sucede con empresas pequeñas o con uso conservador de la tecnología informática.

o Las necesidades, de estas empresas, de personal especialmente preparado, podrían ser consideradas como el objetivo de formación profesional de una carrera de ingeniería informática. Cualquier empresa de menor tamaño tendría menores exigencias en la contratación de su personal, lo que estaría obviamente cubierto por profesionales egresados de una carrera como la mencionada.

Los profesionales interrogados en las empresas fueron gerentes de informática o personas responsables por la contratación del personal de informática en sus empresas. Proporcionaron, desde su posición funcional, los requerimientos de la empresa en cuanto a las competencias de un profesional informático.

En la universidad privada se interrogó a profesores de la carrera de ingeniería informática que proporcionaron, desde su rol de docentes, las competencias que debería poseer un egresado de una carrera de ingeniería informática.

La muestra intencional de empresas está formada por empresas de diversos sectores, como muestra la Tabla 2. 
Tabla 2. Participantes de la muestra según el sector económico al que pertenecen

\begin{tabular}{|c|c|c|}
\hline SECTOR & CARACTERÍSTICAS & $\begin{array}{l}\mathbf{N}^{\circ} \\
\text { PARTICIPANT } \\
\text { ES } \\
\end{array}$ \\
\hline Telecomunicaciones & $\begin{array}{l}\text { Posee todos los procesos administrativos empresariales y } \\
\text { adicionalmente tienen procesos de manejo de telecomunicaciones } \\
\text { con una infraestructura especializada, desarrollo de sistemas de } \\
\text { información, sistemas de seguridad informática, servicio a clientes } \\
\text { entre otros. }\end{array}$ & 3 \\
\hline $\begin{array}{l}\text { Servicios de } \text { Banca y } \\
\text { Administradora de Fondo } \\
\text { de pensiones }\end{array}$ & $\begin{array}{l}\text { Posee además de los procesos empresariales administrativos } \\
\text { procesos específicos relacionados a transacciones económico- } \\
\text { financieras, de créditos, de cartera pesada, sistemas de seguridad } \\
\text { informática de alta sensibilidad y servicio al cliente. Además tienen } \\
\text { la obligación de adaptación a regulaciones gubernamentales. }\end{array}$ & 6 \\
\hline Minería & $\begin{array}{l}\text { Radica su importancia en el manejo de operaciones de producción } \\
\text { (manejo interno) generalmente fuera de Lima y con necesidades } \\
\text { de comunicación entre varias localidades. Generalmente usan } \\
\text { sistemas integrados tipo Entreprise Resource Planning (ERP). }\end{array}$ & 1 \\
\hline Industrial & $\begin{array}{l}\text { Poseen procesos de control de manufactura industrial y } \\
\text { comercialización mayorista. Pueden tener sedes en diferentes } \\
\text { provincias con necesidad des de comunicación interdepartamental. }\end{array}$ & 1 \\
\hline Industria Cosmética & $\begin{array}{l}\text { Poseen los procesos empresariales y producción con estrictos } \\
\text { controles de sanidad, muchas veces con filiales en el extranjero y } \\
\text { con un servicio de comercialización con la modalidad de venta } \\
\text { directa. }\end{array}$ & 1 \\
\hline $\begin{array}{l}\text { Servicios de Consultoría en } \\
\text { Tecnología de la } \\
\text { Información }\end{array}$ & $\begin{array}{l}\text { Ofrecen servicios de consultoría informática en soporte, desarrollo } \\
\text { y/o seguridad informática, cubriendo una gran gama de clientes } \\
\text { pertenecientes a diferentes sectores económicos. }\end{array}$ & 8 \\
\hline Proveedores de Tecnología & $\begin{array}{l}\text { Empresas que desarrollan tecnología y tienen como clientes a las } \\
\text { empresas con diversos requerimientos de tecnología. }\end{array}$ & 3 \\
\hline Educación & $\begin{array}{l}\text { Posee además de los procesos empresariales administrativos } \\
\text { procesos específicos relacionados a manejo de información } \\
\text { sensible relacionada a carreras, alumnos y profesores con manejo } \\
\text { de diversos regímenes laborales. }\end{array}$ & 1 \\
\hline Comercio minorista & $\begin{array}{l}\text { Ofrecen servicios de ventas minorista de diversos artículos y } \\
\text { también ofrecen tarjetas de créditos. Poseen procesos de manejo } \\
\text { de control de inventarios, reposición, ventas, recursos humanos } \\
\text { entre otros. }\end{array}$ & 4 \\
\hline Público & $\begin{array}{l}\text { La importancia de este sector radica en que sus procesos } \\
\text { administrativos están regulados por normativas gubernamentales } \\
\text { con características muy diferentes al sector privado. }\end{array}$ & 1 \\
\hline
\end{tabular}

La muestra está conformada por un total de 68 participantes como detalla la tabla a continuación.

Tabla 3. Conformación de la muestra

\begin{tabular}{ccc}
\hline \multicolumn{3}{c}{ Representantes de empresas } \\
\cline { 1 - 2 } Gerentes & Jefes & Docentes \\
\hline 24 & 5 & 39 \\
rofesionales & encuestados en las empresas debían estar
\end{tabular}

encargados de la contratación de personal del área de informática y fue conformado 
por 24 gerentes y 5 jefes que cumplían con la condición mencionada. A este grupo en todo el estudio, se le denomina gerentes pero incluye a los 5 jefes.

\section{Instrumento de Investigación}

En este estudio se usó como instrumento, una encuesta, elaborada por la autora, de tipo cualitativa mixta, de 37 preguntas cerradas, con la opción de comentarlas, y una pregunta abierta a fin obtener datos que aporten mayor información al estudio. El instrumento mostrando todos los indicadores estudiados se presenta en el Anexo 1.

El objetivo principal fue recoger la opinión de los encuestados sobre las competencias profesionales requeridas para ingenieros informáticos.

En la encuesta se levantaron los datos básicos de los participantes y fueron diferenciados de acuerdo al rol desempeñado en las empresas. Los datos básicos levantados están listados en la Tabla 4.

Tabla 4. Datos de los participantes de la muestra

\begin{tabular}{l}
\hline \multicolumn{1}{c}{ Dato } \\
\hline Identificación de la encuesta \\
\hline Nombre del encuestado \\
\hline Cargo/Curso dictado \\
\hline Nombre de la empresa \\
\hline Número de empleados a cargo \\
\hline
\end{tabular}

Para todos los indicadores estudiados se aplicó la escala de la Tabla 5.

Tabla 5. Escala para indicadores estudiados

\begin{tabular}{l}
\hline \multicolumn{1}{c}{ Escala } \\
\hline No interesa \\
\hline Recomendable \\
\hline Importante \\
\hline Muy importante \\
\hline
\end{tabular}

La validez del instrumento fue determinada usando el coeficiente $V$ de Aiken (ver Anexo 2) sobre el juicio de diez expertos, de los cuales el 30\% son expertos en formación por competencias y $70 \%$ además de ser expertos en informática, también lo son en formación por competencias.

Los resultados (Anexo 2) nos muestran que 29 de los 35 ítems (83\%) superan el valor de 0.80 , lo cual nos indica que existe validez de contenido expresada por los expertos. Cuatro de los ítems (11\%) tuvieron valores entre 0.73 y 0.77 , de los cuales, en dos casos todos estaban "Totalmente de acuerdo" o "De acuerdo" (Otros 
conocimientos y habilidades adquiridas en la Universidad, y Capacidad de diseñar, implantar, validar, mantener y administrar redes de computadoras) y los otros dos ítems con sólo una opinión "En desacuerdo" (Datos generales y Capacidad de programar computadoras), por lo cual a pesar de tener un valor por debajo de 0.80 se decidió mantenerlos, ya que el análisis de las respuestas de los expertos no mostraban un desacuerdo que ameritara retirar esos ítems. Dos ítems (Capacidad de ensamblar, reparar y/o dar soporte a computadoras, y Capacidad de configurar, administrar y dar soporte a equipos de comunicaciones), que representan el $6 \%$ de los ítems, obtuvieron valores entre 0.67 y 0.63 , con solo dos expertos "En desacuerdo".

Con estos resultados podemos entonces concluir que el instrumento, tiene la validez de contenido necesaria para ser usado en esta investigación.

El instrumento fue aplicado a cada uno de los participantes de manera personal, pero en algunos casos y debido a las obligaciones laborales y viajes constantes de los mismos, la encuesta se aplicó por medios electrónicos.

Para verificar la confiabilidad total del instrumento se usó el SPSS v17.0, realizando el análisis Alpha de Cronbanch que arrojó el valor 0.873, lo que nos indica que el instrumento es bastante estable.

\section{Procedimiento}

Se siguieron los siguientes pasos:

\section{Revisión Bibliográfica}

Se realizó una revisión de la literatura que apoyó en la creación de la lista de competencias para este trabajo.

\section{Selección de participantes}

Se escogieron los participantes relevantes para nuestro estudio, que debían representar al mercado laboral o ser docentes de la carrera de ingeniería informática en una universidad.

\section{Establecimiento de la muestra}

Se conformó una muestra intencional no probabilística (Arias, 1999), detallada en la Tabla 3. 


\section{Construcción del Instrumento}

Usando los estudios del proyecto Tunnig (2007) que aportó en lo referente a las competencias genéricas del ingeniero y del Libro Blanco de ANECA (2005) que aportó en lo relacionado a las competencias específicas del profesional informático, se plantearon las competencias profesionales a estudiar, lista que fue sometida al juicio de expertos. El resultado está mostrado en la Tabla 1, que dio origen al instrumento del Anexo 1.

\section{Aplicación del instrumento}

El instrumento fue aplicado a cada uno de los integrantes de la muestra de manera individual.

\section{Análisis de resultados}

Una vez completada la recolección de datos, éstos fueron procesados usando el software SPSS v17.0, para calcular los estadísticos necesarios para el análisis de los resultados correspondientes.

Es importante resaltar que, en la mayoría de los casos, los participantes no realizaron comentarios adicionales a los indicadores interrogados, ni comentaron la pregunta abierta. En los pocos casos que respondieron esta pregunta, las respuestas no aportaban información importante al estudio. 


\section{Resultados}

Para el análisis de la información recogida se usó el programa estadístico SPSS v17.0. En primer lugar se aplicaron las encuestas tanto a la muestra formada por profesionales de la empresa (gerentes), como a la muestra formada por docentes. A seguir se realizaron los cálculos de estadísticos de frecuencias y medias en cada grupo de la muestra. Finalmente se realizaron los cálculos para el análisis comparativo de muestras independientes.

\section{Análisis descriptivo de los resultados obtenidos}

A continuación se analizarán los resultados obtenidos del procesamiento de datos usando el SPSS v17.0, para los estadísticos descriptivos de cada una de las dimensiones de la variable competencia profesional.

\section{Dimensión de comunicación}

De acuerdo al cálculo de frecuencias y porcentajes realizado, obtenemos las Tablas 6 y 7 para los dos indicadores de esta dimensión.

Tabla 6. Resultados obtenidos para el indicador capacidad de comunicación oral y escrita en lengua nativa

\begin{tabular}{lcccc}
\hline & \multicolumn{2}{c}{ Gerentes } & \multicolumn{2}{c}{ Docentes } \\
\hline & Frecuencia & Porcentaje & Frecuencia & Porcentaje \\
\hline No interesa & 0 & 0 & 1 & 2,6 \\
\hline Importante & 5 & 17,2 & 5 & 12,8 \\
\hline Muy Importante & 24 & 82,8 & 33 & 84,6 \\
\hline Total & 29 & 100,0 & 39 & 100,0 \\
\hline
\end{tabular}

El $83 \%$ de los gerentes encuestados considera que la capacidad de comunicación oral y escrita en la lengua nativa, es Muy Importante y el 17\% restante considera que es Importante. Con lo cual esta capacidad sería, cuando menos Importante para la totalidad de los gerentes.

Respecto a los docentes, el 85\% considera que la capacidad de comunicación oral y escrita en la lengua nativa, es Muy Importante. 
Tabla 7. Resultados obtenidos para el indicador capacidad de comunicación oral y escrita en una segunda lengua

\begin{tabular}{ccccc}
\hline & \multicolumn{2}{c}{ Gerentes } & \multicolumn{2}{c}{ Docentes } \\
\hline & Frecuencia & Porcentaje & Frecuencia & Porcentaje \\
\hline Recomendable & 3 & 10,3 & 6 & 15,4 \\
\hline Importante & 16 & 55,2 & 20 & 51,3 \\
\hline Muy importante & 10 & 34,5 & 13 & 33,3 \\
\hline Total & 29 & 100,0 & 39 & 100,0 \\
\hline
\end{tabular}

El $55 \%$ de los gerentes encuestados considera que la capacidad de comunicación oral y escrita en una segunda lengua, es Importante y un 35\% considera que es Muy Importante. Con lo cual esta capacidad sería, para la mayoría de los gerentes encuestados, cuando menos Importante.

El $51 \%$ de los docentes encuestados considera que la capacidad de comunicación oral y escrita en una segunda lengua, es Importante y un 33\% considera que es Muy Importante. Con lo cual este indicador sería, para la mayoría de los docentes encuestados, cuando menos Importante.

\section{Dimensión de actitud y aptitud personal}

De acuerdo al cálculo de frecuencias y porcentajes realizado, obtenemos las Tablas 8 a 16, para los indicadores de esta dimensión.

Tabla 8. Resultados obtenidos para el indicador capacidad de abstracción, análisis y síntesis

\begin{tabular}{lcccc}
\hline & \multicolumn{2}{c}{ Gerentes } & \multicolumn{2}{c}{ Docentes } \\
\hline & Frecuencia & Porcentaje & Frecuencia & Porcentaje \\
\hline Recomendable & 1 & 3,4 & 0 & 0 \\
\hline Importante & 7 & 24,2 & 5 & 12,8 \\
\hline Muy importante & 21 & 72,4 & 34 & 87,2 \\
\hline Total & 29 & 100,0 & 39 & 100,0 \\
\hline
\end{tabular}

El $72 \%$ de los gerentes encuestados considera que la capacidad de abstracción, análisis y síntesis, es Muy Importante y un 24\% considera que es Importante. Con lo cual este indicador sería, para la mayoría de los gerentes encuestados, cuando menos Importante.

El $87 \%$ de los docentes encuestados considera que la capacidad de abstracción, análisis y síntesis, es Muy Importante y el 13\% restante considera que 
es Importante. Con lo cual este indicador sería, cuando menos Importante para la totalidad de los docentes encuestados.

Tabla 9. Resultados obtenidos para el indicador capacidad de razonamiento crítico

\begin{tabular}{lcccc}
\hline & \multicolumn{2}{c}{ Gerentes } & \multicolumn{2}{c}{ Docentes } \\
\hline & Frecuencia & Porcentaje & Frecuencia & Porcentaje \\
\hline Importante & 9 & 31,0 & 10 & 25,6 \\
\hline Muy importante & 20 & 69,0 & 29 & 74,4 \\
\hline Total & 29 & 100,0 & 39 & 100,0 \\
\hline
\end{tabular}

El $69 \%$ de los gerentes encuestados considera que la capacidad de razonamiento crítico, es Muy Importante y el 31\% restante considera que es Importante. Con lo cual esta capacidad sería, cuando menos Importante para la totalidad de los gerentes encuestados.

El 74\% de los docentes encuestados considera que la capacidad razonamiento crítico, es Muy Importante y el $26 \%$ restante considera que es Importante. Con lo cual este indicador sería, cuando menos Importante para la totalidad de los docentes encuestados.

Tabla 10. Resultados obtenidos para el indicador capacidad de organización y planificación

\begin{tabular}{lcccc}
\hline & \multicolumn{2}{c}{ Gerentes } & \multicolumn{2}{c}{ Docentes } \\
\hline & Frecuencia & Porcentaje & Frecuencia & Porcentaje \\
\hline Recomendable & 0 & 0 & 2 & 5,1 \\
\hline Importante & 13 & 44,8 & 11 & 28,2 \\
\hline Muy importante & 16 & 55,2 & 26 & 66,7 \\
\hline Total & 29 & 100,0 & 39 & 100,0 \\
\hline
\end{tabular}

El $55 \%$ de los gerentes encuestados considera que la capacidad de organización y planificación, es Muy Importante y el 45\% restante considera que es Importante. Con lo cual esta capacidad sería, cuando menos Importante para la totalidad de los gerentes encuestados.

El $67 \%$ de los docentes encuestados considera que la capacidad de organización y planificación, es Muy Importante y un $28 \%$ considera que es Importante. Con lo cual este indicador sería, para la mayoría de los docentes encuestados cuando menos Importante. 
Tabla 11. Resultados obtenidos para el indicador capacidad de identificar, plantear, resolver problemas y tomar decisiones

\begin{tabular}{lcccc}
\hline & \multicolumn{2}{c}{ Gerentes } & \multicolumn{2}{c}{ Docentes } \\
\hline & Frecuencia & Porcentaje & Frecuencia & Porcentaje \\
\hline Recomendable & 0 & 0 & 1 & 2,6 \\
\hline Importante & 5 & 17,2 & 9 & 23,0 \\
\hline Muy importante & 24 & 82,8 & 29 & 74,4 \\
\hline Total & 29 & 100,0 & 39 & 100,0 \\
\hline
\end{tabular}

El 83\% de los gerentes encuestados considera que la capacidad de identificar, plantear, resolver problemas y tomar decisiones, es Muy Importante y el 17\% restante considera que es Importante. Con lo cual esta capacidad sería, cuando menos Importante para la totalidad de los gerentes encuestados.

El 74\% de los docentes encuestados considera que la capacidad de identificar, plantear, resolver problemas y tomar decisiones, es Muy Importante y un 23\% considera que es Importante. Con lo cual este indicador sería, para la mayoría de los docentes encuestados, cuando menos Importante.

Tabla 12. Resultados obtenidos para el indicador capacidad de aprender y actualizarse permanentemente

\begin{tabular}{lcccc}
\hline & \multicolumn{2}{c}{ Gerentes } & \multicolumn{2}{c}{ Docentes } \\
\hline & Frecuencia & Porcentaje & Frecuencia & Porcentaje \\
\hline Recomendable & 1 & 3,4 & 1 & 2,6 \\
\hline Importante & 15 & 51,8 & 8 & 20,5 \\
\hline Muy importante & 13 & 44,8 & 30 & 76,9 \\
\hline Total & 29 & 100,0 & 39 & 100,0 \\
\hline
\end{tabular}

El 52\% de los gerentes encuestados considera que la capacidad de aprender y actualizarse permanentemente, es Importante y un $45 \%$ considera que es Muy Importante. Con lo cual esta capacidad sería, para la mayoría de los gerentes encuestados cuando menos Importante.

El $77 \%$ de los docentes encuestados considera que la capacidad de aprender y actualizarse permanentemente, es Muy Importante y un $21 \%$ considera que es Importante. Con lo cual este indicador sería, para la mayoría de los docentes encuestados cuando menos Importante. 
Tabla 13. Resultados obtenidos para el indicador capacidad de adaptarse a nuevas situaciones

\begin{tabular}{lcccc}
\hline & \multicolumn{2}{c}{ Gerentes } & \multicolumn{2}{c}{ Docentes } \\
\hline & Frecuencia & Porcentaje & Frecuencia & Porcentaje \\
\hline Recomendable & 8 & 27,6 & 2 & 5,1 \\
\hline Importante & 21 & 72,4 & 13 & 33,3 \\
\hline Muy importante & 0 & 0 & 24 & 61,5 \\
\hline Total & 29 & 100,0 & 39 & 100,0 \\
\hline
\end{tabular}

El 72\% de los gerentes encuestados considera que la capacidad de adaptarse a nuevas situaciones, es Importante.

El 62\% de los docentes encuestados considera que la capacidad de adaptarse a nuevas situaciones, es Muy Importante y un 33\% considera que es Importante. Con lo cual este indicador sería, para la mayoría de los docentes encuestados, cuando menos Importante.

Tabla 14. Resultados obtenidos para el indicador capacidad de aplicar conocimientos a la práctica

\begin{tabular}{lcccc}
\hline & \multicolumn{2}{c}{ Gerentes } & \multicolumn{2}{c}{ Docentes } \\
\hline & Frecuencia & Porcentaje & Frecuencia & Porcentaje \\
\hline Recomendable & 2 & 6,9 & 2 & 5,1 \\
\hline Importante & 11 & 37,9 & 15 & 38,5 \\
\hline Muy importante & 16 & 55,2 & 22 & 56,4 \\
\hline Total & 29 & 100,0 & 39 & 100,0 \\
\hline
\end{tabular}

El 55\% de los gerentes encuestados considera que la capacidad de aplicar conocimientos a la práctica, es Muy Importante y un $38 \%$ considera que es Importante. Con lo cual esta capacidad, sería para la mayoría de los gerentes encuestados cuando menos Importante.

El 56\% de los docentes encuestados considera que la capacidad de aplicar conocimientos a la práctica, es Muy Importante y un 39\% considera que es Importante. Con lo cual este indicador sería, para la mayoría de los docentes encuestados, cuando menos Importante. 
Tabla 15. Resultados obtenidos para el indicador capacidad de investigación

\begin{tabular}{lcccc}
\hline & \multicolumn{2}{c}{ Gerentes } & \multicolumn{2}{c}{ Docentes } \\
\hline & Frecuencia & Porcentaje & Frecuencia & Porcentaje \\
\hline No interesa & 0 & 0 & 2 & 5,1 \\
\hline Recomendable & 6 & 20,7 & 6 & 15,4 \\
\hline Importante & 13 & 44,8 & 14 & 35,9 \\
\hline Muy importante & 10 & 34,5 & 17 & 43,6 \\
\hline Total & 29 & 100,0 & 39 & 100,0 \\
\hline
\end{tabular}

El $45 \%$ de los gerentes encuestados considera que la capacidad de investigación, es Importante y un 35\% considera que es Muy Importante. Con lo cual esta capacidad sería, para la mayoría de los gerentes encuestados, cuando menos Importante.

El $44 \%$ de los docentes encuestados considera que la capacidad de investigación, es Muy Importante y un 36\% considera que es Importante. Con lo cual este indicador sería, para la mayoría de los docentes encuestados cuando menos Importante.

Tabla 16. Resultados obtenidos para el indicador compromiso hacia la calidad

\begin{tabular}{lcccc}
\hline & \multicolumn{2}{c}{ Gerentes } & \multicolumn{2}{c}{ Docentes } \\
\hline & Frecuencia & Porcentaje & Frecuencia & Porcentaje \\
\hline Recomendable & 1 & 3,4 & 2 & 5,1 \\
\hline Importante & 4 & 13,8 & 8 & 20,5 \\
\hline Muy importante & 24 & 82,8 & 29 & 74,4 \\
\hline Total & 29 & 100,0 & 39 & 100,0 \\
\hline
\end{tabular}

El 83\% de los gerentes encuestados considera que el compromiso hacia la calidad, es Muy Importante y un 14\% considera que es Importante. Con lo cual este indicador, sería para la mayoría de los gerentes encuestados cuando menos Importante.

El 74\% de los docentes encuestados considera que el compromiso hacia la calidad, es Muy Importante y un $21 \%$ considera que es Importante. Con lo cual este indicador sería, para la mayoría de los docentes encuestados, cuando menos Importante. 


\section{Dimensión de relación interpersonal y social}

De acuerdo al cálculo de frecuencias y porcentajes realizado, obtenemos las Tablas 17, 18 y 19 para los indicadores de esta dimensión.

Tabla 17. Resultados obtenidos para el indicador capacidad de trabajo en equipos con miembros del área de informática

\begin{tabular}{lcccc}
\hline & \multicolumn{2}{c}{ Gerentes } & \multicolumn{2}{c}{ Docentes } \\
\hline & Frecuencia & Porcentaje & Frecuencia & Porcentaje \\
\hline Recomendable & 1 & 3,4 & 1 & 2,6 \\
\hline Importante & 10 & 34,5 & 11 & 28,2 \\
\hline Muy importante & 18 & 62,1 & 27 & 69,2 \\
\hline Total & 29 & 100,0 & 39 & 100,0 \\
\hline
\end{tabular}

El $62 \%$ de los gerentes encuestados considera que la capacidad de trabajo en equipos con miembros del área de informática, es Muy Importante y un 35\% considera que es Importante. Con lo cual esta capacidad, sería para la mayoría de los gerentes encuestados cuando menos Importante.

El $69 \%$ de los docentes encuestados considera que la capacidad de trabajo en equipos con miembros del área de informática, es Muy Importante y un $28 \%$ considera que es Importante. Con lo cual este indicador, sería para la mayoría de los docentes encuestados cuando menos Importante.

Tabla 18. Resultados obtenidos para el indicador capacidad de trabajo en equipos interdisciplinarios

\begin{tabular}{lcccc}
\hline & \multicolumn{2}{c}{ Gerentes } & \multicolumn{2}{c}{ Docentes } \\
\hline & Frecuencia & Porcentaje & Frecuencia & Porcentaje \\
\hline Recomendable & 0 & 0 & 1 & 2,6 \\
\hline Importante & 14 & 48,3 & 19 & 48,7 \\
\hline Muy importante & 15 & 51,7 & 19 & 48,7 \\
\hline Total & 29 & 100,0 & 39 & 100,0 \\
\hline
\end{tabular}

El 52\% de los gerentes encuestados considera que la capacidad de trabajo en equipos interdisciplinarios, es Muy Importante y el 48\% restante considera que es Importante. Con lo cual esta capacidad, sería cuando menos Importante para la totalidad de los gerentes encuestados.

El 49\% de los docentes encuestados considera que la capacidad de trabajo en equipos interdisciplinarios, es Importante y el mismo porcentaje considera que es 
Muy Importante. Con lo cual este indicador, sería para la mayoría de los docentes encuestados cuando menos Importante.

Tabla 19. Resultados obtenidos para el indicador compromiso ético

\begin{tabular}{lcccc}
\hline & \multicolumn{2}{c}{ Gerentes } & \multicolumn{2}{c}{ Docentes } \\
\hline & Frecuencia & Porcentaje & Frecuencia & Porcentaje \\
\hline Recomendable & 0 & 0 & 2 & 5,2 \\
\hline Importante & 2 & 6,9 & 10 & 25,6 \\
\hline Muy importante & 27 & 93,1 & 27 & 69,2 \\
\hline Total & 29 & 100,0 & 39 & 100,0 \\
\hline
\end{tabular}

El 93\% de los gerentes encuestados considera que el compromiso ético, es Muy Importante y el 7\% restante considera que es Importante. Con lo cual este indicador, sería cuando menos Importante para la totalidad de los gerentes encuestados.

El 69\% de los docentes encuestados considera que el compromiso ético, es Muy Importante y un $26 \%$ considera que es Importante. Con lo cual este indicador, sería para la mayoría de los docentes encuestados cuando menos Importante.

\section{Dimensión de emprendimiento}

De acuerdo al cálculo de frecuencias y porcentajes realizado, obtenemos las Tablas 20 y 21 para los dos indicadores de esta dimensión.

Tabla 20. Resultados obtenidos para el indicador capacidad de liderazgo

\begin{tabular}{lcccc}
\hline & \multicolumn{2}{c}{ Gerentes } & \multicolumn{2}{c}{ Docentes } \\
\hline & Frecuencia & Porcentaje & Frecuencia & Porcentaje \\
\hline No interesa & 0 & 0 & 1 & 2,6 \\
\hline Recomendable & 1 & 3,4 & 6 & 15,4 \\
\hline Importante & 12 & 41,4 & 14 & 35,9 \\
\hline Muy importante & 16 & 55,2 & 18 & 46,1 \\
\hline Total & 29 & 100,0 & 39 & 100,0 \\
\hline
\end{tabular}

El 55\% de los gerentes encuestados considera que la capacidad de liderazgo, es Muy Importante y un $41 \%$ considera que es Importante. Con lo cual esta capacidad, sería para la mayoría de los gerentes encuestados cuando menos Importante.

El 46\% de los docentes encuestados considera que la capacidad de liderazgo, es Muy Importante y un 36\% considera que es Importante. Con lo cual este 
indicador, sería para la mayoría de los docentes encuestados cuando menos Importante.

Tabla 21. Resultados obtenidos para el indicador capacidad creativa, de iniciativa y espíritu emprendedor

\begin{tabular}{lcccc}
\hline & \multicolumn{2}{c}{ Gerentes } & \multicolumn{2}{c}{ Docentes } \\
\hline & Frecuencia & Porcentaje & Frecuencia & Porcentaje \\
\hline No interesa & 0 & 0 & 1 & 2,6 \\
\hline Recomendable & 2 & 6,9 & 2 & 5,1 \\
\hline Importante & 13 & 44,8 & 15 & 38,5 \\
\hline Muy importante & 14 & 48,3 & 21 & 53,8 \\
\hline Total & 29 & 100,0 & 39 & 100,0 \\
\hline
\end{tabular}

El $48 \%$ de los gerentes encuestados considera que la capacidad creativa, de iniciativa y espíritu emprendedor, es Muy Importante y un 45\% considera que es Importante. Con lo cual esta capacidad, sería para la mayoría de los gerentes encuestados cuando menos Importante.

El 54\% de los docentes encuestados considera que la capacidad creativa, de iniciativa y espíritu emprendedor, es Muy Importante y un 39\% considera que es Importante. Con lo cual este indicador, sería para la mayoría de los docentes encuestados cuando menos Importante.

\section{Dimensión específica de informática}

De acuerdo al cálculo de frecuencias y porcentajes realizados, obtenemos las Tablas 22 a 31 para los indicadores de esta dimensión.

Tabla 22. Resultados obtenidos para el indicador capacidad para elaborar, entender y evaluar especificaciones técnicas y funcionales

\begin{tabular}{lcccc}
\hline & \multicolumn{2}{c}{ Gerentes } & \multicolumn{2}{c}{ Docentes } \\
\hline & Frecuencia & Porcentaje & Frecuencia & Porcentaje \\
\hline Recomendable & 2 & 6,9 & 6 & 15,4 \\
\hline Importante & 15 & 51,7 & 17 & 43,6 \\
\hline Muy importante & 12 & 41,4 & 16 & 41,0 \\
\hline Total & 29 & 100,0 & 39 & 100,0 \\
\hline
\end{tabular}

El 52\% de los gerentes encuestados considera que la capacidad para elaborar, entender y evaluar especificaciones técnicas y funcionales, es Importante y un $41 \%$ 
considera que es Muy Importante. Con lo cual esta capacidad, sería para la mayoría de los gerentes encuestados cuando menos Importante.

El 44\% de los docentes encuestados considera que la capacidad para elaborar, entender y evaluar especificaciones técnicas y funcionales, es Importante y un $41 \%$ considera que es Muy Importante. Con lo cual este indicador, sería para la mayoría de los docentes encuestados cuando menos Importante.

Tabla 23. Resultados obtenidos para el indicador capacidad de entender, seleccionar y aplicar productos y/o tendencias tecnológicas al sector empresarial

\begin{tabular}{lcccc}
\hline & \multicolumn{2}{c}{ Gerentes } & \multicolumn{2}{c}{ Docentes } \\
\hline & Frecuencia & Porcentaje & Frecuencia & Porcentaje \\
\hline Recomendable & 1 & 3,4 & 6 & 15,4 \\
\hline Importante & 15 & 51,8 & 18 & 46,1 \\
\hline Muy importante & 13 & 44,8 & 15 & 38,5 \\
\hline Total & 29 & 100,0 & 39 & 100,0
\end{tabular}

El 52\% de los gerentes encuestados considera que la capacidad de entender, seleccionar y aplicar productos y/o tendencias tecnológicas al sector empresarial, es Importante y un $45 \%$ considera que es Muy Importante. Con lo cual esta capacidad, sería para la mayoría de los gerentes encuestados cuando menos Importante.

El $46 \%$ de los docentes encuestados considera que la capacidad de entender, seleccionar y aplicar productos y/o tendencias tecnológicas al sector empresarial, es Importante y un 39\% considera que es Muy Importante. Con lo cual este indicador, sería para la mayoría de los docentes encuestados cuando menos Importante.

Tabla 24. Resultados obtenidos para el indicador capacidad de planificar, organizar, dirigir y controlar proyectos

\begin{tabular}{lcccc}
\hline & \multicolumn{2}{c}{ Gerentes } & \multicolumn{2}{c}{ Docentes } \\
\hline & Frecuencia & Porcentaje & Frecuencia & Porcentaje \\
\hline Recomendable & 2 & 6,9 & 2 & 5,1 \\
\hline Importante & 11 & 37,9 & 8 & 20,5 \\
\hline Muy importante & 16 & 55,2 & 29 & 74,4 \\
\hline Total & 29 & 100,0 & 39 & 100,0 \\
\hline
\end{tabular}

El 55\% de los gerentes encuestados considera que la capacidad de planificar, organizar, dirigir y controlar proyectos, es Muy Importante y un 38\% considera que es 
Importante. Con lo cual esta capacidad, sería para la mayoría de los gerentes encuestados cuando menos Importante.

El 74\% de los docentes encuestados considera que el indicador capacidad de planificar, organizar, dirigir y controlar proyectos, es Muy Importante y un $21 \%$ considera que es Importante. Con lo cual este indicador, sería para la mayoría de los docentes encuestados cuando menos Importante.

Tabla 25. Resultados obtenidos para el indicador capacidad de evaluar y validar requisitos y necesidades de hardware y software

\begin{tabular}{lcccc}
\hline & \multicolumn{2}{c}{ Gerentes } & \multicolumn{2}{c}{ Docentes } \\
\hline & Frecuencia & Porcentaje & Frecuencia & Porcentaje \\
\hline Recomendable & 6 & 20,7 & 4 & 10,3 \\
\hline Importante & 15 & 51,7 & 21 & 53,8 \\
\hline Muy importante & 8 & 27,6 & 14 & 35,9 \\
\hline Total & 29 & 100,0 & 39 & 100,0 \\
\hline
\end{tabular}

El 52\% de los gerentes encuestados considera que la capacidad de evaluar y validar requisitos y necesidades de hardware y software, es Importante y un $28 \%$ considera que es Muy Importante. Con lo cual esta capacidad, sería para la mayoría de los gerentes encuestados cuando menos Importante.

El 54\% de los docentes encuestados considera que la capacidad de evaluar y validar requisitos y necesidades de hardware y software, es Importante y un 36\% considera que es Muy Importante. Con lo cual este indicador, sería para la mayoría de los docentes encuestados cuando menos Importante.

Tabla 26. Resultados obtenidos para el indicador capacidad de programar computadoras

\begin{tabular}{lcccc}
\hline & \multicolumn{2}{c}{ Gerentes } & \multicolumn{2}{c}{ Docentes } \\
\hline & Frecuencia & Porcentaje & Frecuencia & Porcentaje \\
\hline No interesa & 9 & 31,0 & 3 & 7,7 \\
\hline Recomendable & 7 & 24,2 & 9 & 23,1 \\
\hline Importante & 4 & 13,8 & 24 & 61,5 \\
\hline Muy importante & 9 & 31,0 & 3 & 7,7 \\
\hline Total & 29 & 100,0 & 39 & 100,0 \\
\hline
\end{tabular}


El 31\% de los gerentes encuestados consideran que la capacidad programar computadoras, No Interesa y el mismo porcentaje consideran que es Muy Importante.

El $62 \%$ de los docentes encuestados considera que la capacidad de programar computadoras, es Importante y un 8\% considera que es Muy Importante. Con lo cual este indicador, sería para la mayoría de los docentes encuestados cuando menos Importante.

Tabla 27. Resultados obtenidos para el indicador capacidad de diseñar y administrar bases de datos

\begin{tabular}{lcccc}
\hline & \multicolumn{2}{c}{ Gerentes } & \multicolumn{2}{c}{ Docentes } \\
\hline & Frecuencia & Porcentaje & Frecuencia & Porcentaje \\
\hline No interesa & 5 & 17,2 & 2 & 5,1 \\
\hline Recomendable & 10 & 34,5 & 6 & 15,4 \\
\hline Importante & 11 & 37,9 & 22 & 56,4 \\
\hline Muy importante & 3 & 10,4 & 9 & 23,1 \\
\hline Total & 29 & 100,0 & 39 & 100,0 \\
\hline
\end{tabular}

El 38\% de los gerentes encuestados considera que la capacidad diseñar y administrar bases de datos, es Importante, un 10\% considera que es Muy Importante y un $35 \%$ considera que es Recomendable. Con lo cual esta capacidad, sería para la mayoría de los gerentes encuestados cuando menos Recomendable.

El 56\% de los docentes encuestados considera que la capacidad de diseñar y administrar bases de datos, es Importante y un 23\% considera que es Muy Importante. Con lo cual este indicador, sería para la mayoría de los docentes encuestados cuando menos Importante.

Tabla 28. Resultados obtenidos para el indicador capacidad de diseñar y especificar la arquitectura de sistemas de información

\begin{tabular}{lcccc}
\hline & \multicolumn{2}{c}{ Gerentes } & \multicolumn{2}{c}{ Docentes } \\
\hline & Frecuencia & Porcentaje & Frecuencia & Porcentaje \\
\hline No interesa & 1 & 3,4 & 0 & 0 \\
\hline Recomendable & 10 & 34,6 & 4 & 10,3 \\
\hline Importante & 9 & 31,0 & 27 & 69,2 \\
\hline Muy importante & 9 & 31,0 & 8 & 20,5 \\
\hline Total & 29 & 100,0 & 39 & 100,0 \\
\hline
\end{tabular}


El 35\% de los gerentes encuestados considera que la capacidad diseñar y especificar la arquitectura de sistemas de información, es Recomendable, un 31\% considera que es Importante con igual porcentaje para Muy Importante. Con lo cual esta capacidad, sería para la mayoría de los gerentes encuestados cuando menos Recomendable.

El 69\% de los docentes encuestados considera que la capacidad de diseñar y especificar la arquitectura de sistemas de información, es Importante y un $21 \%$ considera que es Muy Importante. Con lo cual este indicador sería, para la mayoría de los docentes encuestados cuando menos Importante.

Tabla 29. Resultados obtenidos para el indicador capacidad de ensamblar, reparar y/o dar soporte a computadoras

\begin{tabular}{lcccc}
\hline & \multicolumn{2}{c}{ Gerentes } & \multicolumn{2}{c}{ Docentes } \\
\hline & Frecuencia & Porcentaje & Frecuencia & Porcentaje \\
\hline No interesa & 15 & 51,7 & 6 & 15,4 \\
\hline Recomendable & 11 & 37,9 & 23 & 59,0 \\
\hline Importante & 3 & 10,4 & 10 & 25,6 \\
\hline Total & 29 & 100,0 & 39 & 100,0 \\
\hline
\end{tabular}

El 52\% de los gerentes encuestados considera que la capacidad ensamblar, reparar y/o dar soporte a computadoras, No interesa y el $38 \%$ lo considera Recomendable.

El $59 \%$ de los docentes encuestados considera que la capacidad de ensamblar, reparar y/o dar soporte a computadoras, es Recomendable.

Tabla 30. Resultados obtenidos para el indicador capacidad de diseñar, implantar, validar, mantener y administrar redes de computadoras

\begin{tabular}{lcccc}
\hline & \multicolumn{2}{c}{ Gerentes } & \multicolumn{2}{c}{ Docentes } \\
\hline & Frecuencia & Porcentaje & Frecuencia & Porcentaje \\
\hline No interesa & 11 & 37,9 & 2 & 5,1 \\
\hline Recomendable & 10 & 34,5 & 14 & 35,9 \\
\hline Importante & 6 & 20,7 & 20 & 51,3 \\
\hline Muy importante & 2 & 6,9 & 3 & 7,7 \\
\hline Total & 29 & 100,0 & 39 & 100,0 \\
\hline
\end{tabular}


El 38\% de los gerentes encuestados considera que la capacidad diseñar, implantar, validar, mantener y administrar redes de computadoras, No Interesa y el $35 \%$ lo considera Recomendable.

El 51\% de los docentes encuestados considera que la capacidad de diseñar, implantar, validar, mantener y administrar redes de computadoras, es Importante, en tanto que el 36\% lo considera solo Recomendable.

Tabla 31. Resultados obtenidos para el indicador capacidad de configurar, administrar y dar soporte a equipos de comunicaciones

\begin{tabular}{lcccc}
\hline & \multicolumn{2}{c}{ Gerentes } & \multicolumn{2}{c}{ Docentes } \\
\hline & Frecuencia & Porcentaje & Frecuencia & Porcentaje \\
\hline No interesa & 14 & 48,3 & 3 & 7,7 \\
\hline Recomendable & 9 & 31,1 & 21 & 53,8 \\
\hline Importante & 5 & 17,2 & 12 & 30,8 \\
\hline Muy importante & 1 & 3,4 & 3 & 7,7 \\
\hline Total & 29 & 100,0 & 39 & 100,0 \\
\hline
\end{tabular}

El 48\% de los gerentes encuestados considera que la capacidad de configurar, administrar y dar soporte a equipos de comunicaciones, No Interesa.

El 54\% de los docentes encuestados considera que la capacidad de configurar, administrar y dar soporte a equipos de comunicaciones, es Recomendable.

\section{Dimensión específica de gestión empresarial}

De acuerdo al cálculo de frecuencias y porcentajes realizado, obtenemos las Tablas 32 y 33 para los dos indicadores de esta dimensión.

Tabla 32. Resultados obtenidos para el indicador comprensión de las ciencias de la gestión empresarial

\begin{tabular}{lcccc}
\hline & \multicolumn{2}{c}{ Gerentes } & \multicolumn{2}{c}{ Docentes } \\
\hline & Frecuencia & Porcentaje & Frecuencia & Porcentaje \\
\hline Recomendable & 3 & 10,3 & 1 & 2,6 \\
\hline Importante & 17 & 58,6 & 25 & 64,1 \\
\hline Muy importante & 9 & 31,1 & 13 & 33,3 \\
\hline Total & 29 & 100,0 & 39 & 100,0 \\
\hline
\end{tabular}

El 59\% de los gerentes encuestados considera que la comprensión de las ciencias de la gestión empresarial, es Importante y un 31\% considera que es Muy 
Importante. Con lo cual este indicador, sería para la mayoría de los gerentes encuestados cuando menos Importante.

El 64\% de los docentes encuestados considera que la comprensión de las ciencias de la gestión empresarial, es Importante y un 33\% considera que es Muy Importante. Con lo cual este indicador, sería para la mayoría de los docentes encuestados cuando menos Importante.

Tabla 33. Resultados obtenidos para el indicador comprensión de la visión y misión del negocio

\begin{tabular}{lcccc}
\hline & \multicolumn{2}{c}{ Gerentes } & \multicolumn{2}{c}{ Docentes } \\
\hline & Frecuencia & Porcentaje & Frecuencia & Porcentaje \\
\hline Recomendable & 1 & 3,4 & 2 & 5,1 \\
\hline Importante & 8 & 27,6 & 9 & 23,1 \\
\hline Muy importante & 20 & 69,0 & 28 & 71,8 \\
\hline Total & 29 & 100,0 & 39 & 100,0
\end{tabular}

El 69\% de los gerentes encuestados considera que la comprensión de la visión y misión del negocio, es Muy Importante y un 28\% considera que es Importante. Con lo cual este indicador, sería para la mayoría de los gerentes encuestados cuando menos Importante.

El 72\% de los docentes encuestados considera que la comprensión de la visión y misión del negocio, es Muy Importante y un 23\% considera que es Importante. Con lo cual este indicador, sería para la mayoría de los docentes encuestados cuando menos Importante.

\section{Dimensión de conocimientos declarativos}

De acuerdo al cálculo de frecuencias y porcentajes realizado, obtenemos las Tablas 34 a 38 para los dos indicadores de esta dimensión. 
Tabla 34. Resultados obtenidos para el indicador conocimientos generales de la ingeniería informática

\begin{tabular}{lcccc}
\hline & \multicolumn{2}{c}{ Gerentes } & \multicolumn{2}{c}{ Docentes } \\
\hline & Frecuencia & Porcentaje & Frecuencia & Porcentaje \\
\hline No interesa & 1 & 3,4 & 0 & 0 \\
\hline Recomendable & 4 & 13,9 & 5 & 12,8 \\
\hline Importante & 11 & 37,9 & 17 & 43,6 \\
\hline Muy importante & 13 & 44,8 & 17 & 43,6 \\
\hline Total & 29 & 100,0 & 39 & 100,0 \\
\hline
\end{tabular}

El $45 \%$ de los gerentes encuestados considera que los conocimientos generales de ingeniería informática, son Muy Importantes y un 38\% considera que son Importantes. Con lo cual este indicador, sería para la mayoría de los gerentes encuestados cuando menos Importante.

El $44 \%$ de los docentes encuestados considera que los conocimientos generales de la ingeniería informática, son Importantes y el mismo porcentaje considera que son Muy Importantes. Con lo cual este indicador, sería para la mayoría de los docentes encuestados cuando menos Importante.

Tabla 35. Resultados obtenidos para el indicador conocimientos generales de las ciencias de la gestión empresarial

\begin{tabular}{lcccc}
\hline & \multicolumn{2}{c}{ Gerentes } & \multicolumn{2}{c}{ Docentes } \\
\hline & Frecuencia & Porcentaje & Frecuencia & Porcentaje \\
\hline Recomendable & 2 & 6,9 & 6 & 15,4 \\
\hline Importante & 13 & 44,8 & 21 & 53,8 \\
\hline Muy importante & 14 & 48,3 & 12 & 30,8 \\
\hline Total & 29 & 100,0 & 39 & 100,0 \\
\hline
\end{tabular}

El $48 \%$ de los gerentes encuestados considera que los conocimientos generales de las ciencias de la gestión empresarial, son Muy Importantes y un 45\% considera que son Importantes. Con lo cual este indicador, sería para la mayoría de los gerentes encuestados cuando menos Importante.

El $54 \%$ de los docentes encuestados considera que los conocimientos generales de las ciencias de la gestión empresarial, son Importantes y un 31\% considera que son Muy Importantes. Con lo cual este indicador, sería para la mayoría de los docentes encuestados cuando menos Importante. 
Tabla 36. Resultados obtenidos para el indicador otros conocimientos y habilidades adquiridas en la universidad

\begin{tabular}{lcccc}
\hline & \multicolumn{2}{c}{ Gerentes } & \multicolumn{2}{c}{ Docentes } \\
\hline & Frecuencia & Porcentaje & Frecuencia & Porcentaje \\
\hline No interesa & 0 & 0 & 1 & 2,6 \\
\hline Recomendable & 8 & 27,6 & 16 & 41,0 \\
\hline Importante & 18 & 62,1 & 20 & 51,3 \\
\hline Muy importante & 3 & 10,3 & 2 & 5,1 \\
\hline Total & 29 & 100,0 & 39 & 100,0 \\
\hline
\end{tabular}

El $62 \%$ de los gerentes encuestados considera que otros conocimientos y habilidades adquiridas en la universidad, son Importantes y un 10\% considera que son Muy Importantes. Con lo cual este indicador, sería para la mayoría de los gerentes encuestados cuando menos Importante.

El 51\% de los docentes encuestados considera que otros conocimientos y habilidades adquiridas en la universidad, son Importantes, 5\% considera que son Muy Importantes y $41 \%$ los considera Recomendables. Con lo cual este indicador sería para la mayoría de docentes cuando menos Recomendable.

Tabla 37. Resultados obtenidos para el indicador otros conocimientos y habilidades adquiridas en la práctica pre profesional

\begin{tabular}{lcccc}
\hline & \multicolumn{2}{c}{ Gerentes } & \multicolumn{2}{c}{ Docentes } \\
\hline & Frecuencia & Porcentaje & Frecuencia & Porcentaje \\
\hline No interesa & 2 & 6,9 & 0 & 0 \\
\hline Recomendable & 9 & 31,1 & 6 & 15,4 \\
\hline Importante & 11 & 37,9 & 20 & 51,3 \\
\hline Muy importante & 7 & 24,1 & 13 & 33,3 \\
\hline Total & 29 & 100,0 & 39 & 100,0 \\
\hline
\end{tabular}

El 38\% de los gerentes encuestados considera que otros conocimientos y habilidades adquiridas en la práctica pre profesional, son Importantes, el 31\% los considera Recomendables y el $24 \%$ Muy Importantes. Con lo cual este indicador, sería para la mayoría de los gerentes cuando menos Recomendable.

El 51\% de los docentes encuestados considera que otros conocimientos y habilidades adquiridas en la práctica pre profesional, son Importantes y un $33 \%$ considera que son Muy Importantes. Con lo cual este indicador, sería para la mayoría de los docentes encuestados cuando menos Importante. 
Tabla 38. Resultados obtenidos para el indicador otros conocimientos y habilidades adquiridas en cursos de certificación o especialización

\begin{tabular}{lcccc}
\hline & \multicolumn{2}{c}{ Gerentes } & \multicolumn{2}{c}{ Docentes } \\
\hline & Frecuencia & Porcentaje & Frecuencia & Porcentaje \\
\hline No interesa & 0 & 0 & 1 & 2,6 \\
\hline Recomendable & 8 & 27,6 & 2 & 5,1 \\
\hline Importante & 11 & 37,9 & 19 & 48,7 \\
\hline Muy importante & 10 & 34,5 & 17 & 43,6 \\
\hline Total & 29 & 100,0 & 39 & 100,0 \\
\hline
\end{tabular}

El $38 \%$ de los gerentes encuestados considera que otros conocimientos y habilidades adquiridas en cursos de certificación o especialización, son Importantes y un 35\% considera que son Muy Importantes. Con lo cual este indicador, sería para la mayoría de los gerentes encuestados cuando menos Importante.

El $49 \%$ de los docentes encuestados considera que otros conocimientos y habilidades adquiridas en cursos de certificación o especialización, son Importantes y un 44\% considera que son Muy Importantes. Con lo cual este indicador, sería para la mayoría de los docentes encuestados cuando menos Importante.

A modo de resumen, la Tabla 39 muestra, en conjunto los indicadores estudiados en el grupo de gerentes y docentes, con el nivel de mayor aceptación para cada grupo.

Tabla 39. Nivel de mayor aceptación para los indicadores estudiados en ambos grupos

\begin{tabular}{|c|c|c|c|c|}
\hline \multirow[b]{2}{*}{ Indicador } & \multicolumn{2}{|c|}{ Gerentes } & \multicolumn{2}{|c|}{ Docentes } \\
\hline & $\begin{array}{l}\text { Nivel de } \\
\text { Aceptación }\end{array}$ & $\%$ & $\begin{array}{c}\text { Nivel de } \\
\text { Aceptación }\end{array}$ & $\%$ \\
\hline Capacidad de comunicación oral y escrita en la lengua nativa & $\begin{array}{c}\text { Muy } \\
\text { Importante }\end{array}$ & 83 & $\begin{array}{c}\text { Muy } \\
\text { Importante }\end{array}$ & 85 \\
\hline Capacidad de comunicación en una segunda lengua & Importante & 55 & Importante & 51 \\
\hline Capacidad de abstracción, análisis y síntesis & $\begin{array}{c}\text { Muy } \\
\text { Importante }\end{array}$ & 72 & $\begin{array}{c}\text { Muy } \\
\text { Importante }\end{array}$ & 87 \\
\hline Capacidad de razonamiento crítico & $\begin{array}{l}\text { Muy } \\
\text { Importante }\end{array}$ & 69 & $\begin{array}{l}\text { Muy } \\
\text { Importante }\end{array}$ & 74 \\
\hline Capacidad de organización y planificación & $\begin{array}{c}\text { Muy } \\
\text { Importante }\end{array}$ & 55 & $\begin{array}{c}\text { Muy } \\
\text { Importante }\end{array}$ & 67 \\
\hline $\begin{array}{l}\text { Capacidad de Identificar, plantear, resolver problemas y tomar } \\
\text { decisiones }\end{array}$ & $\begin{array}{l}\text { Muy } \\
\text { Importante }\end{array}$ & 83 & $\begin{array}{l}\text { Muy } \\
\text { Importante }\end{array}$ & 74 \\
\hline Capacidad de aprender y actualizarse permanentemente & Importante & 52 & $\begin{array}{l}\text { Muy } \\
\text { Importante }\end{array}$ & 77 \\
\hline Capacidad de adaptarse a situaciones nuevas & Importante & 72 & $\begin{array}{c}\text { Muy } \\
\text { Importante }\end{array}$ & 62 \\
\hline
\end{tabular}




\begin{tabular}{|c|c|c|c|c|}
\hline Capacidad de aplicar conocimientos en la práctica & $\begin{array}{c}\text { Muy } \\
\text { Importante }\end{array}$ & 55 & $\begin{array}{c}\text { Muy } \\
\text { Importante }\end{array}$ & 56 \\
\hline Capacidad de investigación & Importante & 45 & $\begin{array}{l}\text { Muy } \\
\text { Importante }\end{array}$ & 44 \\
\hline Compromiso hacia la calidad & $\begin{array}{c}\text { Muy } \\
\text { Importante }\end{array}$ & 83 & $\begin{array}{c}\text { Muy } \\
\text { Importante }\end{array}$ & 74 \\
\hline Capacidad de trabajo en equipos con miembros del área de informática & $\begin{array}{l}\text { Muy } \\
\text { Importante }\end{array}$ & 62 & $\begin{array}{l}\text { Muy } \\
\text { Importante }\end{array}$ & 69 \\
\hline Capacidad de trabajo en equipos interdisciplinarios & $\begin{array}{l}\text { Muy } \\
\text { Importante }\end{array}$ & 52 & $\begin{array}{l}\text { Importante } \\
\text { Muy } \\
\text { Importante } \\
\end{array}$ & 49 \\
\hline Compromiso ético & $\begin{array}{c}\text { Muy } \\
\text { Importante }\end{array}$ & 93 & $\begin{array}{c}\text { Muy } \\
\text { Importante }\end{array}$ & 69 \\
\hline Capacidad de liderazgo & $\begin{array}{l}\text { Muy } \\
\text { Importante }\end{array}$ & 55 & $\begin{array}{c}\text { Muy } \\
\text { Importante }\end{array}$ & 46 \\
\hline Capacidad creativa, de Iniciativa y espíritu emprendedor & $\begin{array}{l}\text { Muy } \\
\text { Importante }\end{array}$ & 48 & $\begin{array}{c}\text { Muy } \\
\text { Importante }\end{array}$ & 54 \\
\hline $\begin{array}{l}\text { Capacidad para elaborar, entender y evaluar especificaciones técnicas y } \\
\text { funcionales }\end{array}$ & Importante & 52 & Importante & 44 \\
\hline $\begin{array}{l}\text { Capacidad de entender, seleccionar y aplicar productos y/o tendencias } \\
\text { tecnológicas al sector empresarial }\end{array}$ & Importante & 52 & Importante & 46 \\
\hline Capacidad de planificar, organizar, dirigir y controlar proyectos & $\begin{array}{c}\text { Muy } \\
\text { Importante } \\
\end{array}$ & 55 & $\begin{array}{c}\text { Muy } \\
\text { Importante }\end{array}$ & 74 \\
\hline $\begin{array}{l}\text { Capacidad de evaluar y validar requisitos y necesidades de hardware y } \\
\text { software }\end{array}$ & Importante & 52 & Importante & 54 \\
\hline Capacidad de programar computadoras & $\begin{array}{c}\text { No Interesa } \\
\text { Muy } \\
\text { Importante }\end{array}$ & 31 & Importante & 62 \\
\hline Capacidad de diseñar y administrar bases de datos & Importante & 38 & Importante & 56 \\
\hline $\begin{array}{l}\text { Capacidad de diseñar y especificar la arquitectura de sistemas de } \\
\text { información }\end{array}$ & Recomendable & 35 & Importante & 69 \\
\hline Capacidad de ensamblar, reparar y/o dar soporte a computadoras & No Interesa & 52 & Recomendable & 59 \\
\hline $\begin{array}{l}\text { Capacidad de diseñar, implantar, validar, mantener y administrar redes } \\
\text { de computadoras }\end{array}$ & No Interesa & 38 & Importante & 51 \\
\hline $\begin{array}{l}\text { Capacidad de configurar, administrar y dar soporte a equipos de } \\
\text { comunicaciones (Hub, switch, router, etc.) }\end{array}$ & No Interesa & 48 & Recomendable & 54 \\
\hline Capacidad de compresión de las ciencias de la gestión empresarial & Importante & 59 & Importante & 64 \\
\hline Compresión de la visión y misión del negocio & $\begin{array}{c}\text { Muy } \\
\text { Importante }\end{array}$ & 69 & $\begin{array}{c}\text { Muy } \\
\text { Importante }\end{array}$ & 72 \\
\hline Otros conocimientos y habilidades adquiridas en la universidad & Importante & 62 & Importante & 51 \\
\hline Conocimientos generales de las ciencias de la gestión empresarial & $\begin{array}{c}\text { Muy } \\
\text { Importante }\end{array}$ & 48 & Importante & 54 \\
\hline Conocimientos generales de la ingeniería informática & $\begin{array}{l}\text { Muy } \\
\text { Importante }\end{array}$ & 45 & $\begin{array}{c}\text { Importante } \\
\text { Muy } \\
\text { Importante }\end{array}$ & 44 \\
\hline $\begin{array}{l}\text { Otros conocimientos y habilidades adquiridas en la práctica pre } \\
\text { profesional }\end{array}$ & Importante & 38 & Importante & 51 \\
\hline $\begin{array}{l}\text { Otros conocimientos y habilidades adquiridas en cursos de certificación } \\
\text { o especialización }\end{array}$ & Importante & 38 & Importante & 49 \\
\hline
\end{tabular}




\section{Análisis comparativo de los resultados de los grupos de gerentes y de docentes}

Para este análisis se usó la prueba t-student de muestras pequeñas independientes, para comparar la homogeneidad de varianzas y significancia de medias de cada indicador estudiado. Si no hay diferencia entre las medias de un indicador, significa que ambos grupos de encuestados tienen la misma opinión sobre el nivel de importancia del indicador correspondiente.

\section{Dimensión de comunicación}

Realizando el análisis de homogeneidad de varianzas y significancia de medias en las tablas del anexo 3, se obtienen los resultados de la Tabla 40.

Tabla 40. Resultado de la comparación entre el grupo de gerentes y docentes para la dimensión de comunicación

\begin{tabular}{lcc}
\hline \multicolumn{1}{c}{ De Comunicación } & Resultado & Media \\
\hline $\begin{array}{l}\text { Capacidad de comunicación oral y escrita en la lengua } \\
\text { nativa }\end{array}$ & No hay diferencias & 3.79 \\
\hline Capacidad de comunicación en una segunda lengua & No hay diferencias & 3.18 \\
\hline
\end{tabular}

Para esta dimensión el análisis nos muestra que no hay diferencia de percepción entre gerentes y docentes.

\section{Dimensión de actitud y aptitud personal}

Realizando el análisis de homogeneidad de varianzas y significancia de medias en las tablas del anexo 4 se obtienen los resultados mostrados en la Tabla 41

Tabla 41. Resultado de la comparación entre el grupo de gerentes y docentes para la dimensión de actitud y aptitud personal

\begin{tabular}{lcc}
\hline \multicolumn{1}{c}{ De actitud y aptitud personal } & Resultado & Media \\
\hline Capacidad de abstracción, análisis y síntesis & No hay diferencias & 3.87 \\
\hline Capacidad de razonamiento crítico & No hay diferencias & 3.74 \\
\hline Capacidad de organización y planificación & No hay diferencias & 3.62 \\
\hline $\begin{array}{l}\text { Capacidad de Identificar, plantear, resolver problemas y tomar } \\
\text { decisiones }\end{array}$ & No hay diferencias & 3.72 \\
\hline Capacidad de aprender y actualizarse permanentemente & Hay diferencia & $3.41-$ \\
\hline Capacidad de adaptarse a situaciones nuevas & No hay diferencias & 3.74 \\
\hline Capacidad de aplicar conocimientos en la práctica & No hay diferencias & 3.51 \\
\hline
\end{tabular}




\begin{tabular}{lcc}
\hline Capacidad de investigación & No hay diferencias & 3.18 \\
\hline Compromiso hacia la calidad & No hay diferencias & 3.69 \\
\hline
\end{tabular}

Para estas variables sólo hay diferencia de percepción entre gerentes y docentes, en el indicador capacidad de aprender y actualizarse permanentemente. En el resto de indicadores, de la dimensión no hay diferencias de percepción.

\section{Dimensión de relación interpersonal y social}

Realizando el análisis de homogeneidad de varianzas y significancia de medias en las tablas del Anexo 5 se obtienen los resultados de la Tabla 42.

Tabla 42. Resultado de la comparación entre el grupo de gerentes y docentes para la dimensión de relación interpersonal y social

\begin{tabular}{lcc}
\hline \multicolumn{1}{c}{ De relación interpersonal y social } & Resultado & Media \\
\hline $\begin{array}{l}\text { Capacidad de trabajo en equipos con miembros } \\
\text { del área de informática }\end{array}$ & No hay diferencias & 3.67 \\
\hline $\begin{array}{l}\text { Capacidad de trabajo en equipos } \\
\text { interdisciplinarios }\end{array}$ & No hay diferencias & 3.46 \\
\hline Compromiso ético & Hay diferencia & $3.93-3.64$ \\
\hline
\end{tabular}

Para esta dimensión habría una diferencia de percepción en el indicador compromiso ético, que a pesar de ser considerado Muy Importante en ambos grupos el porcentaje de aceptación en los gerentes fue del 93\% mientras que en los docentes fue sólo del 69\% (Tabla 19).

\section{Dimensión de emprendimiento}

Realizando el análisis de homogeneidad de varianzas y significancia de medias en las tablas del Anexo 6 se obtienen los resultados de la Tabla 43.

Tabla 43. Resultado de la comparación entre el grupo de gerentes y docentes para la dimensión de emprendimiento

\begin{tabular}{lcc}
\hline \multicolumn{1}{c}{ De emprendimiento } & Resultado & Media \\
\hline Capacidad de Liderazgo & No hay diferencias & 3.26 \\
\hline $\begin{array}{l}\text { Capacidad creativa, de Iniciativa y espíritu } \\
\text { emprendedor }\end{array}$ & No hay diferencias & 3.44 \\
\hline
\end{tabular}

Para esta dimensión no habría diferencias de percepción entre gerentes y docentes.

\section{Dimensión específica de informática}

Realizando el análisis de homogeneidad de varianzas y significancia de medias en las tablas del anexo 7 se obtienen los resultados de la Tabla 44. 
Tabla 44. Resultado de la comparación entre el grupo de gerentes y docentes para la dimensión específica de informática

\begin{tabular}{llc}
\hline \multicolumn{1}{c}{ Específicas de Informática } & \multicolumn{1}{c}{ Resultado } & Media \\
\hline $\begin{array}{l}\text { Capacidad para elaborar, entender y evaluar } \\
\text { especificaciones técnicas y funcionales }\end{array}$ & No hay diferencias & 3.26 \\
\hline $\begin{array}{l}\text { Capacidad de entender, seleccionar y aplicar } \\
\text { productos y/o tendencias tecnológicas al sector } \\
\text { empresarial }\end{array}$ & No hay diferencias & 3.23 \\
\hline $\begin{array}{l}\text { Capacidad de planificar, organizar, dirigir y } \\
\text { controlar proyectos }\end{array}$ & No hay diferencias & 3.69 \\
\hline $\begin{array}{l}\text { Capacidad de evaluar y validar requisitos y } \\
\text { necesidades de hardware y software }\end{array}$ & No hay diferencias & 3.07 \\
\hline $\begin{array}{l}\text { Capacidad de programar computadoras } \\
\begin{array}{l}\text { Capacidad de diseñar y administrar bases de } \\
\text { datos }\end{array}\end{array}$ & No hay diferencias & 2.69 \\
\hline $\begin{array}{l}\text { Capacidad de diseñar y especificar la arquitectura } \\
\text { de sistemas de información }\end{array}$ & No hay diferencias & 3.10 \\
\hline $\begin{array}{l}\text { Capacidad de ensamblar, reparar y/o dar soporte a } \\
\text { computadoras }\end{array}$ & Hay diferencia & 1.592 .10 \\
\hline $\begin{array}{l}\text { Capacidad de diseñar, implantar, validar, mantener } \\
\text { y administrar redes de computadoras }\end{array}$ & Hay diferencia & $1.97-2.62$ \\
\hline $\begin{array}{l}\text { Capacidad de configurar, administrar y dar soporte } \\
\text { a equipos de comunicaciones }\end{array}$ & Hay diferencia & $1.76-2.38$ \\
\hline
\end{tabular}

Para esta dimensión habría diferencias en 4 indicadores.

En el indicador capacidad de diseñar y administrar bases de datos, a pesar de ser considerado Importante en ambos grupos el porcentaje de aceptación en los gerentes fue sólo del 38\% mientras que en los docentes fue del 56\% (Tabla 27).

Los indicadores capacidad de ensamblar, reparar y/o dar soporte a computadoras; y capacidad de configurar, administrar y dar soporte a equipos de comunicaciones, consideradas como No Interesa en el grupo de gerentes, y como recomendable por los docentes (Tabla 31).

El indicador capacidad de diseñar, implantar, validar, mantener y administrar redes de computadoras, fue considerada como No Interesa por los gerentes pero como Importante por los docentes (Tabla 30).

\section{Dimensión específica de gestión empresarial}

Realizando el análisis de homogeneidad de varianzas y significancia de medias en las tablas del anexo 8 se obtienen los resultados de la Tabla 45. 
Tabla 45. Resultado de la comparación entre el grupo de gerentes y docentes para la dimensión específica de gestión empresarial

\begin{tabular}{lcc}
\hline \multicolumn{1}{c}{ Específicas de gestión empresarial } & Resultado & Media \\
\hline $\begin{array}{l}\text { Capacidad de compresión de las ciencias } \\
\text { de la gestión empresarial }\end{array}$ & No hay diferencias & 3.31 \\
\hline $\begin{array}{l}\text { Compresión de la visión y misión del } \\
\text { negocio }\end{array}$ & No hay diferencias & 3.66 \\
\hline
\end{tabular}

Para este grupo de variables no habría diferencias de percepción entre gerentes y docentes.

\section{Dimensión de conocimiento declarativo}

Realizando el análisis de homogeneidad de varianzas y significancia de medias en las tablas del anexo 9 se obtienen los resultados de la Tabla 46.

Tabla 46. Resultado de la comparación entre el grupo de gerentes y docentes para la dimensión de conocimiento declarativo

\begin{tabular}{lcc}
\hline \multicolumn{1}{c}{ Conocimientos y habilidades adquiridas } & Resultado & Media \\
\hline $\begin{array}{l}\text { Otros conocimientos y habilidades adquiridas en la } \\
\text { universidad }\end{array}$ & No hay diferencias & 3.31 \\
\hline $\begin{array}{l}\text { Conocimientos generales de las ciencias de la gestión } \\
\text { empresarial }\end{array}$ & No hay diferencias & 3.15 \\
\hline $\begin{array}{l}\text { Conocimientos generales de la ingeniería informática } \\
\text { Otros conocimientos y habilidades adquiridas en la } \\
\text { práctica pre profesional }\end{array}$ & No hay diferencias & 2.59 \\
\hline $\begin{array}{l}\text { Otros conocimientos y habilidades adquiridas en cursos } \\
\text { de certificación o especialización }\end{array}$ & No hay diferencias & $2.79-3.18$ \\
\hline
\end{tabular}

Para esta dimensión habría una diferencia de percepción en el indicador otros conocimientos y habilidades adquiridas en la práctica pre profesional, que a pesar de ser considerada importante en ambos grupos, el porcentaje de aceptación en los gerentes fue sólo del 38\% mientras que en los docentes fue del 51\% (Tabla 37).

A modo de resumen la Tabla 47 muestra el resultado de la comparación de todos los indicadores estudiados, remplazando el valor de la media, con los valores de la Tabla 5 (de valor numérico a nivel de importancia). 
Tabla 47. Resultado de la comparación entre el grupo de gerentes y docentes para todos los indicadores

\begin{tabular}{|c|c|c|}
\hline Competencia & Resultado & Valor \\
\hline Capacidad de comunicación oral y escrita en la lengua nativa & No hay diferencias & Muy Importante \\
\hline Capacidad de comunicación en una segunda lengua & No hay diferencias & Importante \\
\hline Capacidad de abstracción, análisis y síntesis & No hay diferencias & Muy Importante \\
\hline Capacidad de razonamiento crítico & No hay diferencias & Muy Importante \\
\hline Capacidad de organización y planificación & No hay diferencias & Muy Importante \\
\hline $\begin{array}{l}\text { Capacidad de Identificar, plantear, resolver problemas y tomar } \\
\text { decisiones }\end{array}$ & No hay diferencias & Muy Importante \\
\hline Capacidad de aprender y actualizarse permanentemente & Hay diferencia & $\begin{array}{l}\text { Importante } \\
\text { Muy Importante }\end{array}$ \\
\hline Capacidad de adaptarse a situaciones nuevas & No hay diferencias & Muy Importante \\
\hline Capacidad de aplicar conocimientos en la práctica & No hay diferencias & Muy Importante \\
\hline Capacidad de investigación & No hay diferencias & Importante \\
\hline Compromiso hacia la calidad & No hay diferencias & Muy Importante \\
\hline $\begin{array}{l}\text { Capacidad de trabajo en equipos con miembros del área de } \\
\text { informática }\end{array}$ & No hay diferencias & Muy Importante \\
\hline Capacidad de trabajo en equipos interdisciplinarios & No hay diferencias & Importante \\
\hline Compromiso ético & Hay diferencia & $\begin{array}{l}\text { Muy Importante } \\
\text { Muy Importante }\end{array}$ \\
\hline Capacidad de Liderazgo & No hay diferencias & Importante \\
\hline Capacidad creativa, de Iniciativa y espíritu emprendedor & No hay diferencias & Importante \\
\hline $\begin{array}{l}\text { Capacidad para elaborar, entender y evaluar especificaciones } \\
\text { técnicas y funcionales }\end{array}$ & No hay diferencias & Importante \\
\hline $\begin{array}{l}\text { Capacidad de entender, seleccionar y aplicar productos y/o } \\
\text { tendencias tecnológicas al sector empresarial }\end{array}$ & No hay diferencias & Importante \\
\hline Capacidad de planificar, organizar, dirigir y controlar proyectos & No hay diferencias & Muy Importante \\
\hline $\begin{array}{l}\text { Capacidad de evaluar y validar requisitos y necesidades de } \\
\text { hardware y software }\end{array}$ & No hay diferencias & Importante \\
\hline Capacidad de programar computadoras & No hay diferencias & Importante \\
\hline Capacidad de diseñar y administrar bases de datos & Hay diferencia & $\begin{array}{l}\text { Importante } \\
\text { Importante }\end{array}$ \\
\hline $\begin{array}{l}\text { Capacidad de diseñar y especificar la arquitectura de sistemas de } \\
\text { información }\end{array}$ & No hay diferencias & Importante \\
\hline Capacidad de ensamblar, reparar y/o dar soporte a computadoras & Hay diferencia & $\begin{array}{c}\text { No interesa } \\
\text { Recomendable }\end{array}$ \\
\hline $\begin{array}{l}\text { Capacidad de diseñar, implantar, validar, mantener y administrar } \\
\text { redes de computadoras }\end{array}$ & Hay diferencia & $\begin{array}{l}\text { No interesa } \\
\text { Importante }\end{array}$ \\
\hline $\begin{array}{l}\text { Capacidad de configurar, administrar y dar soporte a equipos de } \\
\text { comunicaciones }\end{array}$ & Hay diferencia & $\begin{array}{c}\text { No interesa } \\
\text { Recomendable }\end{array}$ \\
\hline $\begin{array}{l}\text { Capacidad de compresión de las ciencias de la gestión } \\
\text { empresarial }\end{array}$ & No hay diferencias & Importante \\
\hline Compresión de la visión y misión del negocio & No hay diferencias & Muy Importante \\
\hline Otros conocimientos y habilidades adquiridas en la universidad & No hay diferencias & Importante \\
\hline Conocimientos generales de las ciencias de la gestión empresarial & No hay diferencias & Importante \\
\hline Conocimientos generales de la ingeniería informática & No hay diferencias & Importante \\
\hline $\begin{array}{l}\text { Otros conocimientos y habilidades adquiridas en la práctica pre } \\
\text { profesional }\end{array}$ & Hay diferencia & $\begin{array}{l}\text { Importante } \\
\text { Importante }\end{array}$ \\
\hline $\begin{array}{l}\text { Otros conocimientos y habilidades adquiridas en cursos de } \\
\text { certificación o especialización }\end{array}$ & No hay diferencias & Importante \\
\hline
\end{tabular}


El indicador capacidad de aprender y actualizarse permanentemente, es percibido por los gerentes como Importante y por los docentes como Muy Importante (Tabla 47).

El indicador compromiso ético, tiene una ligera variación numérica, en cuanto a las medias, en la percepción de gerentes y docentes (Tabla 42) pero al realizar el redondeo correspondiente ambas variables son consideradas Muy Importante (Tabla 47). Lo que indicaría que la diferencia de percepción entre docentes y gerentes es mínima.

La capacidad de diseñar y administrar bases de datos, tiene una ligera variación numérica, en cuanto a las medias, en la percepción de gerentes y docentes (Tabla 44) pero en el análisis de frecuencias, en ambos grupos es considerada como Importante (Tabla 47). Lo que indicaría que la diferencia de percepción entre docentes y gerentes es mínima.

La capacidad de ensamblar, reparar y/o dar soporte a computadoras; y la capacidad de configurar, administrar y dar soporte a equipos de comunicaciones tienen una variación en la percepción de gerentes y docentes (Tabla 44). Los primeros consideran que No interesan, en tanto los segundos las consideran como Recomendables (Tabla 47).

El indicador capacidad de diseñar, implantar, validar, mantener y administrar redes de computadoras es percibido por los gerentes como No interesa y por los docentes como Importante (Tabla 47).

El indicador otros conocimientos y habilidades adquiridas en la práctica pre profesional, tiene una ligera variación numérica, en cuanto a las medias, en la percepción de gerentes y docentes (Tabla 46) pero al realizar el redondeo numérico correspondiente se llega al nivel de variable Importante (Tabla 47). Lo que indicaría que la diferencia de percepción entre ambos grupos es mínima.

En el $36 \%$ de los indicadores hay una coincidencia entre la percepción de ambos grupos que consideran el indicador como Muy Importante.

En el 52\% de los indicadores hay una coincidencia entre la percepción de gerentes y docentes que consideran el indicador como Importante.

En el 6\% de los indicadores hay una diferencia de percepción entre gerentes (No Interesa) y docentes (Recomendable). 
En el 3\% de los indicadores hay una diferencia de percepción entre gerentes (Muy Importante) y docentes (Importante).

En el 3\% de los indicadores hay una diferencia de percepción entre gerentes (No interesa) y docentes (Importante).

Ningún indicador es percibido por ambos grupos como No interesa.

La discrepancia estaría en los indicadores:

Capacidad de aprender y actualizarse permanentemente, lo que indicaría que los docentes se orientarían a formar profesionales capaces de adquirir nuevos conocimientos con una visión de que sean académicamente independientes, entretanto los gerentes estarían más orientados a la obtención de resultados inmediatos.

Los indicadores capacidad de diseñar y administrar bases de datos; capacidad de diseñar, implantar, validar, mantener y administrar redes de computadoras; y capacidad de configurar, administrar y dar soporte a equipos de comunicaciones, muestran que los docentes le da una mayor valoración. Si consideramos que estas variables están asociadas a aspectos operativos de la tecnología, podríamos considerar que los gerentes asumen que estos conocimientos no son indispensables en la formación universitaria ya que podrían ser cubiertos por la formación técnica ofrecida por los institutos tecnológicos. 


\section{Discusión, conclusiones y sugerencias}

Como se expuso en la sección Problema de Investigación, la informática ha sufrido y seguirá sufriendo constantes cambios debido a los avances tecnológicos, por un lado, y a los cambios en la manera de encarar su rol y utilidad dentro de la empresa por el otro. Estos cambios continuos hacen de la informática un área del conocimiento cuya formación profesional requiere de cambios y adaptaciones permanentes, caso contrario se estarían formando profesionales con tecnologías en desuso o que carecerían de conocimientos de acuerdo al nuevo rol de la informática en la empresa.

La preocupación de que el país cuente con carreras que incorporen los requerimientos de la empresa en su formación profesional, da origen a este trabajo de investigación luego de la observación de la no existencia de trabajos similares en el país referidos específicamente al área de informática.

El estudio consistió en indagar en el mercado laboral lo que éste consideraba necesario en un profesional informático y compararlo con lo ofrecido en una carrera de ingeniería informática. Lo importante del estudio fue la preocupación de incorporar las necesidades de la empresa en un plan curricular. Si bien existen trabajos en el Perú como el de CIP (2006), con propuestas de perfiles profesionales para ingeniería informática, no se tiene conocimiento de trabajos que traten de proponer planes de estudios que incorporen los requerimientos de la empresa en el Perú.

Para establecer la muestra se eligió una lista de empresas de diferentes sectores de Lima (industria, comercialización, producción, servicios, privadas, públicas, etc.), reconocidas por el uso intensivo de tecnología de punta y cuyas actividades se concentraran en diferentes rubros. El objetivo era indagar en empresas con procesos diferentes, de alta complejidad y cuyos requerimientos de personal informático eran de altos estándares. Evidentemente se pudo establecer una muestra aleatoria, que incluiría todo tipo de empresas (pequeñas, grandes, complejas, simples, etc.) con diferentes tipos de requerimientos a nivel informático (desde muy simples o mediana o altamente complejos). Se optó por una muestra intencional formada por empresas con altos estándares de requerimientos informáticos, lo que nos llevaría a obtener resultados de alta exigencia, que aplicados a un plan curricular cubrirían, no sólo estas expectativas si no también las expectativas de empresas con estándares no tan altos. 
Para construir los instrumentos se usó como referencia el proyecto Tuning Latinoamérica (2007), que estudió las competencias requeridas para la carrera de ingeniería civil, entre otras, ya que el mencionado proyecto no realizó estudios para la carrera de ingeniería informática. Lo que fue de gran utilidad en relación a Tuning (2007) fue la posibilidad de obtener la lista de competencias genéricas para un ingeniero.

El segundo trabajo que aportó en la creación de los instrumentos fue el presentado en ANECA (2005), que presenta una lista de competencias específicas del ingeniero informático. Este estudio realizado para la realidad de España, dio las pautas para establecer las competencias específicas que fueron estudiadas en el presente trabajo.

El trabajo de Lacerda (2002), no fue usado en nuestro estudio, porque estaba muy dirigido a cursos específicos de informática y los indicadores usados en docentes y egresados no eran los mismos, lo que no permitía la comparación de resultados en ambos grupos.

Se realizó una lista de competencias en base a los trabajos mencionados se consultó a expertos, quienes propusieron básicamente la agrupación de las competencias, dando origen a las dimensiones e indicadores, como se muestra en el instrumento (Anexo 1).

Se aplicaron los instrumentos a una muestra conformada por gerentes (representado el mercado laboral) y a un grupo de docentes (representando la academia), el análisis de lo obtenido se muestra en la sección Resultados.

El mayor problema en la realización del trabajo fue la recolección de los datos, sobre todo en el grupo de gerentes, que por sus responsabilidades laborales y poca disponibilidad de tiempo, el levantamiento de información se dificultó, por lo cual algunas encuestas se realizaron vía medios electrónicos.

El resultado obtenido, en la dimensión capacidad de comunicación en una segunda lengua, que los gerentes considerarían mucho más importante la capacidad de comunicación en la lengua materna, que la comunicación en lengua extranjera, podría ser explicable por la necesidad que tienen los ingenieros informáticos de convencer a la alta dirección de la empresa, de la factibilidad de un proyecto informático, comunicando este hecho de manera oral o escrita. Lo que parecería difícil de entender es que el manejo de una lengua extranjera, como el inglés, no sea 
considerado muy importante, siendo conocido que la mayoría de la lectura de textos o avances tecnológicos está en ese idioma, pero al parecer la importancia del inglés radicaría en la capacidad de leer textos y por tanto centrado en el inglés como lenguaje funcional.

Para la dimensión de actitud y aptitud personal, casi todos los indicadores fueron considerados como muy importantes por los gerentes, salvo la capacidad de aprender y actualizarse permanentemente así como la capacidad de investigación, que serían consideradas solo como importantes.

En relación la capacidad de aprender y actualizarse permanentemente, considerada como importante por los gerentes, parecería indicar que el requerimiento está más dirigido a aspectos de desempeño inmediato, relacionados a orden, solución de problemas bien analizados y toma de decisiones por parte de los ingenieros informáticos, restando importancia a competencias que permitirían enfrentar los cambios tecnológicos de manera adecuada. Al parecer el sector empresarial no está interpretando adecuadamente esta capacidad, que tiene un papel fundamental para un profesional informático, ya que éste deberá permanentemente estar actualizado, aprendiendo de forma autónoma las nuevas tecnologías, para poder aplicarlas adecuadamente a sus labores profesionales.

En el caso de docentes el indicador con menor frecuencia fue la capacidad de investigación, lo que podría indicar que para algunos docentes esta capacidad, a pesar de ser muy importante, puede serlo para algunos (44\%) pero no para la mayoría. Estos resultados nos hacen reflexionar acerca de la posición de algunos docentes y universidades al no dar la debida importancia a la investigación, que debería ser considerada como una tarea primordial por los miembros de la academia. Cabe a los entes rectores de la educación en el país, por supuesto con el apoyo de las universidades, la tarea de cambiar esta situación y encontrar los medios de incentivar el incremento de trabajos de investigación. Esta tarea podría comenzar motivando a los docentes a realizar investigaciones en conjunto con sus alumnos, para ir creando conciencia de la importancia de la investigación en el desarrollo de un país.

Deberían buscarse mecanismos para alcanzar una relación mas estrecha entre la universidad y la empresa, tales que permitan la formación de los profesionales informáticos mas orientada a las necesidades de las organizaciones, pero sin dejar de lado los aspectos formativos en las teorías que sustentan los aspectos procedimentales. Generalmente las empresas están preocupadas por los resultados 
inmediatos y se descuida o no se entiende adecuadamente que, competencias como aprender y actualizarse permanentemente, y capacidad de investigación, tienen como objetivo la adquisición de habilidades que finalmente serán de beneficio para las propias empresas, al tener profesionales que podrán enfrentar adecuadamente el avance de las tecnologías.

Para la dimensión de relacionamiento interpersonal y social, los resultados nos mostrarían que en la percepción de los gerentes, todos los indicadores son considerados como Muy Importantes en el desempeño profesional de los informáticos. En el grupo de docentes lo más resaltante es que capacidad de trabajar en equipos interdisciplinarios que obtiene el mismo porcentaje para Importante y Muy Importante. Lo que indicaría que el docente tendría la percepción de que el relacionamiento con otros profesionales de la empresa es, cuando menos importante, ya que al sumar los dos porcentajes tenemos un nivel de aceptación de 96\%, por tanto se debería trabajar fuertemente en el logro de estos indicadores durante la formación del ingeniero informático, dado que estos estudiantes suelen ser introvertidos y orientados a un trabajo individual.

En cuanto a la dimensión de emprendimiento los indicadores fueron considerados como Muy Importantes en ambos grupos, lo que nos indicaría la tendencia de que la formación del ingeniero informático debería salir del clásico estereotipo de ingeniero tradicional conservador y temeroso de aplicar modelos no convencionales, para dar paso a un ingeniero creativo, capaz de aportar a la empresa con iniciativas que ayuden a la misma a lograr sus objetivos con nuevas formas de aplicar la tecnología.

En la dimensión específica de Informática, para el caso de gerentes hay dos puntos importantes de resaltar, primero la capacidad de programar computadoras consigue el mismo nivel de aceptación para No interesa y Muy importante, segundo hay tres indicadores con resultado predominante de No Interesa.

En el caso de programación de computadores, parecería ser un indicio que hay empresas para las cuales esta capacidad es totalmente dispensable, tal vez por su forma de trabajo con las tecnologías, podría ser que usen el outsourcing para este tipo de trabajos (servicios a terceros) en tanto que en otras empresas sería una labor importante al no usar este tipo de servicios. 
En el caso de los tres indicadores que se considerarían como No Interesa, podemos observar que están muy relacionados con el trabajo de soporte técnico, que generalmente están asociadas a tareas bastantes operativas.

Es importante resaltar que estos cuatro indicadores, estarían relacionadas a competencias desarrolladas a nivel técnico en los institutos tecnológicos superiores, por lo cual es posible que los gerentes no requerirían estas competencias en un profesional universitario ya que podrían ser suplidas por personal técnico, que en general tiene sueldos de menor cuantía.

Para el grupo de docentes, hay dos aspectos importantes de resaltar para los indicadores de esta dimensión: dos indicadores serían considerados solo como Recomendables, en tanto que sólo uno sería considerado Muy Importante.

Los dos indicadores considerados como Recomendables serían la capacidad de ensamblar, reparar y/o dar soporte a computadoras; y la capacidad de configurar, administrar y dar soporte a equipos de comunicaciones, capacidades relacionadas a soporte técnico con tareas bastantes rutinarias. Estas capacidades generalmente están asociadas a la formación técnica en institutos tecnológicos, por lo cual el docente podría considerar que estas competencias podrían no ser indispensables en la formación universitaria ya que serían ofrecidos a las empresas por profesionales técnicos.

El indicador que alcanzó en nivel de Muy Importante en esta dimensión, es la capacidad de planificar, organizar, dirigir y controlar proyectos, lo que reforzaría la tendencia del rol del ingeniero informático hacia la planificación y dirección y no tanto a labores operativas tecnológicas.

En cuanto a la dimensión específica de gestión empresarial, que ambos grupos la perciben cuando menos como importantes, sería un indicativo que para un buen desempeño profesional, el ingeniero informático debe entender muy bien la empresa en la que trabaja y orientar su trabajo al logro de los objetivos esbozados en la misión del negocio

Para la dimensión de conocimientos declarativos, el resultado más relevante de es que en la percepción de los gerentes, los conocimientos de ciencias empresariales serían muy importantes, al igual que los conocimientos de informática. En tanto que para los docentes los conocimientos generales de la ingeniería informática comparten 
porcentajes iguales para Importante y Muy importante, lo que indicaría que sería el conocimiento declarativo de mayor importancia percibido por los docentes.

Relacionando los resultados obtenidos en este estudio, con la propuesta de la ACM (2005), presentamos los Figuras 9 y 10. Es importante resaltar que los gráficos están relacionados a la dimensión específica de informática, que este es el foco de la propuesta de la ACM (2005).

Para el caso de los gerentes, los resultados nos estarían indicando la necesidad de un profesional más orientado al desarrollo de aplicaciones pero con mucho énfasis en los aspectos organizacionales y aplicación de tecnologías, sin énfasis en las teorías y de los aspectos relacionados al hardware de las computadoras. Esto puede ser observado en la Figura 9.

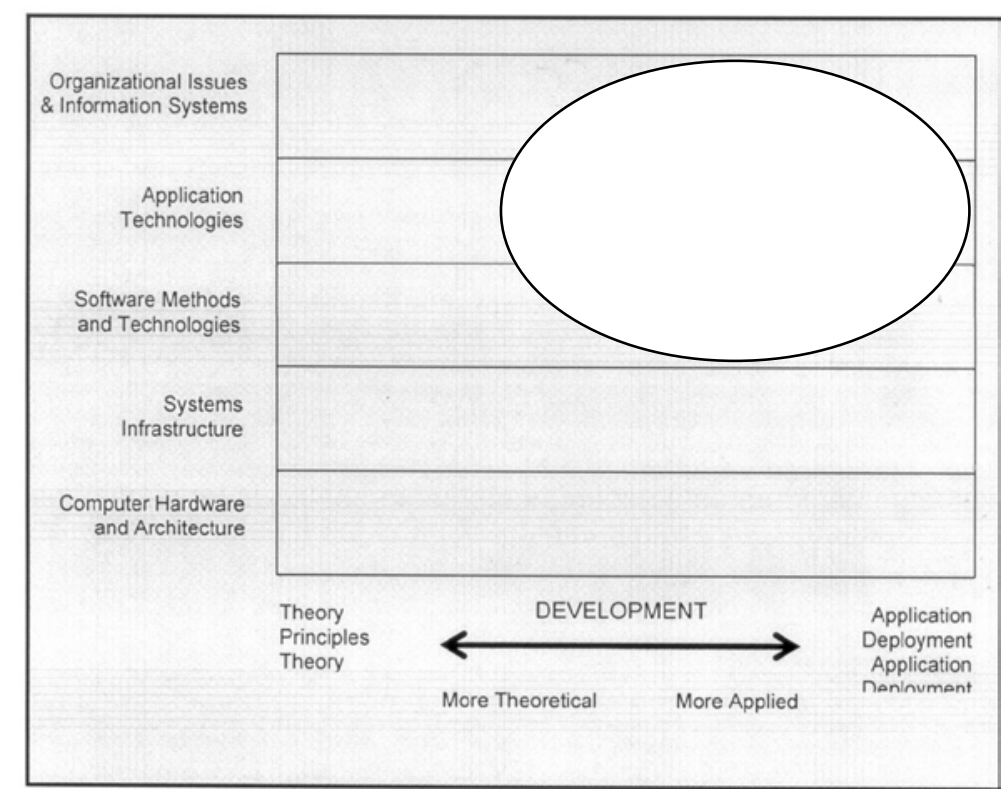

Figura 9. Alcance de la percepción de los gerentes respecto a la competencia profesional del ingeniero informático

Para los docentes los resultados nos estarían indicando la necesidad de un profesional más orientado al desarrollo de aplicaciones pero con mucho énfasis en los aspectos organizacionales, tocando ligeramente los aspectos relacionados al hardware de las computadoras, como mostrado en la Figura 10. 


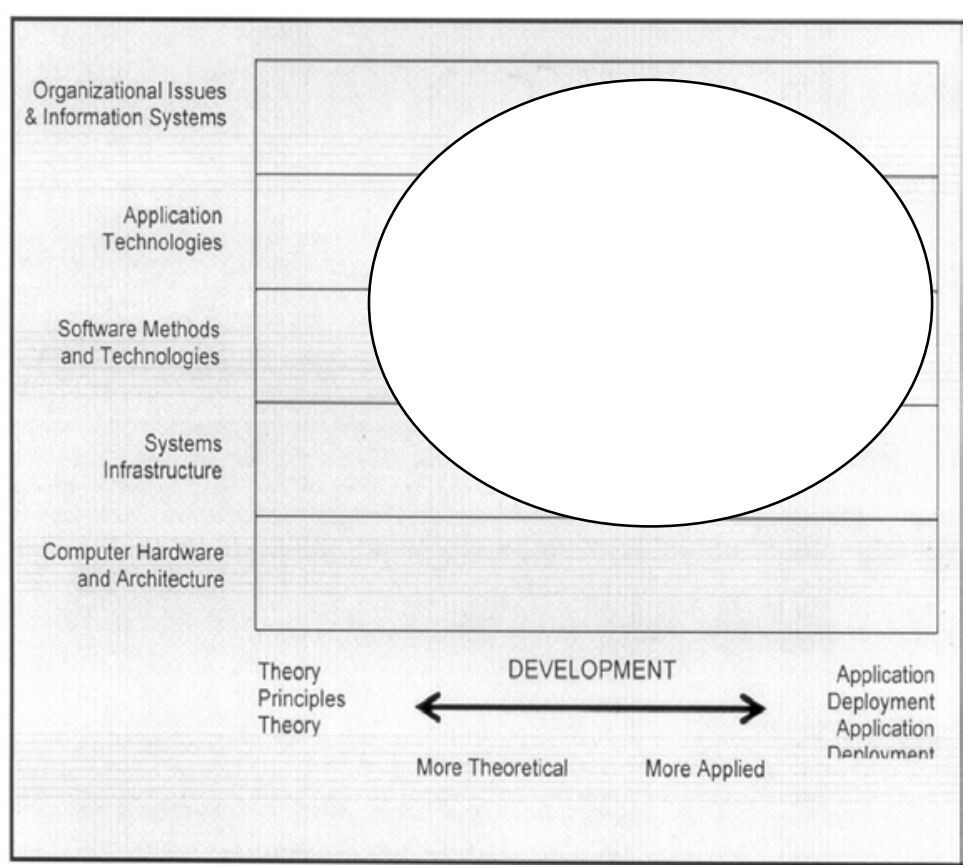

Figura 10. Alcance de la percepción de los docentes respecto a la competencia profesional del ingeniero informático

Estos perfiles parecen no tener en consideración la formación teórica de los ingenieros informáticos, que sabemos es importante, pero parecería que hay una tendencia a dar más valor a la parte procedimental sin tener en cuenta que la práctica debe estar soportada por una buena teoría, partes importantes integrantes de una competencia (Reátegui, 2001).

\section{Conclusiones}

Podría a firmarse que:

No habría diferencias de percepción entre gerentes y docentes en la dimensión de comunicación.

En la dimensión de actitud y aptitud personal, sólo habría una pequeña diferencia de percepción entre gerentes y docentes, en el indicador capacidad de aprender y actualizarse permanentemente. En los otros ocho indicadores no habría diferencia de percepción.

Para la dimensión de relación interpersonal y social habría una ligera diferencia en la percepción de gerentes y docentes, en el indicador compromiso ético. En los otros dos indicadores no habría diferencia de percepción. 
No habría diferencias de percepción entre gerentes y docentes en la dimensión de emprendimiento.

En la dimensión específica de informática, existiría una diferencia de percepción entre el grupo de gerentes y de docentes relacionada a cuatro indicadores. En el resto de indicadores no habría diferencia de percepción.

No habría diferencias de percepción entre gerentes y docentes en la dimensión específica de gestión empresarial.

En la dimensión de conocimientos declarativos, habría una ligera diferencia de percepción en el indicador otros conocimientos y habilidades adquiridas en la práctica pre profesional. En los otros custro indicadores no había diferencias de percepción entre gerentes y docentes.

\section{Sugerencias}

De las discusiones y conclusiones expuestas, podemos realizar las sugerencias para ser incorporadas en el plan de estudios de una carrera de ingeniería informática:

- La comunicación oral y escrita en la lengua materna es muy importante y debería ser trabajada de manera transversal en todos los cursos de la carrera principalmente porque actualmente los jóvenes tienen un manejo deformado del lenguaje, principalmente escrito, debido a los hábitos creados por las herramientas tecnológicas de uso masificado.

o La comunicación en una segunda lengua como el inglés debería ser incorporada en los planes de estudio.

o Los indicadores de la dimensión de actitud y aptitud personal son casi todos considerados muy importantes, por tanto deberían trabajarse en todos los cursos de la carrera de manera transversal.

- La investigación fue considerada importante, con lo cual podría recomendarse la inclusión de un curso de Metodología de la Investigación, pero con recomendación de incluir trabajos de investigación en todos los cursos.

o Sería importante no dejar de lado el curso de lógica proposicional, que sería la base para el planteamiento de algoritmos. 
- Los cursos deberían lograr un buen nivel de inter relación personal tanto entre alumnos de informática como con alumnos de otras carreras, lo que se podría lograr o a través de trabajos o proyectos grupales.

- La competencia de compromiso ético debería tener un mayor énfasis y debería ser transversal a todos los cursos y sería bastante recomendable un curso de ética profesional.

o En lo referente a la dimensión específicas de informática, la recomendación es la de establecer un balance adecuado en los cursos de soporte técnico, que deberían orientarse al análisis, solución de problemas y toma de decisiones dejando de lado tareas operativas. Igualmente para los cursos de programación, que deben estar presentes en el plan de estudios, debería darse énfasis más al planteamiento de soluciones algorítmicas adecuadas y toma de decisiones, que a la destreza del manejo de los lenguajes de programación.

o Considerar que los cursos de soporte técnico podrían ser no necesarios, o en todo caso de ser impartidos, no deberían tener un rol predominante en el plan de estudios. Es importante encontrar el balance adecuado, principalmente para no dejar de lado los aspectos conceptuales que sustentan el soporte técnico.

- Considerar que las habilidades de programación tienen una importancia relativa en la formación de un ingeniero informático, ya que dependiendo de la empresa que contrata esta habilidad podría ser una barrera de contratación.

o Incorporar cursos de gestión empresarial (marketing, contabilidad, finanzas, economía, gerencia entre otros) que permitan lograr competencias relacionadas al emprendimiento, liderazgo y que permitan al ingeniero informático tener las capacidades para la comprensión de la visión y misión del negocio.

- Se deberían incluir cursos de informática relacionados a aspectos gerenciales y de toma de decisiones que sirvan para el mejoramiento de los procesos empresariales como gerencia de proyectos, gestión de procesos, minería de datos, gestión del conocimiento, manejo de sistemas integrados de gestión entre otros.

- El plan de estudios debería tener un buen balance entre cursos de tecnología de la información y cursos de gestión pero teniendo en cuenta el logro de las 
llamadas habilidades blandas como responsabilidad, trabajo en equipo, compromiso con la calidad entre otros.

En lo referente al trabajo de investigación como tal, podemos hace algunas sugerencias que darían origen a nuevas investigaciones:

- La dimensión específica de gestión empresarial, debería detallar indicadores relacionados a las diferentes áreas de la gestión empresarial.

- Para el caso de la dimensión específica de informática podrían hacerse estudios relacionados a los cursos impartidos en la carrera de ingeniería informática incluyendo cursos de ciencias básicas y de humanidades.

o Estudios ampliando la muestra de gerentes y la de docentes para incluir miembros de las diferentes regiones del país.

o Un estudio considerando también a los egresados de ingeniería informática para obtener información no solo de competencias profesionales sino también de su desempeño en el campo laboral. 


\section{Referencias}

Agencia Nacional de Evaluación de la Calidad y Acreditación (2005). El Libro blanco Título de Grado en Ingeniería Informática. Madrid: Omán Impresores.

Arias O., F., G., (1999). El proyecto de investigación. Guía para su elaboración. (3ra ed.). Caracas: Editorial Episteme.

Asamblea general de la Conferencia de Rectores de la Universidad Española. (2000). Declaración de Bolonga: Adaptación del sistema universitario español a sus directrices. Recuperado el 25 de enero de 2008, de http://www.crue.org/apadsisuniv.htm

Association for Computing Machinery. (2004). Model Curriculum and Guidelines for Undergraduate Degree Programs in Computer Engineering. Recuperado el 23 de enero de 2008, de http://www.computer.org.

Association for Computing Machines. (2005). Computing Curricula 2005, The overview report, Joint Task Force on Computing Curricula 2004. Recuperado el 15 de febrero de 2008, de http://www.acm.org/education. http://www.computer.org/education.

Beekman, G. (1995). Computación \& Informática hoy: Una mirada a la tecnología del mañana. Delaware: Addison-Wesley.

Camilo D., J., Tendencias en la administración de la tecnología informática en el 2007. Artículos Delta. Recuperado el 15 de marzo de 2008, de http://www.deltaasesores.com/prof/PRO407.html.

Colegio de Ingenieros del Perú. Consejo Departamental de Lima. Capítulo de Ingeniería Industrial y de Sistemas. (2006). Denominaciones y Perfiles de las carreras en Ingeniería de Sistemas, Computación e Informática. Informe de la Comisión. Lima: [s.n].

Conferencia Mundial sobre Educación Superior. (1998). La Educación Superior en el siglo XXI Visión y Misión. Unesco Paris. Recuperado el 20 de abril de 2008, de http://unesdoc.unesco.org.

Declaración de Bolonia. (1999). Declaración conjunta de los Ministros Europeos de Educación. Recuperado el 30 de abril de 2008, de http://www.educacion.gob.es.

Denning, P., (2005), Is computer science a science?. Communications of ACM, 48, (4), 27-31. 
Gates, H., (1995). Camino al futuro. Santa Fe de Bogota: Mc Graw Hill.

Gottschalk, P., (2007). CIO and corporate Strategic Management Changing role of CIO to CEO. U.S.A.: Idea Group Publising.

Hernandez S., R. Fernández C., C., \& Baptista L., M. P., (2006). Metodología de la investigación. (4ta ed.). México: Mc Graw Hill.

Instituto Nacional de Estadística e Informática. (1997). Manual para la Construcción de un Data Warehouse. Lima: INEI.

Lacerda L., B., (2002). Formação e inserção no mercado de trabalho em computação de e informática: um estudo de caso sobre o curso de informática da UFRJ. Tesis de maestría no publicada, Universidad Federal do Rio de Janeiro, Brasil.

Norton, P. (2003). Introduction to computers. (5ta ed.). California: Mc Graw Hill.

Proyecto Tuning. (2007). Reflexiones y perspectivas de la Educación Superior en América Latina. Informe Final proyecto Tuning. Recuperado el 15 de marzo de 2008, de http://unideusto.org/tuningal.

Proyecto 6X4 UELAC. (2008). Propuestas y acciones universitarias para la transformación de la Educación Superior en América Latina. Recuperado el 24 de junior de 2008, de http://www.6x4uealc.org.

Reátegui, N., Arakaki, M., Flores, C., (2001). El reto de la evaluación. Lima: [s.n].

Rodríguez Z., H., (2007). El paradigma de las competencias hacia la educación superior. Revista de la Facultad de Ciencias Económicas de la Universidad de Nueva Granada, XV, (1), 145-165. Recuperado el 15 de febrero de 2008, de http://www.umng.edu.co/revcieco/2007/julio.2007/VOLXV1/7.paradigma.pdf.

The Internacional Council on Systems Engineering. (s.f.). What is Systems Engineering?. Recuperado el 15 mayo de 2008, de http://www.incose(2006) .org/practice/whatissystemseng.aspx. 
Anexos 


\section{Anexo 1: Instrumento de la Investigación}

\section{Encuesta sobre las competencias profesionales requeridas para un ingeniero informático, dirigida a gerentes de informática}

Indicaciones al encuestado:

Este cuestionario presenta una serie de preguntas relacionadas a las competencias que, desde su experiencia, serían importantes para el éxito de un egresado de la carrera de Ingeniería Informática. Por favor conteste las preguntas considerando las competencias que usted exigiría a una persona para trabajar en su departamento. Sus respuestas serán de invalorable aporte para la mejora de un plan curricular que cubra las necesidades del mercado laboral que usted representa.

En toda la encuesta use la siguiente escala:

\begin{tabular}{|l|l|}
\hline 1 & No interesa \\
\hline 2 & Recomendable \\
\hline 3 & Importante \\
\hline 4 & Muy importante \\
\hline
\end{tabular}

Muchas gracias por su cooperación.

Datos generales.

Empresa:

Cargo:

Número de empleados a su cargo:

En relación a su puesto de trabajo actual, ¿qué conocimientos considera más importantes?

\begin{tabular}{|l|l|l|l|l|}
\hline & $\mathbf{1}$ & $\mathbf{2}$ & $\mathbf{3}$ & $\mathbf{4}$ \\
\hline Conocimientos generales de la Ingeniería Informática & & & & \\
\hline Conocimientos generales de las ciencias de la Gestión Empresarial & & & & \\
\hline Otros conocimientos y habilidades adquiridas en la Universidad & & & & \\
\hline Otros conocimientos y habilidades adquiridas en la práctica pre profesional & & & & \\
\hline $\begin{array}{l}\text { Otros conocimientos y habilidades adquiridas en cursos de certificación o } \\
\text { especialización }\end{array}$ & & & & \\
\hline
\end{tabular}

Para cada una de las competencias de la lista por favor estime, desde su opinión, la importancia de la misma para desempeñarse en su organización.

\begin{tabular}{|c|c|c|c|c|c|c|}
\hline Cor & petencia & 1 & 2 & 3 & 4 & ¿Por qué? \\
\hline De & omunicación & & & & & \\
\hline 8 & Capacidad de comunicación oral y escrita en la lengua nativa & & & & & \\
\hline 9 & Capacidad de comunicación en una segunda lengua & & & & & \\
\hline De & ctitud y aptitud personal & & & & & \\
\hline 10 & Capacidad de abstracción, análisis y síntesis & & & & & \\
\hline 11 & Capacidad de razonamiento crítico & & & & & \\
\hline 12 & Capacidad de organización y planificación & & & & & \\
\hline 13 & $\begin{array}{l}\text { Capacidad de Identificar, plantear, resolver problemas y tomar } \\
\text { decisiones }\end{array}$ & & & & & \\
\hline 14 & Capacidad de aprender y actualizarse permanentemente & & & & & \\
\hline 15 & Capacidad de adaptarse a situaciones nuevas & & & & & \\
\hline
\end{tabular}




\begin{tabular}{|c|c|c|c|c|}
\hline 16 & Capacidad de aplicar conocimientos en la práctica & & & \\
\hline 17 & Capacidad de investigación & & & \\
\hline 18 & Compromiso hacia la calidad & & & \\
\hline \multicolumn{5}{|c|}{ De relación interpersonal y social } \\
\hline 19 & $\begin{array}{l}\text { Capacidad de trabajo en equipos con miembros del área de } \\
\text { informática }\end{array}$ & & & \\
\hline 20 & Capacidad de trabajo en equipos interdisciplinarios & & & \\
\hline 21 & Compromiso ético & & & \\
\hline \multicolumn{5}{|c|}{ De emprendimiento } \\
\hline 22 & Capacidad de Liderazgo & & & \\
\hline 23 & Capacidad creativa, de Iniciativa y espíritu emprendedor & & & \\
\hline \multicolumn{5}{|c|}{ Específicas } \\
\hline 24 & $\begin{array}{l}\text { Capacidad para elaborar, entender y evaluar especificaciones } \\
\text { técnicas y funcionales }\end{array}$ & & & \\
\hline 25 & $\begin{array}{l}\text { Capacidad de entender, seleccionar y aplicar productos y/o } \\
\text { tendencias tecnológicas al sector empresarial }\end{array}$ & & & \\
\hline 26 & Capacidad de planificar, organizar, dirigir y controlar proyectos & & & \\
\hline 27 & $\begin{array}{l}\text { Capacidad de evaluar y validar requisitos y necesidades de } \\
\text { hardware y software }\end{array}$ & & & \\
\hline 28 & Capacidad de programar computadoras & & & \\
\hline 29 & Capacidad de diseñar y administrar bases de datos & & & \\
\hline 30 & $\begin{array}{l}\text { Capacidad de diseñar y especificar la arquitectura de sistemas } \\
\text { de información }\end{array}$ & & & \\
\hline 31 & $\begin{array}{l}\text { Capacidad de ensamblar, reparar y/o dar soporte a } \\
\text { computadoras }\end{array}$ & & & \\
\hline 32 & $\begin{array}{l}\text { Capacidad de diseñar, implantar, validar, mantener y } \\
\text { administrar redes de computadoras }\end{array}$ & & & \\
\hline 33 & $\begin{array}{l}\text { Capacidad de configurar, administrar y dar soporte a equipos de } \\
\text { comunicaciones (Hub, switch, router, etc.) }\end{array}$ & & & \\
\hline \multicolumn{5}{|c|}{ Específicas de gestión empresarial } \\
\hline 34 & $\begin{array}{l}\text { Capacidad de compresión de las ciencias de la gestión } \\
\text { empresarial }\end{array}$ & & & \\
\hline 35 & Compresión de la visión y misión del negocio & & & \\
\hline \multicolumn{5}{|c|}{ A continuación puede indicar las competencias que en su opinión deberían agregarse a la lista } \\
\hline & & & & \\
\hline & & & & \\
\hline
\end{tabular}




\section{Encuesta sobre las competencias profesionales requeridas para un ingeniero informático, dirigida a docentes de informática}

\section{Indicaciones al encuestado:}

Este cuestionario presenta una serie de preguntas relacionadas a las competencias que, desde su opinión, podrían ser importantes para el éxito de un egresado de la carrera de Ingeniería Informática. Por favor conteste las preguntas valorando, desde su opinión, la importancia de lograr en los estudios universitarios de informática, cada una de las siguientes competencias profesionales. Sus respuestas serán de invalorable aporte para la mejora de un plan curricular que cubra los requerimientos de formación profesional en informática.

En toda la encuesta use la siguiente escala:

\begin{tabular}{|l|l|}
\hline 1 & No interesa \\
\hline 2 & Recomendable \\
\hline 3 & Importante \\
\hline 4 & Muy importante \\
\hline
\end{tabular}

Muchas gracias por su cooperación.

\section{Datos generales.}

Curso a su cargo

En relación a su experiencia docente, ¿qué conocimientos procedentes de la formación universitaria considera más importantes?

\begin{tabular}{|l|l|l|l|l|}
\hline & $\mathbf{1}$ & $\mathbf{2}$ & $\mathbf{3}$ & $\mathbf{4}$ \\
\hline Conocimientos generales de la ingeniería informática & & & & \\
\hline Conocimientos generales de las ciencias de la gestión empresarial & & & & \\
\hline Otros conocimientos y habilidades adquiridas en la universidad & & & & \\
\hline Otros conocimientos y habilidades adquiridas en la práctica pre profesional & & & & \\
\hline $\begin{array}{l}\text { Otros conocimientos y habilidades adquiridas en cursos de certificación o } \\
\text { especialización }\end{array}$ & & & & \\
\hline
\end{tabular}

Para cada una de las competencias de la lista por favor estime:

- En su opinión, la importancia de esa competencia en la formación de un profesional en ingeniería informática.

\begin{tabular}{|l|l|l|l|l|l|l|}
\hline Competencia & $\mathbf{1}$ & $\mathbf{2}$ & $\mathbf{3}$ & $\mathbf{4}$ & ¿Por qué? \\
\hline \multicolumn{5}{|l|}{ ¿e comunicación } & \multicolumn{2}{|l|}{} \\
\hline 8 & Capacidad de comunicación oral y escrita en la lengua nativa & & & & & \\
\hline $9 \quad$ Capacidad de comunicación en una segunda lengua & & & & & \\
\hline De actitud y aptitud personal & & & & & \\
\hline 10 & Capacidad de abstracción, análisis y síntesis & & & & \\
\hline 11 & Capacidad de razonamiento crítico & & & & \\
\hline 12 & Capacidad de organización y planificación & & \\
\hline 13 & $\begin{array}{l}\text { Capacidad de Identificar, plantear, resolver problemas y tomar } \\
\text { decisiones }\end{array}$ & & & & \\
\hline 14 & Capacidad de aprender y actualizarse permanentemente & & & & \\
\hline 15 & Capacidad de adaptarse a situaciones nuevas & & & & \\
\hline 16 & Capacidad de aplicar conocimientos en la práctica & & & & \\
\hline 17 & Capacidad de investigación & & & & \\
\hline 18 & Compromiso hacia la calidad & & & & \\
\hline
\end{tabular}




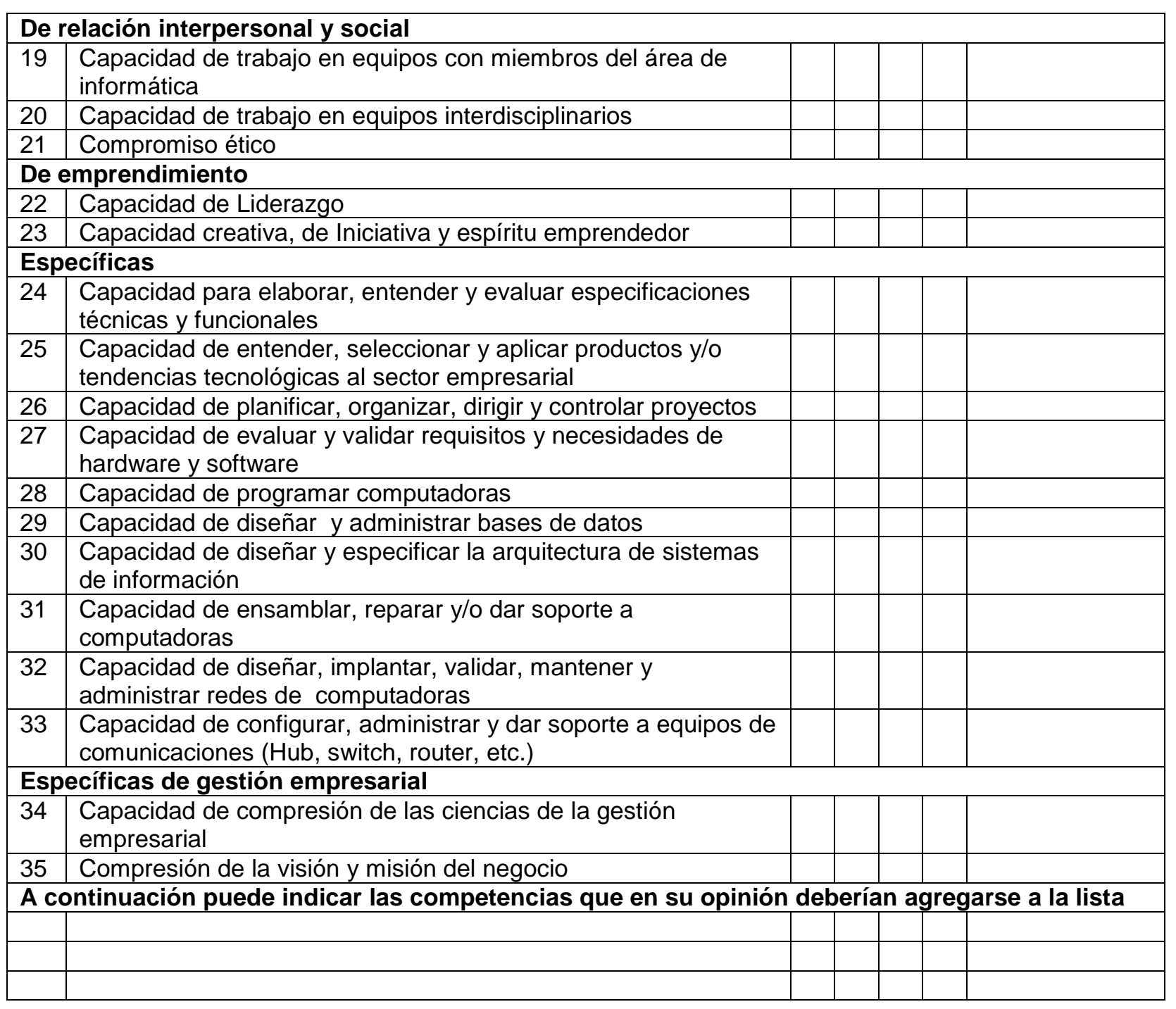


Anexo 2. Prueba de validez de V de Aiken

\begin{tabular}{|c|c|c|c|c|c|c|c|c|c|c|c|c|}
\hline & & \multicolumn{10}{|c|}{ EXPERTO } & \multirow[b]{2}{*}{$\begin{array}{l}\text { V DE } \\
\text { AIKEN }\end{array}$} \\
\hline & Item & 1 & 2 & 3 & 4 & 5 & 6 & 7 & 8 & 9 & 10 & \\
\hline INDICACIONES & 1 & 2 & 4 & 4 & 4 & 3 & 4 & 3 & 3 & 3 & 4 & 0.80 \\
\hline DATOS GENERALES & 2 & 4 & 4 & 4 & 3 & 3 & 3 & 3 & 3 & 3 & 3 & 0.77 \\
\hline \multirow{5}{*}{$\begin{array}{l}\text { VALORACIÓN DE LOS } \\
\text { CONOCIMIENTOS }\end{array}$} & 3 & 4 & 4 & 4 & 4 & 3 & 4 & 3 & 3 & 3 & 4 & 0.87 \\
\hline & 4 & 4 & 4 & 4 & 3 & 4 & 3 & 3 & 3 & 3 & 4 & 0.83 \\
\hline & 5 & 3 & 3 & 4 & 2 & 3 & 3 & 3 & 4 & 3 & 4 & 0.73 \\
\hline & 6 & 4 & 3 & 4 & 3 & 3 & 3 & 3 & 4 & 3 & 4 & 0.80 \\
\hline & 7 & 3 & 4 & 4 & 4 & 3 & 3 & 4 & 3 & 3 & 4 & 0.83 \\
\hline \multirow{2}{*}{ COMUNICACIÓN } & 8 & 4 & 4 & 4 & 4 & 4 & 4 & 4 & 4 & 4 & 4 & 1.00 \\
\hline & 9 & 4 & 3 & 4 & 3 & 4 & 4 & 3 & 4 & 3 & 4 & 0.87 \\
\hline \multirow{9}{*}{$\begin{array}{l}\text { ACTITUD Y APTITUD } \\
\text { PERSONAL }\end{array}$} & 10 & 4 & 4 & 4 & 4 & 4 & 3 & 4 & 4 & 4 & 4 & 0.97 \\
\hline & 11 & 4 & 4 & 4 & 3 & 4 & 4 & 4 & 4 & 4 & 4 & 0.97 \\
\hline & 12 & 4 & 3 & 4 & 3 & 4 & 4 & 4 & 3 & 4 & 4 & 0.90 \\
\hline & 13 & 4 & 4 & 4 & 4 & 4 & 4 & 4 & 4 & 4 & 4 & 1.00 \\
\hline & 14 & 4 & 3 & 4 & 4 & 3 & 4 & 4 & 4 & 3 & 4 & 0.90 \\
\hline & 15 & 4 & 4 & 4 & 3 & 4 & 4 & 4 & 4 & 3 & 4 & 0.93 \\
\hline & 16 & 4 & 4 & 4 & 4 & 4 & 4 & 4 & 4 & 3 & 4 & 0.97 \\
\hline & 17 & 4 & 3 & 4 & 3 & 4 & 3 & 4 & 4 & 3 & 4 & 0.87 \\
\hline & 18 & 4 & 4 & 4 & 3 & 4 & 4 & 4 & 4 & 3 & 4 & 0.93 \\
\hline \multirow{3}{*}{$\begin{array}{l}\text { RELACIÓN PERSONAL Y } \\
\text { SOCIAL }\end{array}$} & 19 & 4 & 4 & 4 & 4 & 4 & 4 & 3 & 4 & 4 & 4 & 0.97 \\
\hline & 20 & 4 & 4 & 4 & 3 & 4 & 4 & 4 & 4 & 3 & 4 & 0.93 \\
\hline & 21 & 4 & 4 & 4 & 4 & 4 & 4 & 4 & 4 & 4 & 4 & 1.00 \\
\hline \multirow{2}{*}{ EMPRENDIMIENTO } & 22 & 4 & 4 & 4 & 3 & 4 & 4 & 3 & 3 & 4 & 4 & 0.90 \\
\hline & 23 & 4 & 4 & 4 & 3 & 4 & 3 & 4 & 3 & 4 & 4 & 0.90 \\
\hline \multirow{10}{*}{$\begin{array}{l}\text { COMPETENCIAS } \\
\text { ESPECÍFICAS }\end{array}$} & 24 & 4 & 4 & 4 & 4 & 3 & 4 & 3 & 4 & 3 & 4 & 0.90 \\
\hline & 25 & 4 & 4 & 4 & 4 & 3 & 4 & 4 & 4 & 3 & 4 & 0.93 \\
\hline & 26 & 4 & 4 & 4 & 3 & 4 & 4 & 3 & 4 & 3 & 4 & 0.90 \\
\hline & 27 & 4 & 4 & 4 & 4 & 3 & 3 & 4 & 4 & 4 & 4 & 0.93 \\
\hline & 28 & 4 & 3 & 4 & 3 & 2 & 3 & 3 & 3 & 3 & 4 & 0.73 \\
\hline & 29 & 4 & 4 & 4 & 3 & 2 & 4 & 3 & 3 & 3 & 4 & 0.80 \\
\hline & 30 & 4 & 4 & 4 & 4 & 4 & 4 & 3 & 3 & 3 & 4 & 0.90 \\
\hline & 31 & 4 & 3 & 3 & 3 & 2 & 2 & 3 & 3 & 3 & 3 & 0.63 \\
\hline & 32 & 4 & 4 & 4 & 3 & 3 & 3 & 3 & 3 & 3 & 3 & 0.77 \\
\hline & 33 & 4 & 3 & 4 & 3 & 2 & 2 & 3 & 3 & 3 & 3 & 0.67 \\
\hline \multirow{2}{*}{$\begin{array}{l}\text { GESTIÓN } \\
\text { EMPRESARIAL }\end{array}$} & 34 & 4 & 4 & 4 & 3 & 3 & 3 & 3 & 3 & 3 & 4 & 0.80 \\
\hline & 35 & 4 & 4 & 4 & 3 & 4 & 4 & 4 & 4 & 4 & 4 & 0.97 \\
\hline
\end{tabular}


Anexo 3: Análisis de homogeneidad de varianzas y significancia de medias para la dimensión de comunicación

Group Statistics

\begin{tabular}{|ll|r|r|r|r|}
\hline & Cargo & N & Mean & Std. Deviation & Std. Error Mean \\
\hline Comunicación lengua nativa & Docente & 39 & 3,79 &, 570 &, 091 \\
& Gerente & 29 & 3,83 &, 384 &, 071 \\
\hline Comunicación segunda & Docente & 39 & 3,18 &, 683 &, 109 \\
lengua & Gerente & 29 & 3,24 &, 636 &, 118 \\
\hline
\end{tabular}

Independent Samples Test

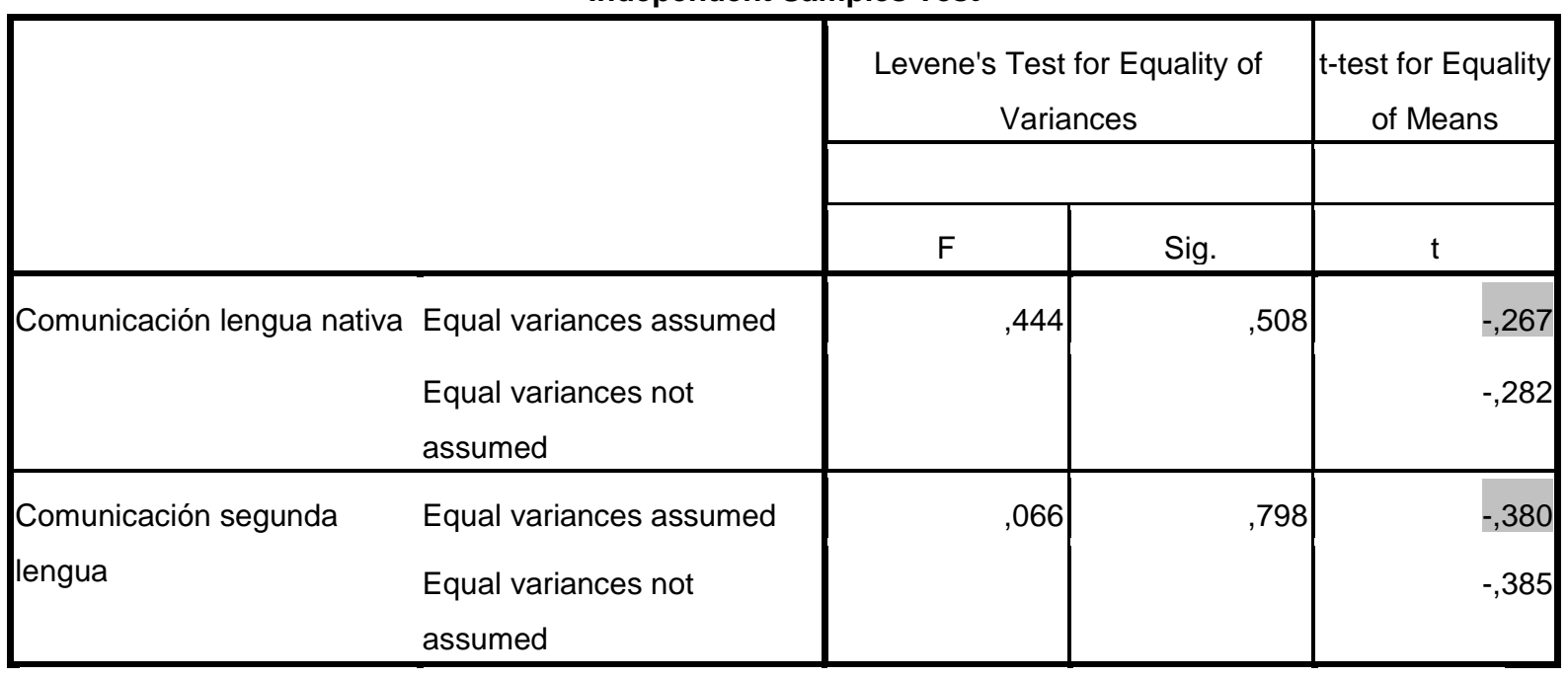

Independent Samples Test

\begin{tabular}{|c|c|c|c|c|}
\hline & & \multicolumn{3}{|c|}{ t-test for Equality of Means } \\
\hline & & $d f$ & Sig. (2-tailed) & Mean Difference \\
\hline Comunicación lengua nativa & $\begin{array}{l}\text { Equal variances assumed } \\
\text { Equal variances not assumed }\end{array}$ & $\begin{array}{r}66 \\
65,459 \\
\end{array}$ & $\begin{array}{l}, 790 \\
, 779\end{array}$ & $\begin{array}{l}-, 033 \\
-, 033\end{array}$ \\
\hline $\begin{array}{l}\text { Comunicación segunda } \\
\text { lengua }\end{array}$ & $\begin{array}{l}\text { Equal variances assumed } \\
\text { Equal variances not assumed }\end{array}$ & $\begin{array}{r}66 \\
62,692\end{array}$ & $\begin{array}{l}, 705 \\
, 702\end{array}$ & $\begin{array}{l}-, 062 \\
-, 062\end{array}$ \\
\hline
\end{tabular}

Independent Samples Test

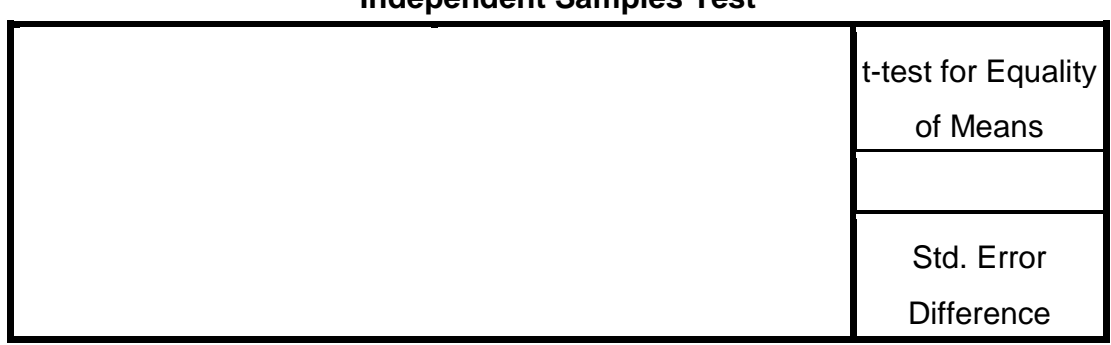




\begin{tabular}{|ll|r|}
\hline Comunicación lengua nativa & Equal variances assumed &, 123 \\
& Equal variances not assumed &, 116 \\
\hline $\begin{array}{l}\text { Comunicación segunda } \\
\text { lengua }\end{array}$ & Equal variances assumed &, 163 \\
\hline
\end{tabular}

Independent Samples Test

\begin{tabular}{|c|c|c|c|}
\hline & & \multicolumn{2}{|c|}{ t-test for Equality of Means } \\
\hline & & \multicolumn{2}{|c|}{$\begin{array}{l}\text { 95\% Confidence Interval of the } \\
\text { Difference }\end{array}$} \\
\hline & & Lower & Upper \\
\hline Comunicación lengua nativa & $\begin{array}{l}\text { Equal variances assumed } \\
\text { Equal variances not assumed }\end{array}$ & $\begin{array}{l}-, 277 \\
-, 264 \\
\end{array}$ & $\begin{array}{l}, 212 \\
, 199 \\
\end{array}$ \\
\hline $\begin{array}{l}\text { Comunicación segunda } \\
\text { lengua }\end{array}$ & $\begin{array}{l}\text { Equal variances assumed } \\
\text { Equal variances not assumed }\end{array}$ & $\begin{array}{l}-, 387 \\
-, 384\end{array}$ & $\begin{array}{l}, 263 \\
, 260\end{array}$ \\
\hline
\end{tabular}


Anexo 4: Análisis de homogeneidad de varianzas y significancia de medias para la dimensión de actitud y aptitud personal.

Group Statistics

\begin{tabular}{|c|c|c|c|c|c|}
\hline & Cargo & $\mathrm{N}$ & Mean & Std. Deviation & Std. Error Mean \\
\hline \multirow[t]{2}{*}{ Capacidad de abstracción } & Docente & 39 & 3,87 & ,339 & 054 \\
\hline & Gerente & 29 & 3,69 &, 541 & 101 \\
\hline \multirow[t]{2}{*}{ Razonamiento crítico } & Docente & 39 & 3,74 & ,442 & 071 \\
\hline & Gerente & 29 & 3,69 & ,471 & 087 \\
\hline \multirow[t]{2}{*}{ Organización y planificación } & Docente & 39 & 3,62 &, 590 & ,094 \\
\hline & Gerente & 29 & 3,55 &, 506 & ,094 \\
\hline \multirow{2}{*}{$\begin{array}{l}\text { Resolución de problemas y } \\
\text { toma de decisiones }\end{array}$} & Docente & 39 & 3,72 &, 510 & ,082 \\
\hline & Gerente & 29 & 3,83 & ,384 & 071 \\
\hline \multirow{2}{*}{$\begin{array}{l}\text { Capacidad de aprender y } \\
\text { actualizarse }\end{array}$} & Docente & 39 & 3,74 & ,498 & 080 \\
\hline & Gerente & 29 & 3,41 &, 568 & 105 \\
\hline \multirow{2}{*}{$\begin{array}{l}\text { Adaptarse a nuevas } \\
\text { situaciones }\end{array}$} & Docente & 39 & 3,56 &, 598 & ,096 \\
\hline & Gerente & 29 & 3,72 & ,455 & 084 \\
\hline \multirow{2}{*}{$\begin{array}{l}\text { Aplicar conocimientos a la } \\
\text { práctica }\end{array}$} & Docente & 39 & 3,51 & ,601 & ,096 \\
\hline & Gerente & 29 & 3,48 & ,634 & ,118 \\
\hline \multirow[t]{2}{*}{ Capacidad de investigación } & Docente & 39 & 3,18 & ,885 & ,142 \\
\hline & Gerente & 29 & 3,14 & ,743 & ,138 \\
\hline \multirow[t]{2}{*}{ Compromiso a la calidad } & Docente & 39 & 3,69 &, 569 & 091 \\
\hline & Gerente & 29 & 3,79 & ,491 & 091 \\
\hline
\end{tabular}


Independent Samples Test

\begin{tabular}{|c|c|c|c|c|}
\hline & & \multicolumn{2}{|c|}{$\begin{array}{l}\text { Levene's Test for Equality of } \\
\text { Variances }\end{array}$} & \multirow{2}{*}{\begin{tabular}{|c} 
t-test for Equality \\
of Means \\
$\mathrm{t}$ \\
\end{tabular}} \\
\hline & & $\mathrm{F}$ & Sig. & \\
\hline Capacidad de abstracción & $\begin{array}{l}\text { Equal variances assumed } \\
\text { Equal variances not } \\
\text { assumed }\end{array}$ & 11,775 &, 001 & $\begin{array}{l}1,702 \\
1,595\end{array}$ \\
\hline Razonamiento crítico & $\begin{array}{l}\text { Equal variances assumed } \\
\text { Equal variances not } \\
\text { assumed }\end{array}$ &, 902 & ,346 & ,484 \\
\hline Organización y planificación & $\begin{array}{l}\text { Equal variances assumed } \\
\text { Equal variances not } \\
\text { assumed }\end{array}$ &, 119 &, 731 & $\begin{array}{l}, 467 \\
, 478\end{array}$ \\
\hline $\begin{array}{l}\text { Resolución de problemas y } \\
\text { toma de decisiones }\end{array}$ & $\begin{array}{l}\text { Equal variances assumed } \\
\text { Equal variances not } \\
\text { assumed }\end{array}$ & 4,102 &, 047 & $\begin{array}{r}-, 970 \\
-1,010\end{array}$ \\
\hline $\begin{array}{l}\text { Capacidad de aprender y } \\
\text { actualizarse }\end{array}$ & $\begin{array}{l}\text { Equal variances assumed } \\
\text { Equal variances not } \\
\text { assumed }\end{array}$ & 4,296 &, 042 & $\begin{array}{r}2,542^{\star} \\
2,494\end{array}$ \\
\hline $\begin{array}{l}\text { Adaptarse a nuevas } \\
\text { situaciones }\end{array}$ & $\begin{array}{l}\text { Equal variances assumed } \\
\text { Equal variances not } \\
\text { assumed }\end{array}$ & 5,836 & ,018 & $\begin{array}{l}-1,204 \\
-1,253\end{array}$ \\
\hline $\begin{array}{l}\text { Aplicar conocimientos a la } \\
\text { práctica }\end{array}$ & $\begin{array}{l}\text { Equal variances assumed } \\
\text { Equal variances not } \\
\text { assumed }\end{array}$ &, 130 &, 719 & $\begin{array}{l}, 199 \\
, 198\end{array}$ \\
\hline Capacidad de investigación & $\begin{array}{l}\text { Equal variances assumed } \\
\text { Equal variances not } \\
\text { assumed }\end{array}$ & 1,069 & ,305 & ,205 \\
\hline Compromiso a la calidad & $\begin{array}{l}\text { Equal variances assumed } \\
\text { Equal variances not } \\
\text { assumed }\end{array}$ & 1,941 &, 168 & $\begin{array}{l}-, 765 \\
-, 782\end{array}$ \\
\hline
\end{tabular}




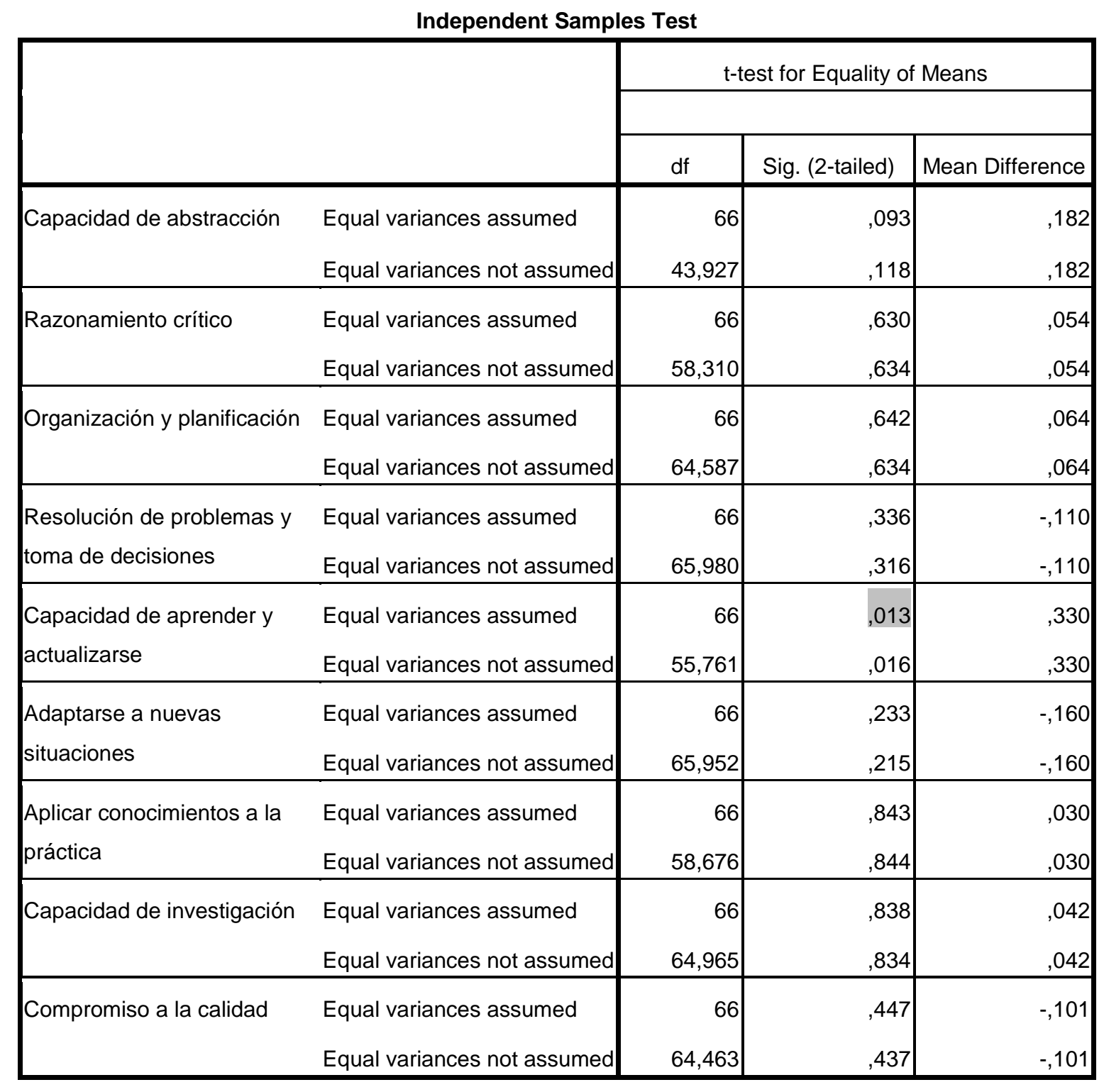

\begin{tabular}{|l|l|r|}
\hline \multicolumn{1}{|l|}{ Independent Samples Test } & \multicolumn{1}{c|}{$\begin{array}{c}\text { t-test for Equality } \\
\text { of Means }\end{array}$} \\
\cline { 3 - 3 } & & Std. Error \\
& & Difference \\
\hline Capacidad de abstracción & Equal variances assumed &, 107 \\
& Equal variances not assumed &, 114 \\
\hline Razonamiento crítico & Equal variances assumed &, 111 \\
& Equal variances not assumed &, 113 \\
\hline
\end{tabular}




\begin{tabular}{|ll|r|}
\hline Organización y planificación & Equal variances assumed &, 136 \\
& Equal variances not assumed &, 133 \\
\hline $\begin{array}{l}\text { Resolución de problemas y } \\
\text { toma de decisiones }\end{array}$ & Equal variances assumed &, 113 \\
\hline Capacidad de aprender y & Equal variances not assumed &, 109 \\
actualizarse & Equal variances not assumed &, 130 \\
\hline Adaptarse a nuevas & Equal variances assumed &, 132 \\
situaciones & Equal variances not assumed &, 133 \\
\hline Aplicar conocimientos a la & Equal variances assumed &, 128 \\
práctica & Equal variances not assumed &, 151 \\
\hline Capacidad de investigación & Equal variances assumed &, 103 \\
\hline Compromiso a la calidad & Equal variances not assumed &, 132 \\
\hline
\end{tabular}

Independent Samples Test

\begin{tabular}{|c|c|c|c|}
\hline & \multicolumn{2}{|c|}{ t-test for Equality of Means } \\
\hline & & \multicolumn{2}{|c|}{$\begin{array}{c}\text { 95\% Confidence Interval of the } \\
\text { Difference }\end{array}$} \\
\hline & & Lower & Upper \\
\hline \multirow[t]{2}{*}{ Capacidad de abstracción } & Equal variances assumed &,- 031 & ,396 \\
\hline & Equal variances not assumed &,- 048 & ,412 \\
\hline \multirow[t]{2}{*}{ Razonamiento crítico } & Equal variances assumed &,- 169 & ,277 \\
\hline & Equal variances not assumed &,- 171 & ,279 \\
\hline \multirow[t]{2}{*}{ Organización y planificación } & Equal variances assumed &,- 209 & ,336 \\
\hline & Equal variances not assumed &,- 203 & ,330 \\
\hline \multirow{2}{*}{$\begin{array}{l}\text { Resolución de problemas y } \\
\text { toma de decisiones }\end{array}$} & Equal variances assumed &,- 335 & ,116 \\
\hline & Equal variances not assumed &,- 326 &, 107 \\
\hline \multirow{2}{*}{$\begin{array}{l}\text { Capacidad de aprender y } \\
\text { actualizarse }\end{array}$} & Equal variances assumed &, 071 &, 589 \\
\hline & Equal variances not assumed &, 065 &, 595 \\
\hline \multirow{2}{*}{$\begin{array}{l}\text { Adaptarse a nuevas } \\
\text { situaciones }\end{array}$} & Equal variances assumed &,- 425 & ,105 \\
\hline & Equal variances not assumed &,- 415 & ,095 \\
\hline \multirow{2}{*}{$\begin{array}{l}\text { Aplicar conocimientos a la } \\
\text { práctica }\end{array}$} & Equal variances assumed &,- 271 & ,331 \\
\hline & Equal variances not assumed &,- 274 & ,334 \\
\hline
\end{tabular}




\begin{tabular}{|ll|r|r|}
\hline Capacidad de investigación & Equal variances assumed &,- 364 &, 447 \\
& Equal variances not assumed &,- 353 &, 436 \\
\hline Compromiso a la calidad & Equal variances assumed &,- 364 &, 162 \\
& Equal variances not assumed &,- 358 &, 157 \\
\hline
\end{tabular}


Anexo 5: Análisis de homogeneidad de varianzas y significancia de medias para la dimensión de relación interpersonal y social

Group Statistics

\begin{tabular}{|ll|r|r|r|r|}
\hline & Cargo & $\mathrm{N}$ & Mean & Std. Deviation & Std. Error Mean \\
\hline Trabajo en equipos de & Docente & 39 & 3,67 &, 530 &, 085 \\
informática & Gerente & 29 & 3,59 &, 568 &, 105 \\
\hline Trabajo en equipos & Docente & 39 & 3,46 &, 555 &, 089 \\
interdisciplinarios & Gerente & 29 & 3,52 &, 509 &, 094 \\
\hline Compromiso ético & Docente & 39 & 3,64 &, 584 &, 094 \\
& Gerente & 29 & 3,93 &, 258 &, 048 \\
\hline
\end{tabular}

Independent Samples Test

\begin{tabular}{|c|c|c|c|c|}
\hline & & \multicolumn{2}{|c|}{$\begin{array}{c}\text { Levene's Test for Equality of } \\
\text { Variances }\end{array}$} & \multirow{2}{*}{\begin{tabular}{|c} 
t-test for Equality \\
of Means \\
$\mathrm{t}$ \\
\end{tabular}} \\
\hline & & $\mathrm{F}$ & Sig. & \\
\hline $\begin{array}{l}\text { Trabajo en equipos de } \\
\text { informática }\end{array}$ & $\begin{array}{l}\text { Equal variances assumed } \\
\text { Equal variances not } \\
\text { assumed }\end{array}$ &, 797 & ,375 &, 601 \\
\hline $\begin{array}{l}\text { Trabajo en equipos } \\
\text { interdisciplinarios }\end{array}$ & $\begin{array}{l}\text { Equal variances assumed } \\
\text { Equal variances not } \\
\text { assumed }\end{array}$ &, 725 & ,398 & $\begin{array}{l}-, 424 \\
-, 430\end{array}$ \\
\hline Compromiso ético & $\begin{array}{l}\text { Equal variances assumed } \\
\text { Equal variances not } \\
\text { assumed }\end{array}$ & 31,581 &, 000 & $\begin{array}{l}-2,495 * \\
-2,759\end{array}$ \\
\hline
\end{tabular}

Independent Samples Test

\begin{tabular}{|c|c|c|c|c|}
\hline & & \multicolumn{3}{|c|}{ t-test for Equality of Means } \\
\hline & & df & Sig. (2-tailed) & Mean Difference \\
\hline $\begin{array}{l}\text { Trabajo en equipos de } \\
\text { informática }\end{array}$ & $\begin{array}{l}\text { Equal variances assumed } \\
\text { Equal variances not assumed }\end{array}$ & $\begin{array}{r}66 \\
58,045 \\
\end{array}$ & $\begin{array}{r}, 550 \\
, 555 \\
\end{array}$ & $\begin{array}{l}, 080 \\
, 080 \\
\end{array}$ \\
\hline $\begin{array}{l}\text { Trabajo en equipos } \\
\text { interdisciplinarios }\end{array}$ & $\begin{array}{l}\text { Equal variances assumed } \\
\text { Equal variances not assumed }\end{array}$ & $\begin{array}{r}66 \\
63,079\end{array}$ & $\begin{array}{l}, 673 \\
, 669\end{array}$ & $\begin{array}{l}-, 056 \\
-, 056\end{array}$ \\
\hline Compromiso ético & Equal variances assumed & 66 & ,015 &,- 290 \\
\hline
\end{tabular}


Independent Samples Test

\begin{tabular}{|c|c|c|c|c|}
\hline & & \multicolumn{3}{|c|}{ t-test for Equality of Means } \\
\hline & & df & Sig. (2-tailed) & Mean Difference \\
\hline $\begin{array}{l}\text { Trabajo en equipos de } \\
\text { informática }\end{array}$ & $\begin{array}{l}\text { Equal variances assumed } \\
\text { Equal variances not assumed }\end{array}$ & $\begin{array}{r}66 \\
58,045 \\
\end{array}$ & $\begin{array}{r}, 550 \\
, 555 \\
\end{array}$ & $\begin{array}{l}, 080 \\
, 080\end{array}$ \\
\hline $\begin{array}{l}\text { Trabajo en equipos } \\
\text { interdisciplinarios }\end{array}$ & $\begin{array}{l}\text { Equal variances assumed } \\
\text { Equal variances not assumed }\end{array}$ & $\begin{array}{r}66 \\
63,079 \\
\end{array}$ & $\begin{array}{r}, 673 \\
, 669 \\
\end{array}$ & $\begin{array}{l}-, 056 \\
-, 056 \\
\end{array}$ \\
\hline Compromiso ético & $\begin{array}{l}\text { Equal variances assumed } \\
\text { Equal variances not assumed }\end{array}$ & $\begin{array}{r}66 \\
55,360\end{array}$ & $\begin{array}{r}, 015 \\
, 008\end{array}$ & $\begin{array}{l}-, 290 \\
-, 290\end{array}$ \\
\hline
\end{tabular}

Independent Samples Test

\begin{tabular}{|c|c|c|}
\hline & $\begin{array}{c}\text { t-test for Equality } \\
\text { of Means } \\
\end{array}$ \\
\hline & & $\begin{array}{l}\text { Std. Error } \\
\text { Difference }\end{array}$ \\
\hline $\begin{array}{l}\text { Trabajo en equipos de } \\
\text { informática }\end{array}$ & $\begin{array}{l}\text { Equal variances assumed } \\
\text { Equal variances not assumed }\end{array}$ & $\begin{array}{l}, 134 \\
, 135 \\
\end{array}$ \\
\hline $\begin{array}{l}\text { Trabajo en equipos } \\
\text { interdisciplinarios }\end{array}$ & $\begin{array}{l}\text { Equal variances assumed } \\
\text { Equal variances not assumed }\end{array}$ & $\begin{array}{l}, 131 \\
, 130\end{array}$ \\
\hline Compromiso ético & $\begin{array}{l}\text { Equal variances assumed } \\
\text { Equal variances not assumed }\end{array}$ & $\begin{array}{l}, 116 \\
, 105\end{array}$ \\
\hline
\end{tabular}

Independent Samples Test

\begin{tabular}{|c|c|c|c|}
\hline & & \multicolumn{2}{|c|}{ t-test for Equality of Means } \\
\hline & & \multicolumn{2}{|c|}{$\begin{array}{l}\text { 95\% Confidence Interval of the } \\
\text { Difference }\end{array}$} \\
\hline & & Lower & Upper \\
\hline $\begin{array}{l}\text { Trabajo en equipos de } \\
\text { informática }\end{array}$ & $\begin{array}{l}\text { Equal variances assumed } \\
\text { Equal variances not assumed }\end{array}$ & $\begin{array}{l}-, 187 \\
-, 190 \\
\end{array}$ & $\begin{array}{r}, 348 \\
, 351 \\
\end{array}$ \\
\hline $\begin{array}{l}\text { Trabajo en equipos } \\
\text { interdisciplinarios }\end{array}$ & $\begin{array}{l}\text { Equal variances assumed } \\
\text { Equal variances not assumed }\end{array}$ & $\begin{array}{l}-, 318 \\
-, 315 \\
\end{array}$ & $\begin{array}{r}, 207 \\
, 203 \\
\end{array}$ \\
\hline Compromiso ético & Equal variances assumed &,- 522 &,- 058 \\
\hline
\end{tabular}


Independent Samples Test

\begin{tabular}{|c|c|c|c|}
\hline & & \multicolumn{2}{|c|}{ t-test for Equality of Means } \\
\hline & & \multicolumn{2}{|c|}{$\begin{array}{c}\text { 95\% Confidence Interval of the } \\
\text { Difference }\end{array}$} \\
\hline & & Lower & Upper \\
\hline $\begin{array}{l}\text { Trabajo en equipos de } \\
\text { informática }\end{array}$ & $\begin{array}{l}\text { Equal variances assumed } \\
\text { Equal variances not assumed }\end{array}$ & $\begin{array}{l}-, 187 \\
-, 190\end{array}$ & $\begin{array}{l}, 348 \\
, 351\end{array}$ \\
\hline $\begin{array}{l}\text { Trabajo en equipos } \\
\text { interdisciplinarios }\end{array}$ & $\begin{array}{l}\text { Equal variances assumed } \\
\text { Equal variances not assumed }\end{array}$ & $\begin{array}{r}-, 318 \\
-, 315 \\
\end{array}$ & $\begin{array}{r}, 207 \\
, 203 \\
\end{array}$ \\
\hline Compromiso ético & $\begin{array}{l}\text { Equal variances assumed } \\
\text { Equal variances not assumed }\end{array}$ & $\begin{array}{l}-, 522 \\
-, 501\end{array}$ & $\begin{array}{l}-, 058 \\
-, 079\end{array}$ \\
\hline
\end{tabular}


Anexo 6: Análisis de homogeneidad de varianzas y significancia de medias para la dimensión de emprendimiento

\begin{tabular}{|ll|r|r|r|r|}
\hline & Cargo & $\mathrm{N}$ & \multicolumn{1}{c|}{ Mean } & Std. Deviation & Std. Error Mean \\
\hline Liderazgo & Docente & 39 & 3,26 &, 818 &, 131 \\
& Gerente & 29 & 3,52 &, 574 &, 107 \\
\hline Espíritu emprendedor & Docente & 39 & 3,44 &, 718 &, 115 \\
& Gerente & 29 & 3,41 &, 628 &, 117 \\
\hline
\end{tabular}

\begin{tabular}{|c|c|c|c|c|}
\hline & & \multicolumn{2}{|c|}{$\begin{array}{c}\text { Levene's Test for Equality of } \\
\text { Variances }\end{array}$} & \multirow{2}{*}{\begin{tabular}{|c} 
t-test for Equality \\
of Means \\
$\mathrm{t}$ \\
\end{tabular}} \\
\hline & & $\mathrm{F}$ & Sig. & \\
\hline Liderazgo & $\begin{array}{l}\text { Equal variances assumed } \\
\text { Equal variances not assumed }\end{array}$ & 3,212 & ,078 & $\begin{array}{r}-1,468 \\
-1,544\end{array}$ \\
\hline Espíritu emprendedor & $\begin{array}{l}\text { Equal variances assumed } \\
\text { Equal variances not assumed }\end{array}$ & 272 & ,603 & $\begin{array}{r}, 132 \\
, 135\end{array}$ \\
\hline
\end{tabular}

Independent Samples Test

\begin{tabular}{|c|c|c|c|c|}
\hline & & \multicolumn{3}{|c|}{ t-test for Equality of Means } \\
\hline & & df & Sig. (2-tailed) & Mean Difference \\
\hline Liderazgo & $\begin{array}{l}\text { Equal variances assumed } \\
\text { Equal variances not assumed }\end{array}$ & $\begin{array}{r}66 \\
65,824 \\
\end{array}$ & $\begin{array}{l}, 147 \\
, 127 \\
\end{array}$ & $\begin{array}{l}-, 261 \\
-, 261 \\
\end{array}$ \\
\hline Espíritu emprendedor & $\begin{array}{l}\text { Equal variances assumed } \\
\text { Equal variances not assumed }\end{array}$ & $\begin{array}{r}66 \\
64,203\end{array}$ & $\begin{array}{l}, 895 \\
, 893\end{array}$ & $\begin{array}{l}, 022 \\
, 022\end{array}$ \\
\hline
\end{tabular}

Independent Samples Test

\begin{tabular}{|c|c|c|c|c|}
\hline & & \multicolumn{3}{|c|}{ t-test for Equality of Means } \\
\hline & & & \multicolumn{2}{|c|}{$\begin{array}{c}\text { 95\% Confidence Interval of the } \\
\text { Difference }\end{array}$} \\
\hline & & $\begin{array}{l}\text { Std. Error } \\
\text { Difference }\end{array}$ & Lower & Upper \\
\hline Liderazgo & $\begin{array}{l}\text { Equal variances assumed } \\
\text { Equal variances not assumed }\end{array}$ & $\begin{array}{l}, 178 \\
, 169\end{array}$ & $\begin{array}{l}-, 616 \\
-, 598\end{array}$ & $\begin{array}{l}, 094 \\
, 077\end{array}$ \\
\hline
\end{tabular}




\begin{tabular}{|ll|r|r|r|}
\hline Espíritu emprendedor & Equal variances assumed &, 167 &,- 311 &, 356 \\
& Equal variances not assumed &, 164 &,- 305 &, 349 \\
\hline
\end{tabular}


Anexo 7: Análisis de homogeneidad de varianzas y significancia de medias para la dimensión específica de informática

Group Statistics

\begin{tabular}{|c|c|c|c|c|c|}
\hline & Cargo & $\mathrm{N}$ & Mean & Std. Deviation & Std. Error Mean \\
\hline $\begin{array}{l}\text { Entender Especificaciones } \\
\text { técnicas y funcionales }\end{array}$ & $\begin{array}{l}\text { Docente } \\
\text { Gerente }\end{array}$ & $\begin{array}{l}39 \\
29\end{array}$ & $\begin{array}{l}3,26 \\
3,34\end{array}$ & $\begin{array}{l}, 715 \\
, 614 \\
\end{array}$ & ,115 \\
\hline $\begin{array}{l}\text { Aplicar tendencias } \\
\text { tecnológicas a empresa }\end{array}$ & $\begin{array}{l}\text { Docente } \\
\text { Gerente }\end{array}$ & $\begin{array}{l}39 \\
29 \\
\end{array}$ & $\begin{array}{l}3,23 \\
3,41 \\
\end{array}$ & $\begin{array}{r}, 706 \\
, 568 \\
\end{array}$ & $\begin{array}{l}, 113 \\
, 105 \\
\end{array}$ \\
\hline Dirigir proyectos & $\begin{array}{l}\text { Docente } \\
\text { Gerente }\end{array}$ & $\begin{array}{l}39 \\
29 \\
\end{array}$ & $\begin{array}{l}3,69 \\
3,48 \\
\end{array}$ & $\begin{array}{l}, 569 \\
, 634 \\
\end{array}$ & $\begin{array}{l}, 091 \\
, 118 \\
\end{array}$ \\
\hline $\begin{array}{l}\text { Evaluar requisitos hardware } \\
\text { y software }\end{array}$ & $\begin{array}{l}\text { Docente } \\
\text { Gerente }\end{array}$ & $\begin{array}{l}39 \\
29 \\
\end{array}$ & $\begin{array}{l}3,26 \\
3,07 \\
\end{array}$ & $\begin{array}{l}, 637 \\
, 704 \\
\end{array}$ & $\begin{array}{l}, 102 \\
, 131 \\
\end{array}$ \\
\hline Programación & $\begin{array}{l}\text { Docente } \\
\text { Gerente }\end{array}$ & $\begin{array}{l}39 \\
29 \\
\end{array}$ & $\begin{array}{l}2,69 \\
2,45 \\
\end{array}$ & $\begin{array}{r}, 731 \\
1,242 \\
\end{array}$ & $\begin{array}{l}, 117 \\
, 231 \\
\end{array}$ \\
\hline Administrar base de datos & $\begin{array}{l}\text { Docente } \\
\text { Gerente }\end{array}$ & $\begin{array}{l}39 \\
29\end{array}$ & $\begin{array}{l}2,97 \\
2,41\end{array}$ & $\begin{array}{l}, 778 \\
, 907\end{array}$ & $\begin{array}{l}, 125 \\
, 168\end{array}$ \\
\hline $\begin{array}{l}\text { Diseñar sistemas de } \\
\text { información }\end{array}$ & $\begin{array}{l}\text { Docente } \\
\text { Gerente }\end{array}$ & $\begin{array}{l}39 \\
29 \\
\end{array}$ & $\begin{array}{l}3,10 \\
2,90 \\
\end{array}$ & $\begin{array}{l}, 552 \\
, 900 \\
\end{array}$ & $\begin{array}{l}, 088 \\
, 167\end{array}$ \\
\hline Ensamblar computadoras & $\begin{array}{l}\text { Docente } \\
\text { Gerente }\end{array}$ & $\begin{array}{l}39 \\
29\end{array}$ & $\begin{array}{l}2,10 \\
1,59 \\
\end{array}$ & $\begin{array}{l}, 641 \\
, 682 \\
\end{array}$ & $\begin{array}{l}, 103 \\
, 127\end{array}$ \\
\hline $\begin{array}{l}\text { Administrar redes de } \\
\text { computadoras }\end{array}$ & $\begin{array}{l}\text { Docente } \\
\text { Gerente }\end{array}$ & $\begin{array}{l}39 \\
29\end{array}$ & $\begin{array}{l}2,62 \\
1,97 \\
\end{array}$ & $\begin{array}{l}, 711 \\
, 944\end{array}$ & $\begin{array}{l}, 114 \\
, 175\end{array}$ \\
\hline $\begin{array}{l}\text { Administrar equipos de } \\
\text { comunicación }\end{array}$ & $\begin{array}{l}\text { Docente } \\
\text { Gerente }\end{array}$ & $\begin{array}{l}39 \\
29\end{array}$ & $\begin{array}{l}2,38 \\
1,76\end{array}$ & $\begin{array}{l}, 747 \\
, 872\end{array}$ & $\begin{array}{l}\text {,120 } \\
\text {,162 }\end{array}$ \\
\hline
\end{tabular}


Independent Samples Test

\begin{tabular}{|c|c|c|c|c|}
\hline & & \multicolumn{2}{|c|}{$\begin{array}{l}\text { Levene's Test for Equality of } \\
\text { Variances }\end{array}$} & \multirow{2}{*}{\begin{tabular}{|c} 
t-test for Equality \\
of Means \\
$\mathrm{t}$ \\
\end{tabular}} \\
\hline & & $\mathrm{F}$ & Sig. & \\
\hline $\begin{array}{l}\text { Entender Especificaciones } \\
\text { técnicas y funcionales }\end{array}$ & $\begin{array}{l}\text { Equal variances assumed } \\
\text { Equal variances not } \\
\text { assumed }\end{array}$ & ,729 & ,396 & $\begin{array}{l}-, 535 \\
-, 547\end{array}$ \\
\hline $\begin{array}{l}\text { Aplicar tendencias } \\
\text { tecnológicas a empresa }\end{array}$ & $\begin{array}{l}\text { Equal variances assumed } \\
\text { Equal variances not } \\
\text { assumed }\end{array}$ &, 763 & ,385 & $\begin{array}{l}-1,147 \\
-1,184\end{array}$ \\
\hline Dirigir proyectos & $\begin{array}{l}\text { Equal variances assumed } \\
\text { Equal variances not } \\
\text { assumed }\end{array}$ & 2,368 & ,129 & $\begin{array}{l}1,431 \\
1,408\end{array}$ \\
\hline $\begin{array}{l}\text { Evaluar requisitos hardware } \\
\text { y software }\end{array}$ & $\begin{array}{l}\text { Equal variances assumed } \\
\text { Equal variances not } \\
\text { assumed }\end{array}$ &, 042 & ,837 & $\begin{array}{l}1,147 \\
1,131\end{array}$ \\
\hline Programación & $\begin{array}{l}\text { Equal variances assumed } \\
\text { Equal variances not } \\
\text { assumed }\end{array}$ & 22,024 &, 000 & $\begin{array}{r}1,015 \\
, 944\end{array}$ \\
\hline Administrar base de datos & $\begin{array}{l}\text { Equal variances assumed } \\
\text { Equal variances not } \\
\text { assumed }\end{array}$ & 4,265 & ,043 & $\begin{array}{r}2,738 * * \\
2,676\end{array}$ \\
\hline $\begin{array}{l}\text { Diseñar sistemas de } \\
\text { información }\end{array}$ & $\begin{array}{l}\text { Equal variances assumed } \\
\text { Equal variances not } \\
\text { assumed }\end{array}$ & 12,524 & ,001 & $\begin{array}{l}1,166 \\
1,089\end{array}$ \\
\hline Ensamblar computadoras & $\begin{array}{l}\text { Equal variances assumed } \\
\text { Equal variances not } \\
\text { assumed }\end{array}$ & 2,419 & ,125 & $\begin{array}{r}3,198 * \star \\
3,168\end{array}$ \\
\hline $\begin{array}{l}\text { Administrar redes de } \\
\text { computadoras }\end{array}$ & $\begin{array}{l}\text { Equal variances assumed } \\
\text { Equal variances not } \\
\text { assumed }\end{array}$ & 1,203 & ,277 & $\begin{array}{r}3,239 * * \\
3,108\end{array}$ \\
\hline $\begin{array}{l}\text { Administrar equipos de } \\
\text { comunicación }\end{array}$ & $\begin{array}{l}\text { Equal variances assumed } \\
\text { Equal variances not } \\
\text { assumed }\end{array}$ & 1,045 & ,310 & $\begin{array}{r}3,180 * \star \\
3,108\end{array}$ \\
\hline
\end{tabular}


Independent Samples Test

\begin{tabular}{|c|c|c|c|c|}
\hline & & \multicolumn{3}{|c|}{ t-test for Equality of Means } \\
\hline & & df & Sig. (2-tailed) & Mean Difference \\
\hline $\begin{array}{l}\text { Entender Especificaciones } \\
\text { técnicas y funcionales }\end{array}$ & $\begin{array}{l}\text { Equal variances assumed } \\
\text { Equal variances not assumed }\end{array}$ & $\begin{array}{r}66 \\
64,573 \\
\end{array}$ & $\begin{array}{l}, 594 \\
, 586 \\
\end{array}$ & $\begin{array}{l}-, 088 \\
-, 088 \\
\end{array}$ \\
\hline $\begin{array}{l}\text { Aplicar tendencias } \\
\text { tecnológicas a empresa }\end{array}$ & $\begin{array}{l}\text { Equal variances assumed } \\
\text { Equal variances not assumed }\end{array}$ & $\begin{array}{r}66 \\
65,540 \\
\end{array}$ & $\begin{array}{l}, 256 \\
, 241 \\
\end{array}$ & $\begin{array}{l}-, 183 \\
-, 183 \\
\end{array}$ \\
\hline Dirigir proyectos & $\begin{array}{l}\text { Equal variances assumed } \\
\text { Equal variances not assumed }\end{array}$ & $\begin{array}{r}66 \\
56,649\end{array}$ & $\begin{array}{l}, 157 \\
, 165\end{array}$ & $\begin{array}{l}, 210 \\
, 210\end{array}$ \\
\hline $\begin{array}{l}\text { Evaluar requisitos hardware } \\
\text { y software }\end{array}$ & $\begin{array}{l}\text { Equal variances assumed } \\
\text { Equal variances not assumed }\end{array}$ & $\begin{array}{r}66 \\
56,965\end{array}$ & $\begin{array}{l}, 255 \\
, 263 \\
\end{array}$ & $\begin{array}{l}, 187 \\
, 187 \\
\end{array}$ \\
\hline Programación & $\begin{array}{l}\text { Equal variances assumed } \\
\text { Equal variances not assumed }\end{array}$ & $\begin{array}{r}66 \\
42,226\end{array}$ & $\begin{array}{l}, 314 \\
, 351 \\
\end{array}$ & $\begin{array}{l}, 244 \\
, 244\end{array}$ \\
\hline Administrar base de datos & $\begin{array}{l}\text { Equal variances assumed } \\
\text { Equal variances not assumed }\end{array}$ & $\begin{array}{r}66 \\
54,887 \\
\end{array}$ & ,008 & $\begin{array}{l}, 561 \\
, 561\end{array}$ \\
\hline $\begin{array}{l}\text { Diseñar sistemas de } \\
\text { información }\end{array}$ & $\begin{array}{l}\text { Equal variances assumed } \\
\text { Equal variances not assumed }\end{array}$ & $\begin{array}{r}66 \\
43,363 \\
\end{array}$ & $\begin{array}{l}, 248 \\
, 282 \\
\end{array}$ & $\begin{array}{r}, 206 \\
, 206 \\
\end{array}$ \\
\hline Ensamblar computadoras & $\begin{array}{l}\text { Equal variances assumed } \\
\text { Equal variances not assumed }\end{array}$ & $\begin{array}{r}66 \\
58,280\end{array}$ & $\begin{array}{l}, 002 \\
, 002 \\
\end{array}$ & $\begin{array}{r}, 516 \\
, 516 \\
\end{array}$ \\
\hline $\begin{array}{l}\text { Administrar redes de } \\
\text { computadoras }\end{array}$ & $\begin{array}{l}\text { Equal variances assumed } \\
\text { Equal variances not assumed }\end{array}$ & $\begin{array}{r}66 \\
50,053\end{array}$ & $\begin{array}{l}, 002 \\
, 003 \\
\end{array}$ & $\begin{array}{l}, 650 \\
, 650\end{array}$ \\
\hline $\begin{array}{l}\text { Administrar equipos de } \\
\text { comunicación }\end{array}$ & $\begin{array}{l}\text { Equal variances assumed } \\
\text { Equal variances not assumed }\end{array}$ & $\begin{array}{r}66 \\
54,865\end{array}$ & $\begin{array}{r}, 002 \\
, 003\end{array}$ & $\begin{array}{l}, 626 \\
, 626\end{array}$ \\
\hline
\end{tabular}




\begin{tabular}{|c|c|c|}
\hline \multicolumn{3}{|c|}{ Independent Samples Test } \\
\hline & & $\begin{array}{c}\text { t-test for Equality } \\
\text { of Means }\end{array}$ \\
\hline & & $\begin{array}{l}\text { Std. Error } \\
\text { Difference }\end{array}$ \\
\hline $\begin{array}{l}\text { Entender Especificaciones } \\
\text { técnicas y funcionales }\end{array}$ & $\begin{array}{l}\text { Equal variances assumed } \\
\text { Equal variances not assumed }\end{array}$ & ,165 \\
\hline $\begin{array}{l}\text { Aplicar tendencias } \\
\text { tecnológicas a empresa }\end{array}$ & $\begin{array}{l}\text { Equal variances assumed } \\
\text { Equal variances not assumed }\end{array}$ & ,160 \\
\hline Dirigir proyectos & $\begin{array}{l}\text { Equal variances assumed } \\
\text { Equal variances not assumed }\end{array}$ & $\begin{array}{l}, 146 \\
, 149\end{array}$ \\
\hline $\begin{array}{l}\text { Evaluar requisitos hardware } \\
\text { y software }\end{array}$ & $\begin{array}{l}\text { Equal variances assumed } \\
\text { Equal variances not assumed }\end{array}$ & $\begin{array}{r}, 163 \\
, 166 \\
\end{array}$ \\
\hline Programación & $\begin{array}{l}\text { Equal variances assumed } \\
\text { Equal variances not assumed }\end{array}$ & $\begin{array}{l}, 240 \\
, 259\end{array}$ \\
\hline Administrar base de datos & $\begin{array}{l}\text { Equal variances assumed } \\
\text { Equal variances not assumed }\end{array}$ & $\begin{array}{l}, 205 \\
, 209\end{array}$ \\
\hline $\begin{array}{l}\text { Diseñar sistemas de } \\
\text { información }\end{array}$ & $\begin{array}{l}\text { Equal variances assumed } \\
\text { Equal variances not assumed }\end{array}$ & $\begin{array}{r}, 177 \\
, 189 \\
\end{array}$ \\
\hline Ensamblar computadoras & $\begin{array}{l}\text { Equal variances assumed } \\
\text { Equal variances not assumed }\end{array}$ & $\begin{array}{l}, 161 \\
, 163 \\
\end{array}$ \\
\hline $\begin{array}{l}\text { Administrar redes de } \\
\text { computadoras }\end{array}$ & $\begin{array}{l}\text { Equal variances assumed } \\
\text { Equal variances not assumed }\end{array}$ & $\begin{array}{l}, 201 \\
, 209 \\
\end{array}$ \\
\hline $\begin{array}{l}\text { Administrar equipos de } \\
\text { comunicación }\end{array}$ & $\begin{array}{l}\text { Equal variances assumed } \\
\text { Equal variances not assumed }\end{array}$ & $\begin{array}{l}\text {,197 } \\
\text { 201 }\end{array}$ \\
\hline
\end{tabular}


Independent Samples Test

\begin{tabular}{|c|c|c|c|}
\hline & \multirow{2}{*}{\multicolumn{2}{|c|}{$\begin{array}{c}\text { t-test for Equality of Means } \\
\text { 95\% Confidence Interval of the } \\
\text { Difference }\end{array}$}} \\
\hline & & & \\
\hline & & Lower & Upper \\
\hline $\begin{array}{l}\text { Entender Especificaciones } \\
\text { técnicas y funcionales }\end{array}$ & $\begin{array}{l}\text { Equal variances assumed } \\
\text { Equal variances not assumed }\end{array}$ & $\begin{array}{l}-, 418 \\
-, 411 \\
\end{array}$ & $\begin{array}{l}, 242 \\
, 234 \\
\end{array}$ \\
\hline $\begin{array}{l}\text { Aplicar tendencias } \\
\text { tecnológicas a empresa }\end{array}$ & $\begin{array}{l}\text { Equal variances assumed } \\
\text { Equal variances not assumed }\end{array}$ & $\begin{array}{l}-, 502 \\
-, 492 \\
\end{array}$ & $\begin{array}{r}, 136 \\
, 126 \\
\end{array}$ \\
\hline Dirigir proyectos & $\begin{array}{l}\text { Equal variances assumed } \\
\text { Equal variances not assumed }\end{array}$ & $\begin{array}{l}-, 083 \\
-, 089 \\
\end{array}$ & $\begin{array}{r}, 502 \\
, 508 \\
\end{array}$ \\
\hline $\begin{array}{l}\text { Evaluar requisitos hardware } \\
\text { y software }\end{array}$ & $\begin{array}{l}\text { Equal variances assumed } \\
\text { Equal variances not assumed }\end{array}$ & $\begin{array}{l}-, 139 \\
-, 145 \\
\end{array}$ & $\begin{array}{r}, 514 \\
, 519 \\
\end{array}$ \\
\hline Programación & $\begin{array}{l}\text { Equal variances assumed } \\
\text { Equal variances not assumed }\end{array}$ & $\begin{array}{l}-, 236 \\
-, 278 \\
\end{array}$ & $\begin{array}{l}, 724 \\
, 766 \\
\end{array}$ \\
\hline Administrar base de datos & $\begin{array}{l}\text { Equal variances assumed } \\
\text { Equal variances not assumed }\end{array}$ &, 152 & $\begin{array}{r}, 969 \\
, 980 \\
\end{array}$ \\
\hline $\begin{array}{l}\text { Diseñar sistemas de } \\
\text { información }\end{array}$ & $\begin{array}{l}\text { Equal variances assumed } \\
\text { Equal variances not assumed }\end{array}$ & $\begin{array}{l}-, 147 \\
-, 175 \\
\end{array}$ & $\begin{array}{r}, 559 \\
, 587 \\
\end{array}$ \\
\hline Ensamblar computadoras & $\begin{array}{l}\text { Equal variances assumed } \\
\text { Equal variances not assumed }\end{array}$ &, 194 & $\begin{array}{r}, 839 \\
, 843 \\
\end{array}$ \\
\hline $\begin{array}{l}\text { Administrar redes de } \\
\text { computadoras }\end{array}$ & $\begin{array}{l}\text { Equal variances assumed } \\
\text { Equal variances not assumed }\end{array}$ & $\begin{array}{l}, 249 \\
, 230 \\
\end{array}$ & $\begin{array}{l}1,050 \\
1,070 \\
\end{array}$ \\
\hline $\begin{array}{l}\text { Administrar equipos de } \\
\text { comunicación }\end{array}$ & $\begin{array}{l}\text { Equal variances assumed } \\
\text { Equal variances not assumed }\end{array}$ & $\begin{array}{l}, 233 \\
, 222 \\
\end{array}$ & $\begin{array}{l}1,019 \\
1,030\end{array}$ \\
\hline
\end{tabular}


Anexo 8: Análisis de homogeneidad de varianzas y significancia de medias para la dimensión específica de gestión empresarial

\begin{tabular}{|ll|r|r|r|r|}
\hline \multicolumn{1}{|c|}{ Group Statistics } \\
\hline Cargo & $\mathrm{N}$ & \multicolumn{1}{c|}{ Mean } & Std. Deviation & Std. Error Mean \\
\hline Comprensión de las ciencias & Docente & 39 & 3,31 &, 521 &, 083 \\
de gestión & Gerente & 29 & 3,21 &, 620 &, 115 \\
\hline Visón del negocio & Docente & 39 & 3,67 &, 577 &, 092 \\
& Gerente & 29 & 3,66 &, 553 &, 103 \\
\hline
\end{tabular}

Independent Samples Test

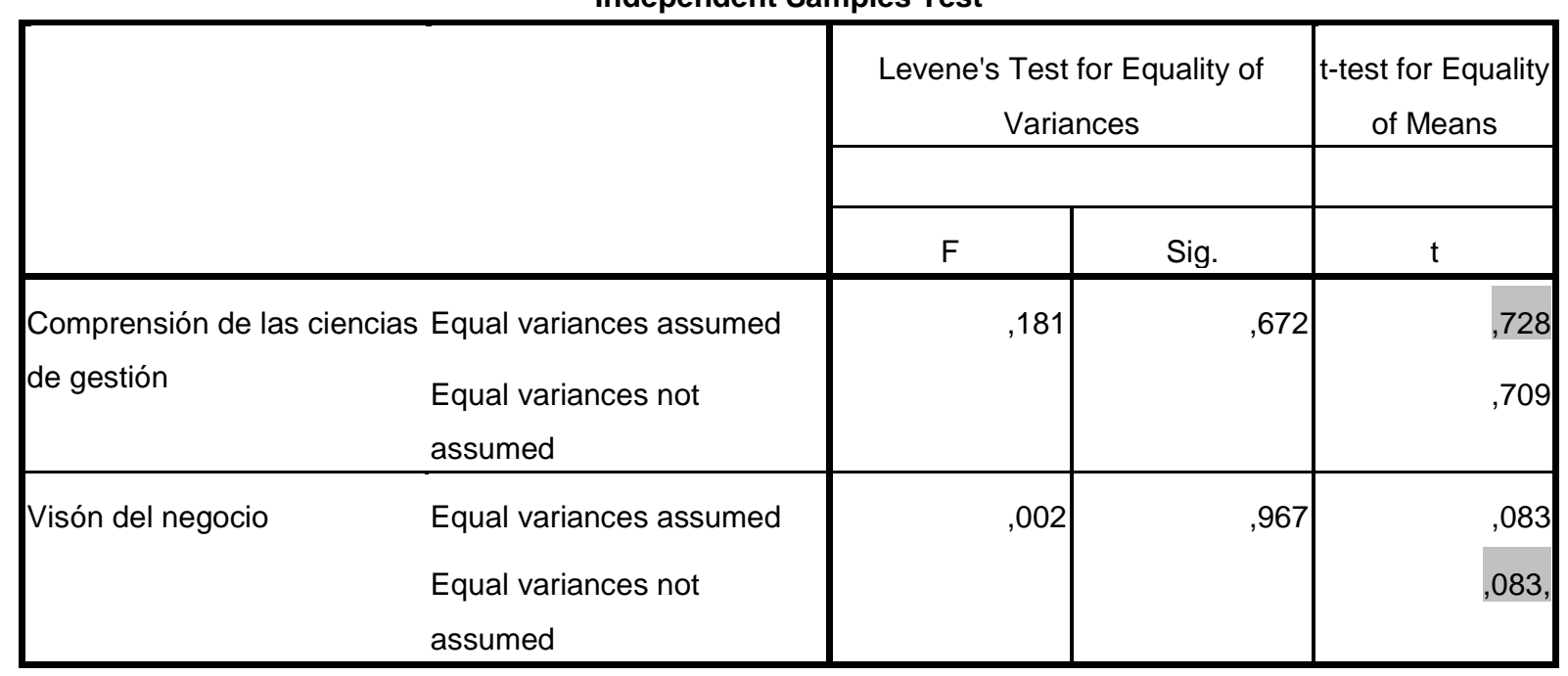

Independent Samples Test

\begin{tabular}{|c|c|c|c|c|}
\hline & & \multicolumn{3}{|c|}{ t-test for Equality of Means } \\
\hline & & df & Sig. (2-tailed) & Mean Difference \\
\hline $\begin{array}{c}\text { Comprensión de las ciencias } \\
\text { de gestión }\end{array}$ & $\begin{array}{l}\text { Equal variances assumed } \\
\text { Equal variances not assumed }\end{array}$ & $\begin{array}{l}66 \\
54,123\end{array}$ & $\begin{array}{r}, 469 \\
, 481 \\
\end{array}$ & ,101 \\
\hline Visón del negocio & $\begin{array}{l}\text { Equal variances assumed } \\
\text { Equal variances not assumed }\end{array}$ & $\begin{array}{r}66 \\
61,865\end{array}$ & $\begin{array}{l}, 934 \\
, 934\end{array}$ & $\begin{array}{l}, 011 \\
, 011\end{array}$ \\
\hline
\end{tabular}




\begin{tabular}{|c|c|c|}
\hline \multicolumn{3}{|c|}{ Independent Samples Test } \\
\hline & & $\begin{array}{c}\text { t-test for Equality } \\
\text { of Means }\end{array}$ \\
\hline & & $\begin{array}{l}\text { Std. Error } \\
\text { Difference }\end{array}$ \\
\hline $\begin{array}{l}\text { Comprensión de las ciencias } \\
\text { de gestión }\end{array}$ & $\begin{array}{l}\text { Equal variances assumed } \\
\text { Equal variances not assumed }\end{array}$ & $\begin{array}{l}, 139 \\
, 142 \\
\end{array}$ \\
\hline Visón del negocio & $\begin{array}{l}\text { Equal variances assumed } \\
\text { Equal variances not assumed }\end{array}$ & $\begin{array}{l}, 139 \\
, 138\end{array}$ \\
\hline
\end{tabular}

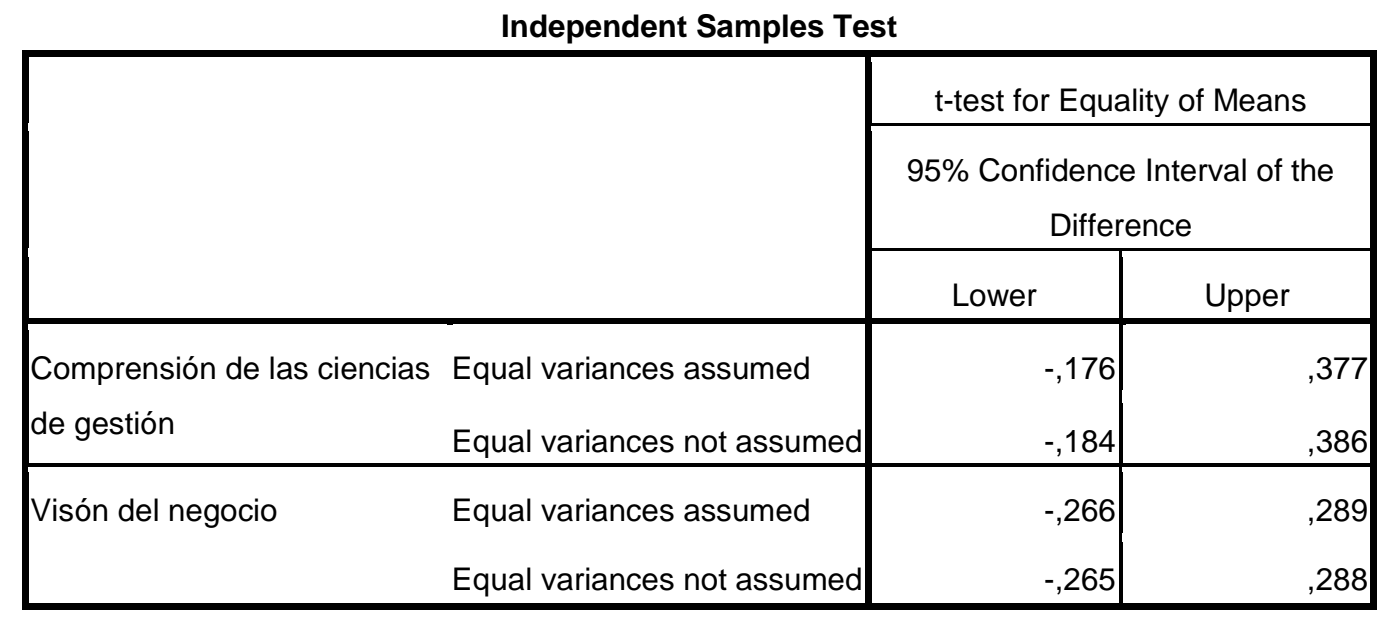


Anexo 9: Análisis de homogeneidad de varianzas y significancia de medias para la dimensión de conocimientos declarativos.

Group Statistics

\begin{tabular}{|ll|r|r|r|r|}
\hline & Cargo & $\mathrm{N}$ & \multicolumn{1}{|c|}{ Mean } & Std. Deviation & Std. Error Mean \\
\hline Conocimientos generales de & Docente & 39 & 3,31 &, 694 &, 111 \\
Informática & Gerente & 29 & 3,24 &, 830 &, 154 \\
\hline Conocimientos generales de & Docente & 39 & 3,15 &, 670 &, 107 \\
Gestion & Gerente & 29 & 3,41 &, 628 &, 117 \\
\hline Habilidades adquiridas en la & Docente & 39 & 2,59 &, 637 &, 102 \\
universidad & Gerente & 29 & 2,83 &, 602 &, 112 \\
\hline Habilidades adquiridas & Docente & 39 & 3,18 &, 683 &, 109 \\
práctica pre profesional & Gerente & 29 & 2,79 &, 902 &, 167 \\
\hline Habilidades adquiridas & Docente & 39 & 3,33 &, 701 &, 112 \\
cursos certificación & Gerente & 29 & 3,07 &, 799 &, 148 \\
\hline
\end{tabular}

Independent Samples Test

\begin{tabular}{|c|c|c|c|c|}
\hline & & \multicolumn{2}{|c|}{$\begin{array}{c}\text { Levene's Test for Equality of } \\
\text { Variances }\end{array}$} & \multirow{2}{*}{\begin{tabular}{|c|}
$\begin{array}{c}\text { t-test for Equality } \\
\text { of Means }\end{array}$ \\
$\mathrm{t}$ \\
\end{tabular}} \\
\hline & & $F$ & Sig. & \\
\hline $\begin{array}{l}\text { Conocimientos generales de } \\
\text { Informática }\end{array}$ & $\begin{array}{l}\text { Equal variances assumed } \\
\text { Equal variances not } \\
\text { assumed }\end{array}$ & ,644 & ,425 & $\begin{array}{l}, 358 \\
, 349\end{array}$ \\
\hline $\begin{array}{l}\text { Conocimientos generales de } \\
\text { Gestion }\end{array}$ & $\begin{array}{l}\text { Equal variances assumed } \\
\text { Equal variances not } \\
\text { assumed }\end{array}$ & ,273 & ,603 & $\begin{array}{l}-1,624 \\
-1,640\end{array}$ \\
\hline $\begin{array}{l}\text { Habilidades adquiridas en la } \\
\text { universidad }\end{array}$ & $\begin{array}{l}\text { Equal variances assumed } \\
\text { Equal variances not } \\
\text { assumed }\end{array}$ & 1,841 & ,179 & $\begin{array}{l}-1,558 \\
-1,572\end{array}$ \\
\hline $\begin{array}{l}\text { Habilidades adquiridas } \\
\text { práctica pre profesional }\end{array}$ & $\begin{array}{l}\text { Equal variances assumed } \\
\text { Equal variances not } \\
\text { assumed }\end{array}$ & 3,139 & ,081 & $\begin{array}{r}2,012 * \\
1,932\end{array}$ \\
\hline $\begin{array}{l}\text { Habilidades adquiridas } \\
\text { cursos certificación }\end{array}$ & $\begin{array}{l}\text { Equal variances assumed } \\
\text { Equal variances not } \\
\text { assumed }\end{array}$ & ,357| & ,552 & $\begin{array}{l}1,449 \\
1,421\end{array}$ \\
\hline
\end{tabular}


Independent Samples Test

\begin{tabular}{|c|c|c|c|c|}
\hline & & \multicolumn{3}{|c|}{ t-test for Equality of Means } \\
\hline & & $d f$ & Sig. (2-tailed) & Mean Difference \\
\hline $\begin{array}{l}\text { Conocimientos generales de } \\
\text { Informática }\end{array}$ & $\begin{array}{l}\text { Equal variances assumed } \\
\text { Equal variances not assumed }\end{array}$ & $\begin{array}{r}66 \\
53,924 \\
\end{array}$ & $\begin{array}{l}, 721 \\
, 729 \\
\end{array}$ & $\begin{array}{l}, 066 \\
, 066 \\
\end{array}$ \\
\hline $\begin{array}{l}\text { Conocimientos generales de } \\
\text { Gestion }\end{array}$ & $\begin{array}{l}\text { Equal variances assumed } \\
\text { Equal variances not assumed }\end{array}$ & $\begin{array}{r}66 \\
62,503 \\
\end{array}$ & $\begin{array}{r}, 109 \\
, 106 \\
\end{array}$ & $\begin{array}{l}-, 260 \\
-, 260 \\
\end{array}$ \\
\hline $\begin{array}{l}\text { Habilidades adquiridas en la } \\
\text { universidad }\end{array}$ & $\begin{array}{l}\text { Equal variances assumed } \\
\text { Equal variances not assumed }\end{array}$ & $\begin{array}{r}66 \\
62,271 \\
\end{array}$ & $\begin{array}{r}, 124 \\
, 121 \\
\end{array}$ & $\begin{array}{r}-, 238 \\
-, 238 \\
\end{array}$ \\
\hline $\begin{array}{l}\text { Habilidades adquiridas } \\
\text { práctica pre profesional }\end{array}$ & $\begin{array}{l}\text { Equal variances assumed } \\
\text { Equal variances not assumed }\end{array}$ & $\begin{array}{r}66 \\
50,272 \\
\end{array}$ & $\begin{array}{r}, 048 \\
, 059 \\
\end{array}$ & $\begin{array}{l}, 386 \\
, 386 \\
\end{array}$ \\
\hline $\begin{array}{l}\text { Habilidades adquiridas } \\
\text { cursos certificación }\end{array}$ & $\begin{array}{l}\text { Equal variances assumed } \\
\text { Equal variances not assumed }\end{array}$ & $\begin{array}{r}66 \\
55,772\end{array}$ & $\begin{array}{l}, 152 \\
, 161\end{array}$ & $\begin{array}{l}, 264 \\
, 264\end{array}$ \\
\hline
\end{tabular}

Independent Samples Test

\begin{tabular}{|c|c|c|}
\hline & & $\begin{array}{c}\text { t-test for Equality } \\
\text { of Means }\end{array}$ \\
\hline & & $\begin{array}{l}\text { Std. Error } \\
\text { Difference }\end{array}$ \\
\hline $\begin{array}{l}\text { Conocimientos generales de } \\
\text { Informática }\end{array}$ & $\begin{array}{l}\text { Equal variances assumed } \\
\text { Equal variances not assumed }\end{array}$ & ,185 \\
\hline $\begin{array}{l}\text { Conocimientos generales de } \\
\text { Gestion }\end{array}$ & $\begin{array}{l}\text { Equal variances assumed } \\
\text { Equal variances not assumed }\end{array}$ & $\begin{array}{l}, 160 \\
, 158 \\
\end{array}$ \\
\hline $\begin{array}{l}\text { Habilidades adquiridas en la } \\
\text { universidad }\end{array}$ & $\begin{array}{l}\text { Equal variances assumed } \\
\text { Equal variances not assumed }\end{array}$ & $\begin{array}{l}, 153 \\
, 151\end{array}$ \\
\hline $\begin{array}{l}\text { Habilidades adquiridas } \\
\text { práctica pre profesional }\end{array}$ & $\begin{array}{l}\text { Equal variances assumed } \\
\text { Equal variances not assumed }\end{array}$ & $\begin{array}{l}, 192 \\
, 200 \\
\end{array}$ \\
\hline $\begin{array}{l}\text { Habilidades adquiridas } \\
\text { cursos certificación }\end{array}$ & $\begin{array}{l}\text { Equal variances assumed } \\
\text { Equal variances not assumed }\end{array}$ & $\begin{array}{l}, 182 \\
, 186\end{array}$ \\
\hline
\end{tabular}


Independent Samples Test

\begin{tabular}{|c|c|c|c|}
\hline & \multirow{2}{*}{\multicolumn{2}{|c|}{$\begin{array}{l}\text { t-test for Equality of Means } \\
\text { 95\% Confidence Interval of the } \\
\text { Difference }\end{array}$}} \\
\hline & & & \\
\hline & & Lower & Upper \\
\hline $\begin{array}{l}\text { Conocimientos generales de } \\
\text { Informática }\end{array}$ & $\begin{array}{l}\text { Equal variances assumed } \\
\text { Equal variances not assumed }\end{array}$ & $\begin{array}{l}-, 303 \\
-, 315 \\
\end{array}$ & $\begin{array}{l}, 436 \\
, 447 \\
\end{array}$ \\
\hline $\begin{array}{l}\text { Conocimientos generales de } \\
\text { Gestion }\end{array}$ & $\begin{array}{l}\text { Equal variances assumed } \\
\text { Equal variances not assumed }\end{array}$ & $\begin{array}{l}-, 579 \\
-, 577\end{array}$ & $\begin{array}{l}, 060 \\
, 057\end{array}$ \\
\hline $\begin{array}{l}\text { Habilidades adquiridas en la } \\
\text { universidad }\end{array}$ & $\begin{array}{l}\text { Equal variances assumed } \\
\text { Equal variances not assumed }\end{array}$ & $\begin{array}{l}-, 543 \\
-, 540 \\
\end{array}$ & $\begin{array}{r}, 067 \\
, 065 \\
\end{array}$ \\
\hline $\begin{array}{l}\text { Habilidades adquiridas } \\
\text { práctica pre profesional }\end{array}$ & $\begin{array}{l}\text { Equal variances assumed } \\
\text { Equal variances not assumed }\end{array}$ & $\begin{array}{r}, 003 \\
-, 015 \\
\end{array}$ & $\begin{array}{r}, 770 \\
, 788 \\
\end{array}$ \\
\hline $\begin{array}{l}\text { Habilidades adquiridas } \\
\text { cursos certificación }\end{array}$ & $\begin{array}{l}\text { Equal variances assumed } \\
\text { Equal variances not assumed }\end{array}$ & $\begin{array}{l}-, 100 \\
-, 108\end{array}$ & $\begin{array}{l}, 629 \\
, 637\end{array}$ \\
\hline
\end{tabular}

